\title{
3. Die Bereitstellung von Arbeitskräften für die „Schwerpunkte der Wirtschaft"
}

\section{Wismut $A G$ in Sachsen und Thüringen}

Der Uranbergbau im Erzgebirge wurde bekanntlich von der sowjetischen Besatzungsmacht geleitet und kontrolliert; Interventionen von seiten der deutschen Verwaltung waren kaum möglich oder bedurften der vorherigen Genehmigung. Dies betraf unter anderem auch die Festlegung von arbeitsrechtlichen und sozialversicherungsrechtlichen Bestimmungen. Insofern ist die Einschätzung von Rainer Karlsch völlig zutreffend, daß es sich hierbei um einen „Staat im Staate“ gehandelt hat ${ }^{1}$. Obwohl dieser Bereich der Grundstoffindustrie der deutschen Arbeitsverwaltung weitgehend entzogen blieb, war die sowjetische Leitung der Wismut AG auf die Mitarbeit der deutschen Arbeitsämter stark angewiesen. Nur so ließen sich, das hatten bereits die Jahre zwischen Kriegsende und DDR-Gründung gezeigt, die Arbeitskräfteanforderungen befriedigen. Eine bedarfs- und termingerechte Abdeckung dieser Anforderungen war letztlich nur auf der Grundlage der Zusammenarbeit zwischen der deutschen und sowjetischen Seite möglich.

Bereits Ende der vierziger Jahre unternahm die HVAS mehrere Versuche, um in den einzelnen Bezirken des Uranbergbaus mehr Einfluß zu gewinnen. Diese zaghaften Vorstöße beschränkten sich zunächst auf die Ausdehnung von geltenden arbeitsrechtlichen Bestimmungen auf das Einzugsgebiet der Wismut AG. So wandte sich die Arbeitsverwaltung etwa gegen die Einziehung von Arbeitsbüchern und Personalausweisen bei der Neueinstellung von Arbeitskräften, welche die Leitung der Wismut AG angeordnet hatte. Die HVAS kritisierte in dem $\mathrm{Zu}$ sammenhang, daß diese Praktiken mit ihr nicht abgesprochen waren, die zudem auch unvereinbar seien mit der Verordnung über die Wiedereinführung des Arbeitsbuches vom 4. Februar 1947 sowie der Verordnung über die Ausgabe einheitlicher Personalausweise vom 18. November 19482. Die Berliner Hauptverwaltung hatte offensichtlich Hinweise dafür, daß „durch unberechtigtes Einbehalten der Papiere die Arbeiter bei Beendigung des Arbeitsvertrages zum Zwecke einer Vertragsverlängerung unter Druck “ gesetzt würden. Dadurch sei das langfristige Ziel, den Arbeitskräftebedarf in erster Linie durch Freiwilligenwerbung abzudecken, gefährdet. Hintergrund für die kritisierte Vorgehensweise der Wismut AG war die Tatsache, daß die überwiegende Mehrzahl der im Uranbergbau tätigen Arbeiter einen zeitlich befristeten Arbeitsvertrag besaß und nach Abschluß der Verträge wieder in die Heimatorte zurückkehrte. Die dadurch bedingte Fluktuationsrate sollte daher deutlich gesenkt werden. Während die sowjetische Werksleitung ein Interesse daran hatte, einen festen Stamm von Arbeitskräften in den Gruben zu halten, verfolgte die HVAS das Ziel, die Gewinnung von neuen Arbeitskräften auf freiwilliger Basis zu erreichen. Die Berliner Hauptverwaltung war davon überzeugt, daß sich nur so die Arbeitsproduktivität steigern sowie die soziale Lage im Uranbergbaugebiet entspannen ließ. Zunächst wurde die Deutsche Verwaltung

1 Karlsch, „Ein Staat im Staate“.

2 BAB, DQ 2/2105, Donau am 5. 8. 1949 an den Minister für Arbeit und Sozialfürsorge Sachsens. 
des Innern gebeten, „entweder das Einbehalten der Personalausweise durch die A.G. Wismuth [sic] zu unterbinden oder aber, sollte [...] das nicht gelingen, die örtlichen Polizeidienststellen anzuweisen, zukünftig den genannten Personenkreis, eventuell nach Begutachtung durch das zuständige Amt für Arbeit, ohne zusätzliche Kosten zu registrieren, und ihm einen Ersatzausweis auszuhändigen “3. Verhandlungen, die das Ministerium des Innern mit der Direktion der Wismut AG mittlerweile aufgenommen hatte, brachten keine Kurskorrektur in dieser Frage: Die sowjetische Werksleitung beharrte darauf, daß sie „aus wichtigen Gründen von dieser Maßnahme nicht abgehen" könnet. Sie erklärte sich allerdings dazu bereit, die Personalausweise von Personen, die nicht mehr bei der Wismut AG beschäftigt waren, wieder auszuhändigen. Dagegen konnte die deutsche Seite den sowjetischen Vorstoß abwehren, die Polizeidienststellen bei der Rückführung von Arbeitern einzuschalten, die eigenmächtig ihren Arbeitsplatz verlassen hatten. Die Direktion der Wismut AG wurde auf den gesetzlich vorgeschriebenen Rechtsweg verwiesen und mußte sich offenbar damit zufriedengeben.

Aufgrund der Verbesserung der Arbeitsbedingungen und der Lebensverhältnisse im Erzbergbaugebiet gewann der Uranbergbau bereits 1948/49 zunehmend an Anziehungskraft. Deutlich verbesserte Löhne, Prämienzahlungen sowie zusätzliche Lebensmittelrationen hatten bald dazu geführt, daß sich immer mehr Arbeitskräfte freiwillig bei der Wismut AG um eine berufliche Einstellung bemühten. Die Arbeitsverwaltung, die ihre Maßnahmen darauf ausgerichtet hatte, sah sich dennoch mit einigen Folgeproblemen dieser beruflich bedingten Binnenwanderung konfrontiert, die im Vorfeld kaum berücksichtigt worden waren. So beklagten sich zahlreiche Betriebe über den Verlust von Arbeitskräften, die zum Uranbergbau abwanderten ${ }^{6}$. Da die sowjetische Besatzungsmacht frühzeitig einen Lohnstopp verhängt hatte, der allerdings nicht sofort und vollständig eingehalten wurde, besaßen diese Betriebe keinen Handlungsspielraum zu angepaßten Lohnerhöhungen. Die Differenzierung der Löhne lag somit zuallererst in der Zuständigkeit der SMAD und der DWK-Hauptverwaltungen. Die betroffenen Betriebe versuchten daher, von der Arbeitsverwaltung in eine höhere Dringlichkeitsstufe eingeordnet zu werden, um auf diese Weise den Verlust an Arbeitskräften rasch wieder ausgleichen zu können. Die Abwanderung von Arbeitern konnte von der HVAS jedoch nicht gesteuert werden und erfaßte auch Betriebe, die zu den "Schwerpunkten der Wirtschaft“" gehörten'. So berichteten einzelne Grubenleitungen des Braun- und Steinkohlebergbaus der zuständigen Hauptverwaltung Kohle, daß sie das Abwandern von Arbeitskräften nicht mehr verhindern könnten. Die Hauptverwaltung Kohle sah daraufhin die Einhaltung der Produktionspläne langfristig gefährdet und drohte damit, in Karlshorst vorstellig zu werden:

3 Ebenda, HVAS (Donau) am 11. 10. 1949 an die DVdI, Abt. Verwaltungspolizei (Huhn).

4 SächsHStA, Landesregierung Sachsen, Ministerium für Arbeit und Sozialfürsorge, Bd. 397, Ministerium für Arbeit und Gesundheitswesen am 18.11. 1949 an den sächsischen Minister für Arbeit und Sozialwesen. Das Schreiben erhielten auch die anderen Landesregierungen zur Information.

5 Ebenda.

6 Vgl. BAB, DQ 2/2105, Gebrüder Solbrig am 7. 9. 1949 an das Landesarbeitsamt in Dresden.

7 BAB, DQ 2/2094, Arbeitsamt Aue am 21. 9. 1949 an die HVAS. Auf dieses Problem geht Ralf Engeln bei seiner Darstellung der Tarifpolitik überhaupt nicht ein. Vgl. Engeln, Betriebliche Arbeitsbeziehungen, S. 403-410. 
„Wir würden aber bei allem weiteren Umsichgreifen dieser Bestrebungen nicht umhin können, vorsorglich auch unsere korrespondierende Fachabteilung in Karlshorst auf die sich möglicherweise ergebenden Folgerungen aufmerksam zu machen, würden es aber begrüßen, wenn vorher von Ihrer Seite [der HVAS] alle Möglichkeiten untersucht würden, die zu einer Beseitigung der erwähnten Abwanderungsbestrebungen führen könnten." ${ }^{8}$ Ähnlich lautende Klagen leitete die Hauptverwaltung Maschinenbau und Elektrotechnik an die HVAS weiter9.

Die Arbeitsverwaltung stand der Abwanderung zur Wismut AG weitgehend hilflos gegenüber. Die von ihr eingeleiteten Maßnahmen konnten nur geringfügig entlastend wirken: So wurde die Werbung von Arbeitskräften in Heimkehrerund Umsiedlerlagern durch einzelne Betriebe untersagt. Diese Praktiken waren in der unmittelbaren Nachkriegszeit zunächst noch toleriert worden, konnten aber nunmehr aufgrund der wachsenden Arbeitskräfteknappheit von den Arbeitsämtern nicht mehr hingenommen werden. Darüber hinaus mußten die einzelnen Hauptverwaltungen für die Abdeckung des Arbeitskräftebedarfes in ihrem $\mathrm{Zu}$ ständigkeitsbereich letztlich selber Sorge tragen. Das konnte mitunter dazu führen, daß etwa die Hauptverwaltung Kohle Arbeiter aus dem Braunkohlenbergbau abzog, um eine akut aufgetretene Nachfragelücke im Steinkohlenbergbau zu schließen ${ }^{10}$. In dem Zusammenhang schlug die HVAS-Abteilung I a vor, die Wismut AG solle sich verpflichten, Arbeitskräfte nicht einzustellen, die aus dem Zwickauer Steinkohlenrevier kamen ${ }^{11}$. Dieser Vorstoß war jedoch illusorisch und hatte keine Realisierungschancen, da die sowjetische Bergwerksleitung zu solch einer Selbstverpflichtung nicht bereit war. Resigniert stellten Vertreter des Ministeriums für Arbeit und Gesundheitswesen, des Ministeriums für Industrie sowie einzelner volkseigener Betriebe bei einer gemeinsamen Besprechung übereinstimmend fest, daß ,alle von deutschen Seiten bestehenden und zu ergreifenden Maßnahmen wirkungslos sind und bleiben, solange die Wismut AG die deutschen Ge-

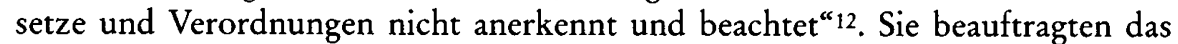
Ministerium für Arbeit und Gesundheitswesen, „Material über die gegenwärtigen Schwierigkeiten in den volkseigenen Betrieben, deren Gefährdung der Produktionserfüllung und die zahlenmäßige Stärke der Abwanderungen " zusammenzutragen und anschließend dem Ministerpräsidenten zu übergeben. Dieser solle dann gebeten werden, „auf diplomatischem Wege bei der Sowjetunion zu erwirken, daß die Wismut AG in jeder Beziehung die deutschen Gesetze und Verordnungen anerkennt und befolgt oder wenn möglich, die Umwandlung der Wismut AG in einen volkseigenen Betrieb erfolgt" ${ }^{13}$. Dem Ministerium für Arbeit und Gesundheitswesen ging es bei der Aufhebung des Sonderstatus der Wismut AG vor allem darum, Einzelprüfungen über die Belegschaften in den einzelnen Schachtanlagen vornehmen zu können ${ }^{14}$. Dadurch sollte zum einen eine Überbelegung mit Ar-

8 BAB, DQ 2/2094, DWK-Hausmitteilung der HV Kohle vom 17. 9. 1949 an die HVAS.

9 Ebenda, DWK-Hausmitteilung der HV Maschinenbau und Elektrotechnik vom 30.9. 1949 an die HVAS.

$10 \mathrm{BAB}, \mathrm{DQ} 2 / 2105$, Aktennotiz der Abt. I a (Krüger) vom 13. 10. 1949.

11 Ebenda.

$12 \mathrm{BAB}, \mathrm{DQ} 2 / 2094$, Bericht der Abt. I a über die Arbeitsbesprechung am 25. 10. 1949, S. $1 \mathrm{f}$.

13 Ebenda, S. 2.

14 BAB, DQ 2/2094, Ministerium für Arbeit und Gesundheitswesen am 5.12. 1949 an die SKK- 
beitskräften sowie zum anderen eine berufsfremde Arbeitskräftelenkung verhindert werden. Dieses Vorhaben scheiterte allerdings an der Direktion der Wismut AG, die sich darauf überhaupt nicht einließ.

Das Ministerium für Industrie, Hauptabteilung Kohle, wies auf den Zusammenhang von Beschäftigungsrückgang und Produktionseinbrüchen hin. Nach Angaben der Hauptabteilung war die Anzahl der Arbeiter im Zwickauer Steinkohlenbergbau von 21070 (Januar 1949) auf 19933 (September 1949) gefallen ${ }^{15}$. Dagegen war die Anzahl der Angestellten im gleichen Zeitraum von 1203 auf 1312 gestiegen. Die Steinkohlenförderung sank innerhalb der ersten neun Monate 1949 von 255540 auf 212630 Tonnen; die Kokserzeugung fiel von 19820 auf 18980 Tonnen. Da die Entwicklung der Fördermenge etwas wellenförmig verlief und der Wert vom Jahresbeginn im März und Mai übertroffen werden konnte, müssen noch andere Gründe dafür ausschlaggebend gewesen sein, daß die Gesamtmenge an geförderter Steinkohle am Ende des III. Quartals diesen Tiefststand erreicht hatte, durch den die Hauptabteilung Kohle aufgerüttelt worden war. Der Arbeitskräftemangel im Steinkohlenbergbau sollte sich im Laufe des I. Quartals 1950 weiter vergrößern'16; die Fluktuationsbewegung zum Uranbergbau war von der Arbeitsverwaltung auch weiterhin nicht zu steuern. Einen spürbaren Rückgang des Beschäftigtenstandes und eine damit einhergehende Gefährdung des Produktionsprozesses meldeten auch andere Ministerien: So berichtete das Ministerium für Post- und Fernmeldewesen, daß bei der Oberpostdirektion Leipzig über 10 Prozent des Personals zur Wismut AG abgewandert seien ${ }^{17}$.

Die einzelnen Landesverwaltungen bekamen die Arbeitskräfteanforderungen für den Uranbergbau nach wie vor von der HVAS mitgeteilt, die ihrerseits Befehle von der SMAD erhielt. Auf diese Weise sollte verhindert werden, daß die Arbeitsverwaltung von sowjetischen Befehlen überhäuft wird. Dennoch blieb auch weiterhin nicht ausgeschlossen, daß die SMA der Länder bzw. die Direktion der Wismut AG eigene Anweisungen erteilten. Die Mobilisierung zusätzlicher Arbeitskräfte besaß, darauf ist bereits hingewiesen worden, sehr starken Improvisationscharakter und basierte nicht auf einer langfristigen Planung. Das hing bekanntlich mit der nicht abzusehenden Entwicklung sowohl auf der Angebots- als auch auf der Nachfrageseite zusammen: Die Fluktuation und die unregelmäßigen Anforderungen von seiten der sowjetischen Besatzungsmacht erschwerten eine bedarfsgerechte Arbeitskräftelenkung erheblich. Darüber hinaus wurde es für die Arbeitsverwaltung immer schwieriger, den Gesamtbestand der Erwerbsbevölkerung zu vergrößern. Nach Einschätzung des Ministeriums für Arbeit und Sozialwesen in Sachsen-Anhalt waren die „Umsiedler“ häufig bergbauuntauglich ${ }^{18}$, so daß die

Abt. Arbeitskraft (Morenow). Das Schreiben enthällt den handschriftlichen Zusatz „nicht abgegangen!".

15 BAB, DQ 2/2094, Statistik der HA Kohle vom 17. 11. 1949.

$16 \mathrm{BAB}, \mathrm{DQ}$ 2/2092, Mitteilung des FDGB-Vertreters in Zwickau (Weber) vom 21. 3. 1950 an den FDGB-Bundesvorstand.

$17 \mathrm{BAB}, \mathrm{DQ}$ 2/2094, Ministerium für Arbeit und Gesundheitswesen am 5.12. 1949 an die SKKAbt. Arbeitskraft (Morenow).

18 Es deutet einiges darauf hin, daß der Anteil der erwerbsfähigen Bevölkerung unter den „Umsiedlern" deutlich niedriger lag als unter der Gesamtbevölkerung. Vgl. Hoffmann, Vertriebenenintegration durch Arbeitsmarktlenkung?, S. 179. Dies könnte auch die Erklärung für den vermehrten 
einzige Reserve auf dem Arbeitsmarkt aus „nichtvolleinsatzfähigen Männern und volleinsatzfähigen Frauen" bestehe ${ }^{19}$. Man könne sich - so ein Vertreter des Ministeriums - „den Luxus nicht erlauben, weiterhin Arbeitskräfte brach liegen zu lassen" 20 . Im einzelnen sollten, hier griff das Ministerium eine alte Forderung wieder auf, männliche Arbeitskräfte in der Leicht- und Konsumgüterindustrie durch weibliche ersetzt werden.

Für die Arbeitsverwaltung war die Anwerbung von Arbeitskräften für den Uranbergbau unmittelbar mit dem Problem der wohnlichen Unterbringung verbunden. Dabei konnte die Bereitstellung von Wohnraum nicht mit der stetig wachsenden Gesamtzahl der Wismut-Arbeiter Schritt halten. Allein im Landkreis Aue war die Gesamtbevölkerung von 180351 (Dezember 1947) auf 245727 (September 1949) angestiegen; im Gegensatz dazu war der gesamte vorhandene Wohnraum nach Schätzungen der zuständigen Abteilung Wohnungswesen in Aue zwischen Kriegsende und DDR-Gründung um rund 30 Prozent zurückgegangen $^{21}$. Sowohl kriegsbedingte Abrißmaßnahmen als auch Räumungen für die Besatzungsmacht hatten diesen Rückgang bewirkt. Nach Angaben der Abteilung Mutter und Kind des Berliner Arbeitsministeriums lag die durchschnittliche Wohnfläche in einzelnen Bezirken des Uranbergbaugebietes nur bei ca. $4 \mathrm{qm}$ pro Person $^{22}$. Somit waren auch keine weiteren Privatunterkünfte zu gewinnen. Der Bau von Baracken und die Bereitstellung von Sammelquartieren, die nur als zeitlich begrenzte Übergangslösungen betrachtet wurden, verlangsamte sich aufgrund des Baustoffmangels sowie der fehlenden Ausstattung mit Mobiliar und Sanitäreinrichtungen. Das Problem der wohnlichen Unterbringung sei daher - so ein Mitarbeiter des Ministeriums für Arbeit und Gesundheitswesen nach einer

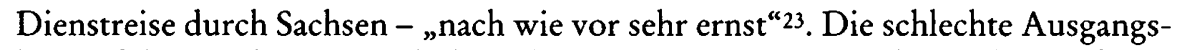
lage auf dem Wohnungsmarkt hatte bereits vor 1949 unter anderem dazu geführt, daß zahlreiche Arbeiter ohne ihre Familien angesiedelt werden mußten. Die kommunalen Wohnungsbehörden versuchten auf Anweisung der Berliner Zentralverwaltung sowie der zuständigen Landesverwaltung, Arbeitskräfte aus dem Erzbergbaugebiet auszusiedeln, wenn sie nicht bei der Wismut AG beschäftigt waren. Diese sogenannten Umsiedlungen, die auf freiwilliger Basis beruhen sollten,

Unterstützungsempfang durch Flüchtlinge und Vertriebene sein. Vgl. Boldorf, Fürsorgeunterstützung in Deutschland, S. 238.

19 LA Magdeburg LHA, Rep. K MW, Nr. 10660, Bl. 409-418, hier Bl. 409, Niederschrift über die am 20. 10. $1949 \mathrm{im}$ Ministerium für Arbeit und Sozialwesen, Halle, stattgefundene Amtsleitertagung.

20 Ebenda, Bl. 410.

21 SächsHStA, Landesregierung Sachsen, Ministerium für Arbeit und Sozialfürsorge, Bd. 401, Bl. 77, Bericht der Abt. Soziale Fürsorge/Wohnungswesen vom 27. 10. 1949 an das Ministerium für Arbeit und Sozialwesen in Dresden.

$22 \mathrm{BAB}, \mathrm{DQ} 2 / 906, \mathrm{Bl} .227 \mathrm{f}$., hier Bl. 227, Aktenvermerk vom 3. 4. 1950. Dieser Wert lag jedoch eher im unteren Bereich. Letztlich gab es auch hier beträchtliche Schwankungen: Im Kreis Annaberg variierten die Angaben zwischen 3,9 (Hammer-Unterwiesenthal) und 7,6 qm (Mildenau); im Kreis Aue wurde der Wohnraum mit einem Durchschnittswert von 2,8 (Johanngeorgenstadt) bis $9,5 \mathrm{qm}$ (Grüna) angegeben. SächsHStA, Landesregierung Sachsen, Ministerium für Arbeit und Sozialfürsorge, Bd. 401, Bl. 6-9, Aufstellung des sächsischen Arbeitsministeriums vom 12.5. 1950. Diese Wohnungsknappheit herrschte auch noch 1951 vor. Im Herbst 1951 standen jedem DDR-Bürger durchschnittlich 7,9 qm Wohnfläche zur Verfügung, während der Wert für einige Kreise des Erzbergbaugebietes nach wie vor bei 4 qm lag. Vgl. SAPMO, NY 4182/986, Bl. 33-37, hier Bl. 33, Bericht vom 10.11. 1951 (o.Verf.).

23 Ebenda. 
konnten letztlich die Wohnraumfrage nicht befriedigend lösen. Vertreter der betroffenen sächsischen Landkreise wiesen gegenüber Mitarbeitern des Ministeriums für Arbeit und Gesundheitswesen am 20. Oktober 1949 in Chemnitz auf die "unhaltbaren Wohnverhältnisse“ im Erzbergbaugebiet hin ${ }^{24}$. Gefordert wurde ein Sonderbauprogramm, das von der DDR-Regierung zu finanzieren sei. Nur durch den Bau „schnell fabrikmäßig herzustellender massiver winterfester Wohnbarakken" ließen sich nach Ansicht der Landräte die aufgetretenen Probleme auf dem Wohnungsmarkt lösen. Darüber hinaus müsse eine Abstimmung mit der Direktion der Wismut AG angestrebt werden, die ihrerseits ein Wohnungsbauprogramm verfolge und deshalb Baumaterial sowie Arbeitskräfte abziehe, wodurch wiederum die Bautätigkeit der deutschen Stellen lahmgelegt werde ${ }^{25}$. Alle Beteiligten vertraten aber einhellig die Meinung, $\mathrm{da} ß \mathrm{der} B$ au von Baracken nur eine Interimslösung sein konnte. Die Erfahrungen, welche die kommunalen Behörden sowie die Landes- und Zentralverwaltungen mit den Heimkehrer- und Umsiedlerlagern seit Kriegsende gesammelt hatten, beeinflußten wesentlich die skeptische Einschätzung dieses Konzeptes.

Der FDGB-Bundesvorstand schaltete sich Ende 1949 in die Debatte über die Hemmnisse der Arbeitskräftegewinnung bei der Wismut AG ein. Dabei wandte er sich sogar direkt an die SKK und wies auf die Schwierigkeiten bei der Versorgung mit Wohnraum aber auch auf die bestehenden Verkehrsprobleme im Erzgebirge hin. Die Gewerkschaftsleitung begründete ihre Forderung nach einer grundlegenden Verbesserung der Infrastruktur mit dem Hinweis auf die bevorstehenden Volkskammerwahlen, die erst am 15. Oktober 1950 stattfanden: „Eine unzufriedene Wismut-Belegschaft, deren unzufriedene Familien und eine unzufriedene Einwohnerschaft des Erzbergbau-Gebietes würden den Wahlausgang im Herbst nächsten Jahres in ungünstiger Weise beeinträchtigen. "26 In der Folgezeit bemühte sich der FDGB-Bundesvorstand um eine verstärkte Zusammenarbeit mit dem Ministerium für Arbeit und Gesundheitswesen ${ }^{27}$ und unterbreitete auch Vorschläge zur Eindämmung der Fluktuation, die sich auf den Wohnungsbau, das Transportwesen und die „kulturelle Betreuung der Werktätigen“ konzentrierten $^{28}$. Dies entsprach im übrigen den Vorstellungen der sowjetischen Besatzungsmacht sowie der SED-Führung, welche die Massenorganisationen für die Aufgabe, Arbeitskräfte für den Uranbergbau bereitzustellen, verstärkt mobilisieren wollten. Rasch wurde allerdings deutlich, daß die Gewerkschaftsseite kaum Einfluß auf grundsätzliche Entscheidungen der Arbeitsverwaltung nehmen konnte, sondern primär für Propagandaaufgaben eingesetzt werden sollte. Anfang 1950

24 SächsHStA, Landesregierung Sachsen, Ministerium für Arbeit und Sozialfürsorge, Bd.401, Bl. $75 \mathrm{f}$.

25 Ebenda, Bl. 76.

26 SAPMO, DY 34, 15/26/1067, FDGB-Bundesvorstand am 19.11. 1949 an die SKK (Morenow).

$27 \mathrm{BAB}, \mathrm{DQ}$ 2/2092, FDGB-Bundesvorstand am 22. 11. 1949 an das Ministerium für Arbeit und Gesundheitswesen (Staatssekretär Peschke).

28 Ebenda, Vorschläge einer FDGB-Kommission vom 22. 12. 1949; SächsHStA, Landesregierung Sachsen, Ministerium für Arbeit und Sozialfürsorge, Bd.401, Bl. 59-66, Empfehlungen des FDGB-Bundesvorstandes vom 30. 12. 1949. Diese wurden am 2. 1. 1950 an die Direktion der Wismut AG (General Malzew) verschickt. BAB, DQ 2/2093. Zur Abdeckung des künftigen Arbeitskräftebedarfs schlug der FDGB vor, die Ermittlung und Erfassung der bergbautauglichen männlichen Arbeitskräfte bereits auf Kreisebene durchführen zu lassen. 
richtete der FDGB seine Vorschläge auch an das immer wichtiger werdende Ministerium für Planung, das von Heinrich Rau geleitet wurde. Um die bestehende Wohnungsnot wirksam zu bekämpfen, sollte neben das von der Direktion der Wismut AG initiierten Bauprogramm ein weiteres Sofortprogramm treten, das die DDR-Regierung zu übernehmen hatte. Der Bau von mindestens 2000 Arbeiterwohnungen in den Landkreisen Annaberg, Aue und Marienberg sowie in der Nähe von Johanngeorgenstadt sei - so die Gewerkschaftsführung - im Rahmen eines Nachtrages zum Wirtschaftsplan für 1950 zu finanzieren ${ }^{29}$.

Genaue quantitative Angaben über die bei der Wismut AG beschäftigten Arbeiter und Angestellten sind kaum verfügbar - auch dies war eine Folge der Abschottung durch die sowjetische Besatzungsmacht. Die Arbeitsämter waren deshalb nicht in der Lage, eine regelmäßige und detaillierte Statistik des Belegschaftsstandes zu führen. Statt dessen liegen nur für einzelne Monate Zahlen vor, die zum Teil nicht unerheblich von den Jahresberichten der sowjetischen Generaldirektion abweichen ${ }^{30}$, aus denen kürzlich Rainer Karlsch zitiert hat. Fest steht, daß die Nachfrage nach Arbeitskräften auch nach der Gründung der DDR weiter anstieg und erst ab 1953 spürbar zurückging. Der höchste Stand der Beschäftigung im Uranbergbau wurde vermutlich Ende 1950 erreicht, als 195906 Beschäftigte gezählt wurden ${ }^{31}$. Darunter befanden sich 6897 Personen, die zum sowjetischen Personal zählten. Ein Jahr später wurden nur noch 153112 Arbeiter und Angestellte angegeben; die Anzahl der sowjetischen Beschäftigten war dagegen auf 10925 gestiegen. Für Dezember 1953 wurden insgesamt 133000 Beschäftigte registriert ${ }^{32}$. Aufgrund der zunehmenden Mechanisierung sowie der Stillegung unrentabler Schachtanlagen sank der Bedarf und letztlich auch der Beschäftigtenstand weiter: auf ca. 100000 (1956), 47000 (1961), und in den Jahren von 1962 bis 1989 lag die Gesamtzahl zwischen 43000 und 4600033.

Ende 1949 gab das Ministerium für Arbeit und Gesundheitswesen den Landesverwaltungen den Auftrag, Arbeitskräfte für den sächsischen Erzbergbau zu gewinnen. Dabei verwies das Ministerium für Arbeit und Sozialpolitik von SachsenAnhalt, das innerhalb von sechs Monaten 13000 Arbeiter zu stellen hatte, auf die angespannte arbeitsmarktpolitische Lage des Landes und bat darum, von einer weiteren Auflage befreit zu werden ${ }^{34}$. Zur Begründung wurde auf die wachsende Zahl von Betrieben der Schwerindustrie verwiesen, die einen großen Arbeitskräftebedarf angemeldet hätten. Darüber hinaus habe Sachsen-Anhalt in den Jahren

29 BAB, DQ 2/2093, FDGB-Bundesvorstand am 13.1. 1950 an das Ministerium für Planung, S. $1 \mathrm{f}$.

30 In seiner Monographie gibt Karlsch die Zahl der registrierten Arbeitskräfte für Dezember 1946 mit 10000 an. Vgl. Karlsch, Allein bezahlt?, S. 141. In seinem 1998 erschienenen Sammelbandbeitrag erscheinen nur 2257 Beschäftigte. Vgl. Karlsch, Heimkehrer bei der Wismut AG, S. 265. Die letzte Zahlenangabe stammt aus Jahresberichten der sowjetischen Generaldirektion, ohne daß Karlsch eine Quellensignatur angibt. Für Dezember 1947 gibt er einmal 46000 Beschäftigte an (Karlsch, Allein bezahlt?, S. 141), ein anderes Mal 18775 (Karlsch, Heimkehrer bei der Wismut AG, S. 265). Die deutschen Angaben liegen auch im Dezember 1948 erheblich über den sowjetischen: 100000 (Karlsch, Allein bezahlt?, S. 141) bzw. 63383 (Karlsch, Heimkehrer bei der Wismut AG, S. 265).

31 Karlsch, Heimkehrer bei der Wismut AG, S. 265.

32 Karlsch, Allein bezahlt?, S. 141.

33 Karlsch, Der Aufbau der Uranindustrien in der SBZ/DDR und CSR, S. 15.

34 BAB, DQ 2/906, Bl. 240f., Ministerium für Arbeit und Sozialpolitik von Sachsen-Anhalt am 28. 12. 1949 an Minister Steidle. 
von 1947 bis 1949 insgesamt 32284 Arbeitskräfte für die Wismut AG zur Verfügung gestellt. Das Arbeitsministerium in Berlin zeigte zwar Verständnis für die Reaktion einzelner Landesregierungen auf die erneuten Arbeitskräfteanforderungen für den Uranbergbau, bestand aber letztlich darauf, daß das Soll erfüllt wurde ${ }^{35}$. Gespräche mit der Generaldirektion der SAG-Betriebe in Weißensee hatten offenbar kein Entgegenkommen der sowjetischen Seite gebracht. Diese sagte unverbindlich zu, die Arbeitskräftepläne der Wismut AG überprüfen zu lassen. Solange jedoch von der dortigen Direktion der Gesamtbedarf in Höhe von 93000 für das erste Halbjahr 1950 aufrecht erhalten werde, sei es leider nicht möglich, Sachsen-Anhalt von der Auflage zu entbinden ${ }^{36}$. Auch die mecklenburgische Landesregierung sah sich außerstande, das Auflagesoll von 9000 Arbeitskräften im ersten Halbjahr 1950 zu erfüllen, und bat um eine deutliche Reduzierung entsprechend der „Leistungsfähigkeit“ des Landes ${ }^{37}$. Nachdem das Ministerium in Berlin nicht reagiert hatte, wiederholte das mecklenburgische Ministerium die bereits vorgetragene Position nochmals und kam zum Ergebnis, daß die erteilte Auflage „um mindestens 20\% überhöht“ sei ${ }^{38}$. Dem Lande Mecklenburg stünden vollarbeitsfähige Arbeitskräfte für die Erfüllung des Volkswirtschaftsplanes 1950 nicht mehr zur Verfügung. Alle Landesverwaltungen hatten Kritik an der Auflagenhöhe geübt, so auch abschließend das Ministerium für Arbeit und Sozialwesen in Potsdam, das eine Verringerung der vom Land Brandenburg zu stellenden Arbeiter von 9000 auf 3500 beantragte ${ }^{39}$. Daraufhin sah sich das Ministerium für Arbeit und Gesundheitswesen in Berlin zum Handeln gezwungen. Zum einen unternahmen leitende Mitarbeiter Inspektionsreisen in die einzelnen Länder, um sich einen Eindruck über die angespannte Arbeitsmarktlage vor Ort zu verschaffen ${ }^{40}$. Dabei rückte erneut der Wohnungsbau in den Mittelpunkt des Interesses: Die Arbeitsverwaltung beabsichtigte, Massenunterkünfte für Frauen verstärkt anzubieten, die bei der Wismut AG beschäftigt waren. Major Furmin von der Personalabteilung der Wismut AG sagte bei einer Besprechung am 30. März zu, daß Unterbringungsmöglichkeiten für Frauen bereitgestellt würden ${ }^{41}$. Zum anderen reiste Abteilungsleiter Litke nach Sachsen, um am 27. März mit der Direktion der Wismut AG zusammenzutreffen und über die sowjetische Arbeitskräfteanforderung $\mathrm{zu}$ verhandeln ${ }^{42}$. Vermutlich sollte eine einstweilige Aussetzung der Auflagenerfüllung erreicht werden. Es gibt keinerlei Hinweise darauf, daß die sowjetische Seite eine solche Zusage machte. Vielmehr muß davon ausgegangen werden, daß die einmal erhobene Auflagenhöhe bestehen blieb.

35 BAB, DQ 2/2093, Entwurf der Abt. A III vom 4. 2. 1950 an Minister Steidle, S. 1 f.

36 Ebenda.

$37 \mathrm{BAB}, \mathrm{DQ}$ 2/2093, Ministerium für Arbeit und Gesundheitswesen von Mecklenburg am 2. 1. 1950 an das Ministerium für Arbeit und Gesundheitswesen in Berlin.

38 Ebenda, Ministerium für Arbeit und Gesundheitswesen von Mecklenburg am 8. 2. 1950 an das Ministerium für Arbeit und Gesundheitswesen (HA Arbeit), S. 3.

39 Ebenda, Ministerium für Arbeit und Sozialwesen Brandenburgs am 8. 2. 1950 an das Ministerium für Arbeit und Gesundheitswesen (HA Arbeit), S. 1 .

40 Ebenda, Bericht über die durchgeführte Dienstreise nach Sachsen und dem Erzbergbaugebiet (28.3.-1.4.1950).

4 BAB, DQ 2/906, Bl. 229, Bericht der Abt. Wohnung und Siedlung über die Dienstreise nach Dresden, Aue und Siegmar-Schönau (28.-31.3. 1950).

42 BAB, DQ 2/2093, Aktenvermerk der Abt. A III vom 25. 3. 1950. 
Sicherheitspolitische Überlegungen standen mitunter der angestrebten Arbeitskräftegewinnung entgegen bzw. schränkten sie ein. Angesichts des sich verschärfenden Ost-West-Gegensatzes Anfang der fünfziger Jahre erübrigte sich sehr bald der Versuch, Arbeiter aus der Bundesrepublik anzuwerben: Die Direktion der Wismut AG lehnte dies grundsätzlich ab und gab als Begründung an, daß sie keinerlei Möglichkeit habe, die sich meldenden Personen zu überprüfen ${ }^{43}$. Dagegen wurde der Vorschlag, Strafgefangene im Uranbergbau einzusetzen, vom sächsischen Landesarbeitsamt mit dem Hinweis verworfen, es könne ansonsten der Eindruck entstehen, bei der Tätigkeit im Erzbergbau handele es sich um „Strafarbeit" ${ }^{44}$. Letztlich konnten aber diese Lösungsansätze für die Arbeitsverwaltung nur von untergeordneter Bedeutung sein: Zum einen hatte sich schon vor 1949 gezeigt, daß der Arbeitseinsatz von Strafgefangenen außerhalb der Gefängnismauern mit erheblichen Problemen verbunden war und in keinem Verhältnis zum erhofften Nutzen stand. Zum anderen hatte die Berichterstattung in der westlichen Presse über die Arbeits- und Lebensbedingungen im sächsischen Uranbergbau zu einem negativen Image dieses Wirtschaftsbereiches beigetragen. Freiwillige Bewerbungen aus der Bundesrepublik waren daher kaum in nennenswertem Umfange zu erwarten. Übertriebene Sicherheitsbedenken gab es offensichtlich gegen die Einstellung von Personen, die sich in westlicher Kriegsgefangenschaft befunden hatten. Außerdem wurden Personen zurückgewiesen, die zwar ihren Wohnsitz in der DDR hatten, jedoch besuchsweise in die westlichen Besatzungszonen bzw. die Bundesrepublik gereist waren. Nach Ansicht des Ministers für Arbeit und Gesundheitswesen von Sachsen-Anhalt, Leopold Becker, schränkte diese Vorgehensweise den Handlungsspielraum der Arbeitsämter erheblich ein ${ }^{45}$. Es gebe - so Becker - kaum Menschen, „die nicht verwandtschaftliche Beziehungen in der Westzone haben und es ist eine Vielzahl, die aufgrund der verwandtschaftlichen Verhältnisse besuchsweise die Westzone aufgesucht haben."

Bei gemeinsamen Besprechungen mit SKK-Mitarbeitern wiesen Vertreter des Ministeriums für Arbeit und Gesundheitswesen auf die Schwierigkeiten hin, Arbeitskräfte für den Uranbergbau in der angeforderten Anzahl zu gewinnen. Dabei machte die deutsche Seite explizit deutlich, daß die Planerfüllung für die übrigen Industriezweige nicht gefährdet werden dürfe ${ }^{46}$. Der erste Fünfjahrplan sah den Aufbau der Schwerindustrie vor, der einen entsprechenden Arbeitskräftebedarf nach sich zog. Zu den "Schwerpunkten der Wirtschaft" gehörten deshalb nicht nur der Uranbergbau, sondern auch die Stahl- und Eisenindustrie, die ebenfalls mit Arbeitskräften versorgt werden mußten. Da die Menge der verfügbaren Arbeiter, die eine Arbeit suchten, begrenzt war, mußten zwangsläufig Verteilungskonflikte ausbrechen. Nach Einschätzung des Berliner Arbeitsministeriums waren zudem einzelne Schachtanlagen im Erzbergbau personell überbelegt, teilweise

43 BAB, DQ 2/1766, Bl. 126-129, hier Bl. 128, Bericht der Abt. I a vom 11. 1. 1950 über Dienstreise nach Dresden, Pirna und Königstein.

44 Ebenda.

45 BAB, DQ 2/2093, Minister für Arbeit und Gesundheitswesen von Sachsen-Anhalt am 18. 1. 1950 an das Ministerium für Arbeit und Gesundheitswesen, S. 1.

$46 \mathrm{BAB}, \mathrm{DQ} 2 / 2040, \mathrm{Bl} .218 \mathrm{f}$., hier Bl. 218, Kurzbericht über Besprechung mit SKK (Serow) am 28. 1.1950. 
bis zu 30 Prozent ${ }^{47}$. Die Zuteilung von Arbeitskräften erfolge daher nicht nach Effizienzkriterien und mache Überprüfungen der Belegschaften dringend erforderlich. Diese Vermutung hatten deutsche Stellen schon zuvor geäußert und in dem Zusammenhang einen direkten Zugang von Mitarbeitern der Arbeitsämter zu den Gruben gefordert, die allein unter sowjetischem Kommando standen. Festzuhalten bleibt, daß die Arbeitsverwaltung ein geschlossenes Auftreten gegenüber der SKK anstrebte. Dazu lud das leitende Ministerium in Berlin in unregelmäßigen Abständen zu Arbeitsbesprechungen ein. Wenige Tage vor der Unterredung mit dem sowjetischen Vertreter Serow hatte eine Konferenz mit den zuständigen Abteilungsleitern in den Landesämtern stattgefunden, auf der die Kritik am Auflagensoll für den Uranbergbau nochmals zusammengefaßt wurde ${ }^{48}$.

Anfang 1950 häuften sich die Berichte über eine Zuspitzung der sozialen Lage im Einzugsbereich der Wismut AG. Die deutlich verbesserten Löhne hatten - wie bereits angesprochen - eine Magnetwirkung entfaltet, dem etwa die kommunalen Wohnungsämter mit der Bereitstellung von Unterbringungsmöglichkeiten nicht nachkommen konnten. So ergab sich die besondere Situation, daß der Beschäftigtenstand der Wismut AG unaufhörlich anstieg, während sich der Wohnungsmarkt weiter verschlechterte. So übertrieben die sicherheitspolitischen Bedenken der deutschen und sowjetischen Dienststellen im einzelnen auch waren, so darf doch andererseits das soziale Konfliktpotential nicht übersehen werden, das sich angesichts dieser Ausgangslage allmählich verschärfte. Der Uranbergbau war Anziehungspunkt für zahlreiche Arbeiter in der DDR geworden, und es mag zum Teil durchaus zutreffend sein, wenn die Arbeitsverwaltung die Entwicklung im Erzgebirge mit der Goldgräberzeit der USA im 19. Jahrhundert verglich ${ }^{49}$. Vor diesem Hintergrund muß auch die Forderung des Ministeriums für Arbeit und Gesundheitswesen gesehen werden, die Belegschaftsstärke der einzelnen Schachtanlagen zu überprüfen und Arbeitskräfte an andere Produktionsorte zu lenken, sofern sie am alten Arbeitsplatz nicht sinnvoll beschäftigt werden konnten. Diese Frage entschied jedoch die sowjetische Direktion letztlich allein; die Arbeitsämter und die Landesarbeitsämter konnten nur Appelle an die Wismut AG richten.

Ein zentrales Problem blieb dagegen nach wie vor bestehen: die Entpflichtung durch die Direktion der Wismut AG. Da den Wismut-Arbeitern, deren Verträge ausgelaufen waren, häufig nicht rechtzeitig die Arbeitsbücher sowie die Personalausweise ausgehändigt wurden, konnte dieser Personenkreis auch nicht die Heimreise antreten, um sich dort beim zuständigen Arbeitsamt wieder anzumelden. Die Folge war, das sich eine ständig wachsende Gruppe von de facto entlassenen Arbeitern im Erzgebirge aufhielt und von den Kommunalverwaltungen aufmerksam beobachtet wurde. Stellenweise wurde diese Entwicklung mit dem Ansteigen der Kriminalitätsstatistik in einen kausalen Zusammenhang gebracht. Das Amtsgericht Aue unterstrich in einem Schreiben an den SED-Landesvorstand: „Um das Bergbaugebiet von Elementen zu säubern, die keiner geregelten Arbeit nachge-

47 Ebenda.

$48 \mathrm{BAB}, \mathrm{DQ} 2 / 1152$, Protokoll über Sitzung am 24. 1. 1950, S. 2-4.

$49 \mathrm{BAB}, \mathrm{DQ} 2 / 2093$, Bericht des Ministeriums für Arbeit und Gesundheitswesen (Kliemann) über eine Arbeitstagung in Zwickau am 9./10. 2. 1950 und über eine Besprechung in Siegmar-Schönau am 11. 2. 1950, S. 2. Vgl. Roeling, Arbeiter im Uranbergbau, S. $118 \mathrm{f}$. 
hen, muß die Entpflichtungsfrage gelöst werden. “50 Als Sofortmaßnahme wurde sogar die Einrichtung von Heimen "für soziale Betreuung" gefordert, in der alle diejenigen untergebracht werden sollten, "die sich heute noch im Bergbaugebiet herumtreiben." Ende April 1950 sprach sich Karl Litke vom Ministerium für Arbeit und Gesundheitswesen dafür aus, daß in den Fällen, wo Arbeitskräfte nach Ablauf ihres Vertrages ohne Entlassungspapiere zurückgekehrt waren, der Bürgermeister des Heimatortes zunächst einen Ersatz-Personalausweis ausstellen sollte ${ }^{51}$. Anschließend hatte das zuständige Arbeitsamt eine Ersatz-Arbeitsbuchkarte auszustellen. Damit versuchte das Ministerium, eine pragmatische Lösung in dieser Frage herbeizuführen, nachdem die sowjetische Besatzungsmacht offensichtlich nicht bereit gewesen war, selber eine Entscheidung zu treffen. Litke vertrat den Standpunkt, der im übrigen den arbeitsrechtlichen Bestimmungen entsprach, daß mit Ablauf eines Arbeitsvertrages auch kein Arbeitsverhältnis mehr bestand. Das Arbeitsministerium in Berlin blieb bei dieser Position und machte die Landesverwaltungen wiederholt darauf aufmerksam, daß erst nach Aushändigung der Ersatzpapiere (Arbeitsbuch, Personalausweis) soziale Leistungen wie die Arbeitslosenunterstützung ausgezahlt werden könnten ${ }^{52}$.

Um den Zustrom in das Erzgebirge besser koordinieren zu können, gab die sächsische Landesregierung am 27. Februar 1950 ein Merkblatt an alle Arbeitsämter in der DDR heraus, welches Richtlinien über die Abfertigung von Bergarbeitertransporten enthielt ${ }^{53}$. Entsprechende Vorschriften hatte das Ministerium für Arbeit und Gesundheitswesen bereits am 11. Februar 1949 veröffentlicht, die aber nunmehr der sich verändernden Situation im Uranbergbau angepaßt werden sollten. Von zentraler Bedeutung für die Arbeitsverwaltung war die darin enthaltene Forderung, einzelne Arbeiter "nach Möglichkeit“ nicht zu überweisen. Statt dessen sollten die jeweiligen Arbeitsämter Sammeltransporte zusammenstellen und diese vorab mit der sächsischen Landesverwaltung abstimmen. Auf diese Weise sollte eine reibungslose Unterbringung in den einzelnen Bezirken des Erzgebirges gewährleistet werden. Darüber hinaus wurde erneut auf die Tauglichkeitsprüfung hingewiesen, die vor Transportbeginn durch eine Ärztekommission durchzuführen war. Die Rückführung von Arbeitskräften, die untertage nicht eingesetzt werden konnten, sollte dadurch von vornherein vermieden werden. Die anderen Landesregierungen begannen etwa zeitgleich damit, Arbeitskräftekontingente aus den Reihen der Angestellten bei den öffentlichen Verwaltungen für die Wismut AG zusammenzustellen ${ }^{54}$. Diese Maßnahme, die auf einen Beschluß der DDR-Regierung vom 13. Februar 1950 zurückging, sollte Mobilisierungseffekte für die gesamte Wirtschaft auslösen sowie einen ersten Beitrag dazu

50 BAB, DQ 2/2095, Bericht des Amtsgerichts Aue vom 8. 3. 1950 an den SED-Landesvorstand in Dresden, S. 3.

51 Ebenda, Litke am 25.4. 1950 an die Abteilungen A V und A III.

$52 \mathrm{BAB}, \mathrm{DQ} 2 / 1870$, Hauptabteilungsleiter Litke am 14.7. 1950 an die Landesregierungen von Brandenburg, Mecklenburg und Sachsen-Anhalt. Ein gleichlautendes Schreiben ging auch an die Landesregierung Sachsen. Vgl. SächsHStA, Landesregierung Sachsen, Ministerium für Arbeit und Sozialfürsorge, Bd. 397.

53 SächsHStA, Landesregierung Sachsen, Ministerium für Arbeit und Sozialfürsorge, Bd. 404.

54 Vgl. ThHStA, Land Thüringen, Büro des Ministerpräsidenten, Bd. 1685-1688, Bl. 74-76, Rundverfügung Nr. 43/50 des MdI des Landes Thüringen vom 7. 3. 1950. 
leisten, den gestellten Anforderungen einigermaßen gerecht zu werden. Über den weiteren Verlauf dieser Aktion in dieser Phase ist jedoch nichts bekannt, so daß von einem raschen Abbruch zunächst ausgegangen werden muß.

Die Arbeitsämter erhielten von Mitarbeitern der zuständigen Landesverwaltung bzw. des Ministeriums für Arbeit und Gesundheitswesen wiederholt die Anweisung, auf die Prüfung der Bergbautauglichkeit zu achten. Anfallende Transport- und Rückführungskosten sollten - wie bereits erwähnt - eingespart werden. Außerdem wurde stets der Personenkreis aufgezählt, der für die Tätigkeit bei der Wismut AG nicht in Frage kam. Dazu gehörten die sogenannten "Westgänger" sowie die Kriegsgefangenen, die sich in Lagern der drei Westalliierten befunden hatten. Neben diesen sicherheitspolitischen Aspekten waren jedoch auch arbeitsschutzrechtliche Kriterien ausschlaggebend, deren Einhaltung die deutsche Arbeitsverwaltung anstrebte. So durften beispielsweise keine Jugendlichen unter 18 Jahren zugewiesen werden ${ }^{55}$, und für Frauen galten besondere Einstellungsbedingungen. Die Beschäftigung von weiblichen Arbeitskräften im Untertagebergbau wurde ausdrücklich untersagt. Inwieweit sich die Direktion der Wismut AG bzw. die einzelnen Schachtleitungen an diese Bestimmungen hielten, läßt sich nicht eindeutig beantworten. Die Arbeitsverwaltung war zwar für die Zuführung von Arbeitskräften zum Uranbergbau verantwortlich, dies schloß allerdings nicht die Eigenwerbung durch einzelne sowjetische Direktoren aus. Da die Schachtanlagen für die Vertreter der Arbeitsämter verschlossen blieben, konnte auch keine Überprüfung der Belegschaften durchgeführt werden. Die Einstellung von Frauen beschränkte sich wiederum auf Tätigkeiten außerhalb der Schachtanlagen, vor allem wohl auf Verwaltungstätigkeiten. Dennoch waren die sowjetischen Anforderungen auch hier beträchtlich: So sollten im Laufe des Monats April 19506000 weibliche Arbeitskräfte gewonnen werden, die allein das Land Sachsen aufzubringen hatte 56 .

Die sowjetische Besatzungsmacht kritisierte des öfteren den ihrer Ansicht nach schleppenden Verlauf der Werbemaßnahmen zugunsten der Wismut AG. Wilhelm Pieck notierte nach einem Treffen mit führenden SKK-Vertretern, daß während des I. Quartals statt 45000 nur 16000 Arbeitskräfte gewonnen worden seien. Dem Politbüro wurde offenbar ein Beschlußentwurf vorgelegt, demzufolge jeweils 40000 Arbeiter für das II. und III. Quartal sowie 25000 für das IV. Quartal zu stellen waren ${ }^{57}$. Kurz darauf erteilte die SED-Führung einer Kommission den Auftrag, zu überprüfen, „wie die nötigen Arbeitskräfte aufgebracht und wie zugleich die Anforderungen herabgesetzt werden können" ${ }^{58}$. Die Kritik der SKK richtete sich im übrigen nicht nur gegen die SED und das Arbeitsministerium,

55 SächsHStA, Landesregierung Sachsen, Ministerium für Arbeit und Sozialfürsorge, Bd. 307, Niederschrift über die Amtsleitertagung vom 21.3. 1950 in Kirchberg/Sa., S. 2.

$56 \mathrm{BAB}, \mathrm{DQ} 2 / 2093$, Protokoll der HA Arbeit über die Tagung der Amtsleiter und Sonderbeauftragten für den Bergbau am 4. 4. 1950 bei der Landesregierung Sachsen, S. $2 \mathrm{f}$.

57 SAPMO, NY 4090/736, Bl. 103, Besprechung am 6. 4. 1950 mit Tschuikow und Iljitschow. Badstübner/Loth geben für das IV. Quartal die Zahl 40000 an. Vgl. Badstübner/Loth, Wilhelm Pieck, S. 341 .

58 SAPMO, DY 30/IV 2/2/83, Bl. 29, Protokoll der Sitzung des Politbüros am 11. 4. 1950. Der Kommission gehörten an: Max Herm, Willi Stoph, Alexander Starck, Ernst Zöllner, Paul Peschke und Karl Litke. 
sondern auch gegen die sächsische Landesregierung, die nach wie vor die Hauptlast bei der Bereitstellung von Arbeitskräften für die Wismut AG trug59. Gleichzeitig erschwerte die sowjetische Besatzungsmacht die Werbeaktivitäten der deutschen Verwaltungen, indem etwa die Genehmigung zur Drucklegung von Werbebroschüren nicht erteilt wurde ${ }^{60}$. Sicherheitspolitische Bedenken hatten vermutlich die SKK dazu bewogen, auf eine Thematisierung des Uranbergbaus in der Öffentlichkeit zu verzichten. Damit befand sich jedoch die Arbeitsverwaltung in einem Dilemma: Auf der einen Seite sollte sie Maßnahmen ergreifen, um verstärkt Arbeitskräfte zu gewinnen, auf der anderen Seite wurde ihr Handlungsspielraum auf diese Weise erheblich eingeschränkt. In der Folgezeit wurden Eigeninitiativen einzelner Arbeitsämter sofort unterbunden. So hatte etwa das Arbeitsamt Merseburg in einem Rundschreiben an alle Betriebe und gesellschaftlichen Organisationen den Abbau von uranhaltigen Erzen kurz angedeutet. Daraufhin wurden alle Arbeitsämter darüber informiert, daß „eine Mitteilung über den Charakter der Produktion" der Wismut AG zukünftig nicht mehr zugelassen werden könne ${ }^{61}$.

Verwaltungstechnische Gründe sowie die fehlende Bereitschaft der Direktion der Wismut AG, konkrete Absprachen zu treffen, waren jedoch nicht alleine ausschlaggebend für die wachsende Diskrepanz zwischen Bedarfsanmeldung und -deckung. Hier wäre vor allem auf den Umstand zu verweisen, daß Arbeitskraftreserven in nennenswertem Umfange nicht mehr zur Verfügung standen. Außerdem wurde erneut deutlich, daß die Interessen von Arbeitsämtern und Betrieben auch in der sich immer stärker herausbildenden Zentralverwaltungswirtschaft nicht zwangsläufig kongruent waren. $\mathrm{Da}$ auf das Instrument der Zwangseinweisung nicht mehr zurückgegriffen werden durfte, meldeten zahlreiche Arbeitsämter, daß sich volkseigene Betriebe weigerten, Arbeitskräfte für den Uranbergbau abzustellen ${ }^{62}$. Darüber hinaus verfügte die Arbeitsverwaltung nicht über die entsprechenden Möglichkeiten, die Betriebe systematisch auf eine mögliche Überbelegung zu durchkämmen, um dadurch Arbeitskräfte für den sächsischen Erzbergbau freisetzen zu können. Bis zu ihrer Auflösung im Sommer 1951 konnten die Arbeitsämter nur Appelle an die Betriebe richten, einen Beitrag zur Abdeckung des Arbeitskräftebedarfs zu leisten. Vertreter der SED-Führung, des Arbeitsministeriums und des FDGB gelangten angesichts dieser Lage zu der Schlußfolgerung, daß die Werbung der Arbeitskräfte "vor allen Dingen auf dem Lande erfolgen“ müsse ${ }^{63}$. Dort wurden offenbar keine bzw. sehr viel geringere Schwierigkeiten bei der Mobilisierung neuer Arbeitskräfte für den Uranbergbau erwartet. Die Verantwortung für die ausgebliebene Plansoll-Erfüllung schob das Berliner Arbeitsministerium auf einzelne Landesverwaltungen ab: Im Zentrum der Kritik standen da-

59 SächsHStA, Landesregierung Sachsen, Ministerium für Arbeit und Sozialfürsorge, Bd. 401, Bl. 16, Vermerk des Ministeriums für Arbeit und Gesundheitswesen in Dresden vom 4. 5. 1950.

60 SächsHStA, Landesregierung Sachsen, Ministerium für Arbeit und Sozialfürsorge, Bd. 336, Schreiben (vermutlich vom sächsischen Arbeitsministerium) vom 29.4. 1950 an das Ministerium für Arbeit und Gesundheitswesen in Berlin.

61 SAPMO, NY 4090/315, Bl. 95, Merkblatt vom Mai 1950 (o.Verf.).

$62 \mathrm{BAB}, \mathrm{DQ} 2 / 2125$, Amt für Arbeit und Sozialfürsorge Nordhausen am 20.4. 1950 an das Ministerium für Arrbeit und Sozialwesen in Erfurt.

63 SAPMO, DY 30/IV 2/2.027/25, Bl. 165 f., Aktennotiz Herms über die Sitzung der Aue-Kommission am 11. 5. 1950. 
bei Brandenburg und Thüringen ${ }^{64}$, denen eine schlechte Arbeit bescheinigt wurde. Dagegen setzte sich das Arbeitsamt Aue sehr kritisch mit der Tätigkeit der mecklenburgischen Arbeitsämter auseinander, die offenbar bei einigen Transporten ins sächsische Erzgebirge eine eingehende Untersuchung der Arbeitskräfte auf Bergbautauglichkeit unterlassen hatten ${ }^{65}$.

Max Herm, der 1949 von der HVAS in den Apparat des SED-Parteivorstandes ${ }^{66}$ bzw. des ZK gewechselt war und dort die Abteilung IV leitete, unterbreitete Mitte Mai 1950 zunächst intern einen Katalog von Vorschlägen, die zu einer deutlichen Verbesserung der Arbeitskräfteversorgung und der Arbeitsbedingungen im Uranbergbau beitragen sollten. Die Werbung von Arbeitskräften konnte seiner Auffassung nach nicht mehr allein Aufgabe der Arbeitsämter sein, sondern sollte „als nationale Aufgabe zur Erfüllung [der] Wirtschaftspläne" angesehen werden ${ }^{67}$. Daraus zog Herm die Konsequenz, die SED-Landesvorstände stärker als bisher zur Erfüllung der sowjetischen Anforderungen einzubinden. Diese sollten sogar „die Führung bei der Werbung für die Wismut AG [...] übernehmen" und für die Einhaltung der Arbeitskräftepläne sorgen. Auch Herm sprach sich dafür aus, mit Unterstützung der VdgB und der IG Land- und Forstwirtschaft Arbeiter vor allem aus der Landwirtschaft für die Wismut AG abzuwerben. Der primäre Wirtschaftssektor sei mit männlichen Arbeitskräften überbesetzt, die sich im Gegensatz zum sekundären Sektor zu über 50 Prozent aus den Altersgruppen der 18- bis 50-Jährigen zusammensetzen würden. Gerade diese Personengruppen kämen für den Einsatz im Uranbergbau besonders in Frage. Der SED-Funktionär, der sich kaum Gedanken über die Konsequenzen dieser Lenkungsmaßnahmen machte, ging davon aus, daß im Zuge der fortschreitenden Mechanisierung der Landwirtschaft eine Nachfragelücke gar nicht erst entstehen würde. Darüber hinaus griff Herm das Konzept wieder auf, Verwaltungsangestellte für die Tätigkeit im Erzbergbau zu mobilisieren. Diese "Umsetzung“ von Arbeitskräften weitete er jedoch auch auf die SAG-Betriebe sowie die volkseigenen Betriebe aus. Um die Verwaltungsarbeit effektiver gestalten und zwischen der Zentral- und Landesverwaltung eine reibungslose Zusammenarbeit gewährleisten zu können, sollte beim Ministerium für Arbeit und Gesundheitswesen eine Zentralstelle „für alle Fragen der Wismut AG" eingerichtet werden ${ }^{6}$. Daneben plädierte Herm für den Aufbau einer eigenen Abteilung innerhalb der Generaldirektion der Wismut AG, die sich ausschließlich mit Fragen der Arbeitskräftelenkung befassen sollte; dieser Vorschlag war jedoch von der sowjetischen Zustimmung abhängig und angesichts der bisherigen Kooperation eher unwahrscheinlich.

Herms Vorschlag, innerhalb des Ministeriums eine eigene Abteilung für den Uranbergbau aufzubauen, wurde allerdings nicht aufgegriffen, obwohl die Abdeckung des sowjetischen Bedarfs nach wie vor eine vordringliche Aufgabe der Arbeitsverwaltung blieb. Statt dessen versuchte das Arbeitsministerium in Berlin,

64 Ebenda, Bl. $165 \mathrm{f}$.

65 SächsHStA, Landesregierung Sachsen, Ministerium für Arbeit und Sozialfürsorge, Bd. 397, Arbeitsamt Aue am 13. 5. 1950 an das Landesarbeitsamt Sachsen.

66 Vgl. Die SED. Ein Handbuch, S. 974.

67 SAPMO, DY 30/IV 2/2.027/25, Bl. 167-169, hier Bl. 167, Vorschläge Herms vom 16. 5. 1950.

68 Ebenda, Bl. 168. 
den zuständigen Landesämtern direkte Anweisungen zu erteilen. Gleichzeitig wurde die Zusammenarbeit mit dem FDGB, der IG Bergbau und der FDJ intensiviert: Auf Initiative des Ministeriums für Arbeit und Gesundheitswesen hatte sich eine Kommission gebildet, die Maßnahmen zur Plansollerfüllung ausarbeitete, welche jedoch keine wesentlichen Neuerungen enthielten und vor allem unverbindlich gehalten waren ${ }^{69}$. Demzufolge sollten FDGB und FDJ in den Betrieben „freiwillige Aktivs" mobilisieren, die sich verpflichten, ein Jahr bei der Wismut AG zu arbeiten. Außerdem waren sich die Kommissionsmitglieder darüber einig, die Werbemaßnahmen auf die Landarbeiter ${ }^{70}$ auszudehnen. Nur vereinzelt wurde vor einem überhasteten Vorgehen gewarnt ${ }^{71}$ : Erst nach Vorlage eines genauen Arbeitskräfteplanes für die einzelnen Länder, der mit den Industrieministerien abzustimmen war, sollten die Arbeitsämter dazu übergehen, Arbeiter aus anderen Betrieben abzuziehen, sofern diese überbelegt waren. Die Landesregierungen gerieten wiederum in den Mittelpunkt der Kritik von seiten der Gewerkschaften. Der Zentralvorstand der IG Bergbau bemängelte beispielsweise, daß Arbeiter ohne vorherige ärztliche Untersuchung zum Uranbergbau überwiesen würden ${ }^{72}$. Im Sommer 1950 erfolgte eine nicht unwichtige organisatorische Veränderung: Der Uranbergbau wurde aus dem Zuständigkeitsbereich der IG Bergbau herausgelöst und in einer eigenen Industriegewerkschaft zusammengefaßt. Die Gründung der IG Wismut, die innerhalb des FDGB nicht nur auf Zustimmung gestoßen war ${ }^{73}$, entsprang vermutlich auch dem sowjetischen Bestreben, die Wismut AG verwaltungstechnisch unabhängig zu belassen. Für eine vorsichtige Bewertung des Verhältnisses von Wismut AG und deutschen Ministerien ist im übrigen die Tatsache aufschlußreich, daß einzelne Abteilungen der sowjetischen Generaldirektion Anfang Juli 1950 noch keine Kenntnis von der Existenz der neuen Industriegewerkschaft hatten ${ }^{74}$.

Erschwerend kam hinzu, daß sich das Ministerium für Arbeit und Gesundheitswesen wiederholt mit Klagen einzelner Betriebe auseinandersetzen mußte, die gegen die anhaltende Abwanderung von Beschäftigten zum Uranbergbau protestierten. Es war offenbar nicht gelungen, die Interessen der Wismut AG und der übrigen Wirtschaftszweige in Einklang zu bringen. Angesichts der begrenzten Verfügbarkeit an bergbautauglichen Arbeitskräften war dies letztlich nicht verwunderlich. Gleichwohl war die SED-Führung mit dem Anspruch angetreten, im Zuge der allgemeinen Wirtschaftsplanung für eine reibungslose und bedarfsgerechte Steuerung des Faktors ,Arbeit' sorgen zu können. Einzelne Betriebe, wie etwa die Papierfabrik Antonsthal der VVB Papier, wandten sich zunächst an den zuständigen SED-Kreisverband, um auf die drohenden Produktionseinbußen

69 BAB, DQ 2/906, Bl. 216-218, Bericht von Staatssekretär Peschke vom 24. 5. 1950.

70 Vgl. zur Politik gegenüber dieser sozialen Gruppe die Überlegungen von Bauerkämper, Aufwertung und Nivellierung.

$71 \mathrm{BAB}, \mathrm{DQ} 2 / 2094$, Schreiben Sindermanns vom 31. 5. 1950 an Max Herm.

72 Das geht aus einem Schreiben von Hauptabteilungsleiter Litke hervor. Vgl. BAB, DQ 2/2092, Hauptabteilungsleiter Litke am 19.5. 1950 an das thüringische Ministerium für Arbeit und Gesundheitswesen (HA Arbeit).

73 Engeln, Die industriellen Beziehungen im Uranbergbau, S. 193.

74 So äußerte sich etwa der Leiter der Informationsabteilung. Vgl. SAPMO, DY 34, 15/25/1067, Bericht Ernst Zöllners vom 3. 7. 1950. 
aufmerksam zu machen ${ }^{75}$. Außerdem wurde in diesem Einzelfall das Ministerium für Industrie, Hauptabteilung Leichtindustrie, mit der Bitte eingeschaltet, Verhandlungen mit der Generaldirektion der Wismut AG aufzunehmen, um einen Einstellungsstopp zu erwirken ${ }^{76}$. Das Arbeitsministerium sah keine Möglichkeit, die bisherige Praxis der Arbeitskräftegewinnung für den Uranbergbau im Interesse des betroffenen Betriebes zu revidieren: „Die Wismut AG zu bitten, eine Anweisung an ihre Personalabteilungen zu geben, daß sie grundsätzlich keine Arbeitskräfte aus volkseigenen Betrieben einstellen dürfen, ist unmöglich, abgesehen davon, daß sich die Wismut AG hier keine Vorschriften machen läßt. "77 Darüber hinaus befürchtete das Arbeitsministerium einen drastischen Rückgang der Arbeitskräftezuweisungen, falls die sowjetische Generaldirektion dem Anliegen nachkommen würde. $\mathrm{Da}$ die Abdeckung des Arbeitskräftebedarfs eine herausgehobene Bedeutung besitze und gleichzeitig auf das Zwangsinstrument der Arbeitseinweisung nicht mehr zurückgegriffen werden solle, bleibe den Arbeitsämtern kein anderer Ausweg, als Beschäftigte aus anderen Betrieben abzuwerben. In dem Zusammenhang forderte der zuständige Abteilungsleiter Huth das Ministerium für Industrie auf, vermehrt Frauen einzustellen und weibliche Jugendliche gezielt auszubilden.

Die sächsische Landesregierung berichtete Anfang Juni 1950 ausführlich über die ergriffenen Maßnahmen zur Werbung zusätzlicher Arbeitskräfte und listete dabei die Aktivitäten der einzelnen Arbeitsämter des Landes detailliert auf ${ }^{78}$. Dabei wurde erneut deutlich, daß Sachsen nicht in der Lage war, die Hauptlast der Arbeitskräfteanforderungen alleine zu tragen, ohne den Produktionsablauf in anderen Wirtschaftszweigen durch die Abwanderung von Arbeitern zu gefährden. Ein Hauptproblem stellte in dem Zusammenhang die unkontrollierte Fluktuation vom Stein- und Braunkohlenbergbau zum Uranbergbau dar, die bereits frühzeitig durch die Arbeitsverwaltung registriert worden war. Einige Landesregierungen hatten daraufhin versucht durchzusetzen, daß Beschäftigte nur nach vorheriger Zustimmung des jeweiligen Arbeitsamtes ihren Arbeitsplatz wechseln durften. Diese Forderung wäre de facto einem Einstellungsstopp durch die Generaldirektion der Wismut AG gleichgekommen, was wiederum unrealistisch war: Die sowjetische Grubenleitung ließ sich in ihren Kompetenzen in dem Maße nicht einengen. Es konnte kein Zweifel daran bestehen, daß der Gewinnung neuer Arbeitskräfte immer noch oberste Priorität eingeräumt wurde. Gleichwohl schien die Wismut AG bereit zu sein, die im Zuge der Fluktuation auftretende Belastung für die anderen Zweige der Grundstoffindustrie so gering wie möglich zu halten. Der Leiter der Personalabteilung bei der Wismut AG, Oberstleutnant Kolopkow, betonte gegenüber Mitarbeitern des Berliner Arbeitsministeriums am 26. Mai 1950, daß „er es nicht billige, wenn einzelne Objekte der Wismut AG Arbeitskräfte aus dem Steinkohlenbergbau [...] einstellen, ohne daß das zuständige Amt für Arbeit

$75 \mathrm{BAB}, \mathrm{DQ}$ 2/2147, Papierfabrik Antonsthal am 26.5. 1950 an den SED-Kreisvorstand in Aue/Sa. (Abt. Wirtschaft).

76 Ebenda, VVB Papier am 17.6. 1950 an das Ministerium für Industrie (HA Leichtindustrie).

77 Ebenda, Abteilungsleiter Huth am 22.7. 1950 an das Ministerium für Industrie (HA Leichtindustrie).

$78 \mathrm{BAB}, \mathrm{DQ}$ 2/2093, Ministerium für Arbeit und Gesundheitswesen in Dresden am 5.6. 1950 an das Ministerium für Arbeit und Gesundheitswesen in Berlin. 


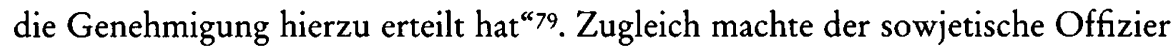
jedoch deutlich, daß die benötigten Arbeiter "auf jeden Fall“ zu stellen seien.

Der Freiwilligenwerbung widersetzten sich bekanntlich zahlreiche SAG-Betriebe. Die Landesregierungen mußten daher dem Berliner Arbeitsministerium des öfteren mitteilen, daß sie entsprechende Maßnahmen dort nicht durchführen konnten. Hauptabteilungsleiter Litke wandte sich am 15. Juni 1950 mit der Bitte an die SKK in Karlshorst, die Leitungen der SAG-Betriebe darauf hinzuweisen, daß es zweckmäßig sei, wenn Einzelabsprachen mit den zuständigen Arbeitsämtern getroffen würden und die Werbung zugelassen werde ${ }^{80}$. Der Kreis der bergbautauglichen Personen sei - so Litke - „nicht allzu groß“, so daß es durchaus möglich sei, „Ersatzkräfte für die abgehenden Arbeitskräfte zu stellen“. Als Arbeitskraftreserve nannte der Hauptabteilungsleiter Erwerbsbeschränkte und Frauen. Es liegen keine Hinweise vor, inwieweit es gelang, zu solchen bilateralen Vereinbarungen zwischen den Arbeitsämtern und den SAG-Betrieben zu kommen. Angesichts der zuvor gemeldeten Blockadehaltung muß allerdings der mögliche Erfolg als sehr gering eingeschätzt werden. Letztlich war die Besatzungsmacht an fortlaufenden Reparationsentnahmen interessiert; dieses Ziel sollte nicht gefährdet werden ${ }^{81}$.

Die Arbeitsämter im Einzugsbereich der Wismut AG wurden stellenweise unzureichend und verspätet über eintreffende Bergarbeitertransporte aus den anderen Ländern informiert. Mitunter gingen die Transporte direkt zu den sogenannten Objekten, d.h. den Schachtanlagen, wobei die zuständigen Arbeitsämter erst anschließend Kenntnis erhielten. Auf diese Weise wurde jedoch das Bestreben zunichte gemacht, die Zuweisung von Arbeitskräften besser zu koordinieren und damit effektiver zu gestalten. Das Arbeitsamt Aue zeigte sich verärgert über die ausgebliebene Absprache bei einzelnen Transporten und protestierte bei der sächsischen Landesregierung ${ }^{82}$, welche die Klage an das Ministerium in Berlin weiterleitete ${ }^{83}$. Die Landesarbeitsämter waren zwar in der Vergangenheit mehrfach aufgefordert worden, darauf zu achten, daß sämtliche Arbeitskräfte, die der Wismut AG zugeteilt werden sollten, auf ihre Bergbautauglichkeit überprüft werden. $\mathrm{Da}$ die zeitlichen Fristen oftmals kurz gesetzt und die Landesverwaltungen mit dieser Aufgabe offensichtlich überfordert waren, kam es immer häufiger vor, daß diese Anweisung nicht befolgt wurde. Die daraus resultierende Fehlvermittlungsquote, die im ersten Halbjahr 1950 merklich angestiegen war, ließ sich nicht wirksam bekämpfen, weil die Arbeitsämter des Uranbergbaus bei zahlreichen Bergarbeitertransporten übergangen wurden. Somit entfiel nämlich die letzte Kontrollinstanz, und die sächsische Arbeitsverwaltung sah sich mit einer neuen Aufgabe konfrontiert: der Rückführung der von den Schachtleitungen abgelehnten Arbeiter. Nach

$79 \mathrm{BAB}, \mathrm{DQ}$ 2/2094, Hauptabteilungsleiter Litke am 15.6. 1950 an das Ministerium für Industrie (HA Kohle).

80 BAB, DQ 2/2094.

81 Karlsch, Die Arbeitsverhältnisse in den Betrieben der SAG, S. 298.

82 BAB, DQ 2/2094, Arbeitsamt Aue am 10.5. 1950 an das sächsische Ministerium für Arbeit und Gesundheitswesen (HA Arbeit).

$83 \mathrm{Im}$ vorliegenden Einzelfall ging es um Transporte aus Mecklenburg. BAB, DQ 2/2094, Ministerium für Ärbeit und Gesundheitswesen der Landesregierung Sachsen am 25. 5. 1950 an das Ministerium für Arbeit und Gesundheitswesen (HA Arbeit). 
Mitteilung von Hauptabteilungsleiter Litke betrug der Anteil der Fehlvermittlungen Ende Mai bereits 12 Prozent $^{84}$. Der damit zusammenhängende finanzielle Mehraufwand, den er mit 100 DM pro Person angab, sei untragbar. Das Berliner Arbeitsministerium strebte im übrigen eine Kostenübernahme durch die Länder an. Die Landesregierung Mecklenburg, die wegen der unzureichenden Durchführung der Bergarbeitertransporte besonders in die Kritik geraten war, gab daraufhin eine Anweisung an alle Arbeitsämter des Landes heraus, die sowohl die Werbung als auch die Zuweisung von Arbeitskräften für den Uranbergbau in Sachsen genau festlegen sollten ${ }^{85}$. Dabei wurden die Arbeitsämter darauf hingewiesen, „eine sorgfältige Auswahl“ der Arbeitskräfte vorzunehmen ${ }^{86}$. Die hinzuzuziehenden Amtsärzte sollten die Untersuchungen „nach den strengsten Maßstäben“ vornehmen. Darüber hinaus sah die Anweisung detaillierte Vorschriften für den Transportverlauf sowie dessen Übergabe an die einzelnen Objekte vor. Dennoch gingen nach wie vor Klagen von seiten der sächsischen Landesregierung ein, so $\mathrm{da}$ sich das Berliner Arbeitsministerium veranlaßt sah, nochmals zu betonen, daß durch die direkte Lenkung der Bergarbeitertransporte zu den einzelnen Schachtanlagen „ein völliges Durcheinander" entstehe ${ }^{87}$. Diese Auseinandersetzung machte erneut deutlich, daß die Anweisungen der Verwaltungen auch zu diesem Zeitpunkt nur eine begrenzte Durchschlagskraft besaßen.

Die Generaldirektion der Wismut AG ging von einem Arbeitskräftebedarf für das laufende Jahr 1950 in Höhe von 100000 aus $^{88}$. Diese Zahl demonstrierte die anhaltend große Nachfrage, die letztlich mit den in den Arbeitsverträgen enthaltenen kurzen Laufzeiten von maximal sechs Monaten zusammenhing. Die dadurch bedingte, quasi natürliche Fluktuationsrate wurde noch verstärkt durch die eigenständige Abwanderung einzelner Bergarbeiter, die mit den Arbeits- und Lebensbedingungen im sächsischen Erzbergbau unzufrieden waren. Der FDGBBundesvorstand regte in dem Zusammenhang die Ausarbeitung eines Arbeitskräfteabdeckungsplanes an, der die Abwanderungsbewegung zu berücksichtigen hatte. Darüber hinaus sollte dieser Plan aber gleichzeitig die Prioritäten bei der Zuteilung von Arbeitskräften deutlich werden lassen. Das Ministerium für Arbeit und Gesundheitswesen informierte die Landesministerien über diesen Vorstoß und bat um Stellungnahme ${ }^{89}$. Die sächsische Landesregierung hielt die Erstellung eines Gesamtplanes, in dem die Auflagen für den Erzbergbau auf die einzelnen Betriebe aufgeschlüsselt werden sollten, für undurchführbar ${ }^{90}$. Bereits 1948 seien die Betriebe in drei Dringlichkeitsstufen eingeteilt worden. In dem Zusammenhang hätten die Arbeitsämter die Anweisung erhalten, Arbeitskräfte aus den zur

84 BAB, DQ 2/2094, Hauptabteilungsleiter Litke am 22. 5. 1950 an das mecklenburgische Ministerium für Arbeit und Gesundheitswesen.

85 Ebenda, Anweisung I a - 34/50 vom 28. 6. 1950.

86 Ebenda, S. 1.

87 BAB, DQ 2/2094, Abt. Arbeitskraftlenkung am 5. 7.1950 an das Ministerium für Arbeit und Gesundheitswesen in Schwerin.

88 SAPMO, DY 34, 15/25/1067, Bericht Ernst Zöllners vom 3. 7. 1950. Zöllner hatte kurz zuvor eine Unterredung mit dem stellvertretenden Leiter der Informationsabteilung in Chemnitz geführt.

89 BAB, DQ 2/2094, Abt. Arbeitskräftelenkung am 17.7. 1950 an alle Ministerien für Arbeit und Gesundheitswesen in den Ländern.

90 Ebenda, Ministerium für Arbeit und Aufbau des Landes Sachsen am 9. 9.1950 an das Ministerium für Arbeit und Gesundheitswesen. 
Dringlichkeitsstufe I zählenden Betrieben nicht abzuziehen. Dadurch seien wiederum die Möglichkeiten der Arbeitsverwaltung, Arbeitskräfte für den Uranbergbau zu gewinnen, erheblich eingeschränkt worden, so das sächsische Landesministerium in seiner Begründung. Eine zusätzliche Belastung bedeutete außerdem die Erteilung besonderer Auflagen, die dazu führen konnten, daß Betriebe aus der III. in die I. Stufe aufrückten und auf diese Weise keine Arbeiter abzugeben brauchten.

Während sich die Arbeitsverwaltung darum bemühte, Arbeitskräfte für den Uranbergbau zu gewinnen, wiesen Betriebe der Schwerindustrie immer häufiger auf die Folgen der lohnbedingten Fluktuation für die eigene betriebliche Produktion hin ${ }^{91}$. Das Ministerium für Arbeit und Gesundheitswesen registrierte zwar die Klagen einzelner volkseigener Betriebe, ordnete deren Anliegen aber stets dem Ziel der Plansollerfüllung für die Wismut AG unter. Die Bereitschaft der übrigen Wirtschaftszweige und der sie leitenden Industrieministerien, einen Beitrag zur Stabilisierung bzw. zum Ausbau des Beschäftigtenbestandes bei der Wismut AG zu leisten, war begrenzt und schien sogar deutlich abzunehmen. So weigerten sich offenbar zahlreiche thüringische Textilbetriebe im Sommer 1950, Arbeitskräfte abzugeben'2. Das zuständige Ministerium für Arbeit und Sozialwesen in Erfurt zeigte Verständnis für diese Reaktionen auf betrieblicher Ebene ${ }^{93}$. Gleichzeitig verpflichtete jedoch die thüringische Landesregierung offiziell alle Verwaltungen des Landes, aktiv an der Werbung von Arbeitskräften mitzuwirken. Das aufgestellte Plansoll wurde "als verbindlich“ und zur „Schwerpunktaufgabe“ der Landesverwaltung erklärt ${ }^{94}$. Auf Anfrage stellte das Arbeitsministerium in Berlin fest, daß Facharbeiter, ,an denen ein Mangel besteht, der Wismut AG nicht zur Verfügung zu stellen [sind], auch wenn sie sich freiwillig melden "95. Diese Bestimmung bezog sich ausdrücklich auf die Textilindustrie, galt jedoch auch für andere Wirtschaftszweige und schränkte letztlich den zuvor erlassenen Aufruf erheblich ein. Die thüringische Landesregierung bemühte sich zwar auch weiterhin, den Auflagen nachzukommen, das zukünftige Hauptinteresse lag jedoch vor allem in der Senkung der sogenannten Fehllenkungsquote ${ }^{96}$. Es sollte verhindert werden, daß Bergarbeitertransporte wieder zurückgeschickt werden mußten.

In einem Bericht über die Entwicklung der „Arbeitslage“ in der DDR im ersten Halbjahr 1950 mußte das Ministerium für Arbeit und Gesundheitswesen einräu-

9 Vgl. BAB, DQ 2/1886, VVB VESTA Leipzig am 21.7. 1950 an das Ministerium für Arbeit und Gesundheitswesen in Berlin.

92 $\mathrm{BAB}, \mathrm{DQ}$ 2/2148, Amt für Arbeit und Sozialfürsorge Gera am 22.7. 1950 an das Ministerium für Arbeit und Sozialwesen in Erfurt.

93 Ebenda, Ministerium für Arbeit und Sozialwesen des Landes Thüringen am 27.7. 1950 an das Ministerium für Arbeit und Gesundheitswesen (HA Arbeit) in Berlin.

94 ThHStA, Land Thüringen, Büro des Ministerpräsidenten, Bd. 1685-1688, Bl. 53, Regierungsbeschluß vom 15. 8. 1950. Die einzelnen Arbeitsämter gaben diese Anweisung an die Betriebsleitungen und Betriebsgewerkschaftsleitungen weiter. Vgl. ThHStA, Land Thüringen, Ministerium für Wirtschaft und Arbeit, Bd. 3597, Bl. 233, Rundschreiben des Amtes für Arbeit und Sozialfürsorge Erfurt am 28. 8. 1950.

95 BAB, DQ 2/2148, Abt. Arbeitskraftlenkung am 21.8. 1950 an das thüringische Ministerium für Arbeit und Gesundheitswesen.

96 ThHStA, Land Thüringen, Büro des Ministerpräsidenten, Bd. 1685-1688, Bl. 49, Schreiben von Ministerpräsident Eggerath am 20.9. 1950 an den Minister für Arbeit und Sozialwesen Willy Albrecht. 
men, die Anziehungskraft des Erzbergbaus sei weiterhin so groß, daß „im Interesse wichtiger Produktionsbetriebe teilweise dem Abwandern Einhalt geboten

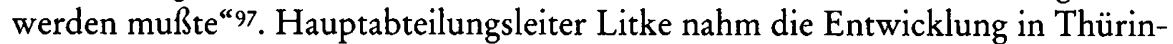
gen zum Anlaß, die Arbeitsämter hinsichtlich ihrer Werbung für den sächsischen Uranbergbau zu überprüfen. Er bemängelte, daß in den ländlichen Gebieten keine "Sichtwerbung" in Form von Plakaten betrieben worden sei98. Kurz zuvor hatte das thüringische Ministerium für Arbeit und Sozialwesen sämtliche Arbeitsamtsleiter zu einer Tagung eingeladen, um die Dringlichkeit der Arbeitskräftelenkung für die Wismut AG nochmals zu unterstreichen, die als nationale Aufgabe herausgestellt wurde 99 . Die Abteilung Arbeitskraftlenkung beim Ministerium für Arbeit und Gesundheitswesen registrierte Ende August einen erheblichen Rückstand bei der Erfüllung des Plansolls, die noch nicht einmal bei 50 Prozent lag100. Während für den Monat Juli insgesamt 25000 Arbeitskräfte angefordert worden waren, konnten doch nur 11824 gestellt werden. Mehr als die Hälfte der Arbeiter stammten aus Sachsen, das damit nach wie vor die Hauptlast bei der Abdeckung der Arbeitskräfteanforderungen trug. Die Leitung der Wismut AG hatte zuvor festgelegt, daß im III. Quartal 195070000 Arbeitskräfte bereitzustellen waren. Angesichts der geschilderten Problemlagen schien es jedoch illusorisch zu sein, den sowjetischen Erwartungen gerecht zu werden.

Die Generaldirektion der Wismut AG verhängte einen kurzfristigen Einstellungsstopp, da die Belegschaften einzelner Schachtanlagen zusammengelegt werden sollten, um dadurch Arbeitsplätze einzusparen 101. Diese Maßnahme, die weder mit der Arbeitsverwaltung noch mit der sächsischen Landesregierung abgesprochen worden war, konterkarierte die Anstrengungen der deutschen Verwaltungen, den sowjetischen Anforderungen nachzukommen und die Bergarbeitertransporte zügig in das Uranbergbaugebiet zu entsenden. Das Ministerium für Arbeit und Gesundheitswesen sah sich daraufhin gezwungen, den Landesregierungen die Einstellungssperre mitzuteilen ${ }^{102}$. Sämtliche geplanten Transporte waren daher zu stornieren und sollten erst dann wieder in Gang gesetzt werden, wenn die Wismut AG die Sperre aufheben würde. Die Beschäftigungspolitik der Wismut AG erfuhr allerdings noch eine weitere zentrale Veränderung: Neben dem vorläufigen Abbruch der Neueinstellung erfolgten im September 1950 erstmals Massenentlassungen durch die Direktion der Wismut AG, die ebenfalls mit der deutschen Arbeitsverwaltung nicht abgestimmt worden waren und am 1. September im Kreis Annaberg begannen ${ }^{103}$. Das genaue quantitative Ausmaß dieser Aktion ist nicht zu ermitteln. Es scheint aber festzustehen, daß die Entlassungen in engem Zusammenhang mit einer Mechanisierung in den einzelnen Gruben standen. Die sowjetische Leitung räumte anläßlich einer Besprechung

\footnotetext{
$97 \mathrm{BAB}, \mathrm{DQ} 2 / 1007$, Bericht vom 9. 8. 1950, S. 2.

$98 \mathrm{BAB}, \mathrm{DQ} 2 / 2094$, Vermerk Litkes vom 22. 8. 1950 für Staatssekretär Peschke.

99 Ebenda, Protokoll über die am 18. 8. 1950 im Hotel „Erfurter Hof" stattgefundene Tagung.

100 Ebenda, Abt. Arbcitskraftlenkung am 24. 8. 1950 an Staatssekretär Peschke.

101 Ebenda, Aktenvermerk der Abt. Arbeitskraftlenkung (Timme) vom 1. 9. 1950.

102 Ebenda, Abt. Arbeitskraftlenkung (Krüger) am 7.9. 1950 an den Magistrat von Groß-Berlin.

103 SächsHStA, Landesregierung Sachsen, Ministerium für Arbeit und Sozialfürsorge, Bd. 402, Ministerium für Arbeit und Aufbau Sachsen (HA Arbeit) am 10.11. 1950 an die SED-Abteilungsbetriebsgruppe Arbeit.
} 
mit deutschen Vertretern des Arbeitsministeriums aus Berlin, Dresden und Halle ein, daß die Wismut AG „in den Jahren von 1946 bis zum 1. 9. 1950 völlig falsch und unrentabel gewirtschaftet" habe ${ }^{104}$. Es sei „nicht auf Geld geachtet“ worden, und die Arbeitskräfte seien angefordert worden, „ohne zu berücksichtigen, daß diese völlig ungerechtfertigten Kräfteanforderungen weitaus höhere Kosten verursachen, als vorgesehen war." Nach Angaben der Generaldirektion wurden die Entlassungen jedoch nicht planlos vorgenommen. Vielmehr habe man - so der Stellvertreter von General Malzew, Ponomarenko - drei Kategorien gebildet: „Arbeitsbummelanten“, Personen, „die die Arbeitsmoral und Disziplin untergraben haben", und Bergarbeiter, die den Uranbergbau wieder verlassen wollten ${ }^{105}$. Die Direktion der Wismut AG schloß sich insgesamt gesehen der kritischen Beurteilung durch die deutsche Arbeitsverwaltung an. Offenbar hatten in erster Linie sicherheitspolitische Gründe für den Sinneswandel gesorgt. So räumte Ponomarenko dem Ziel sozialer Stabilität im sächsischen und thüringischen Erzbergbau eindeutig Vorrang ein: „Durch die überstürzten Kräfteanforderungen sind naturgemäß auch ,Parasiten" mit hineingekommen, die es verstanden haben, auch ohne zu arbeiten, einen ausreichenden Lohn zu erhalten. [...] Durch diese Elemente wurde die Arbeitsmoral stark untergraben, die Arbeitsdisziplin sank, und die in großer Zahl vorhandenen guten Kräfte wurden verdorben. Es war also dringend notwendig, die Ordnung in den Objekten [der Wismut AG] wieder herzustellen." 106 Abschließend vereinbarten die Vertreter der Generaldirektion und der Arbeitsverwaltung, daß zukünftig nur diejenigen Arbeitskräfteanforderungen gültig seien, die zuvor von der Leitung der Wismut AG dem Ministerium für Arbeit und Gesundheitswesen zugeleitet wurden. Dies war ein erneuter Anlauf, um zu verhindern, daß die einzelnen Grubenleitungen eigene Anweisungen herausgaben ${ }^{107}$.

Parallel dazu ging die Suche nach beschäftigungslosen Erwerbsfähigen als potentielle Arbeitskraftreserve weiter. Der Minister für Industrie Fritz Selbmann vermutete in einzelnen Ländern noch nicht erfaßte Arbeitskräfte, die es in enger Zusammenarbeit mit den Kommunalverwaltungen zu mobilisieren galt ${ }^{108}$. Somit könne das Plansoll der zu stellenden Arbeiter erfüllt werden, ohne daß Eingriffe in die Belegschaften der volkseigenen Betriebe vorgenommen werden müßten. Nach Auffassung des Arbeitsministeriums konnte es sich bei der in Frage kommenden Personengruppe nur um „arbeitsscheue Elemente“ handeln, bei denen die zuständigen Volkspolizeidienststellen eingeschaltet werden sollten ${ }^{109}$. Dagegen wurde das Instrument der Arbeitseinweisung als möglicher Lösungsweg kategorisch ausgeschlossen, da eine Verschlechterung der Stimmungslage befürchtet wurde. Die Werbung für den Erzbergbaus sollte vielmehr so durchgeführt wer-

$10+\mathrm{BAB}, \mathrm{DQ} 2 / 2094$, Bericht über die Besprechung mit der Hauptverwaltung der Wismut AG in Siegmar-Schönau am 28. 9. 1950, S. 1 f.

105 Ebenda, S. 2.

106 Ebenda, S. 2 f.

107 Ebenda, S. 4.

108 BAB, DQ 2/2094, Minister Selbmann am 10. 6. 1950 an den Ministerpräsidenten des Landes Brandenburg.

109 Ebenda, Aktenvermerk vom 29. 7. 1950. 
den, daß „eine Beunruhigung der Bevölkerung nicht eintritt" ${ }^{110}$. Statt dessen schlug die Abteilung Arbeitskraftlenkung die Auszahlung von Prämien an Mitarbeiter der Landesministerien, der Arbeitsverwaltung sowie der Massenorganisationen vor. Über Leistungsanreize erhoffte sich das Ministerium eine Verbesserung der Werbeaktivitäten und eine Steigerung der neugewonnenen Arbeiter für den Uranbergbau'111. Die Parteileitung der LDP sprach sich dafür aus, Arbeitskräften, die sich freiwillig für den Einsatz im Uranbergbau meldeten, die Rückkehr auf den angestammten Arbeitsplatz zu garantieren ${ }^{112}$. Dem Ministerium für Arbeit und Gesundheitswesen wurde vorgeschlagen, eine entsprechende Anordnung zu erlassen. Mit diesem Vorstoß rannte die Blockpartei offene Türen ein: Abteilungsleiter Huth verwies in seinem Antwortschreiben darauf, daß dieses Konzept bereits „seit einigen Monaten“ praktiziert werde"113. Es sei - so der leitende Mitarbeiter des Arbeitsministeriums - mittlerweile möglich, innerhalb der Betriebe sogenannte Betriebsaktivs zu bilden, die sich geschlossen für den Arbeitseinsatz im Uranbergbau melden. Nach Ablauf eines Jahres könnten die Mitglieder des Betriebsaktivs entscheiden, ob sie weiterhin bei der Wismut AG beschäftigt bleiben oder auf den alten Arbeitsplatz zurückkehren möchten.

Mit der Freiwilligenwerbung zum Uranbergbau sollte erst wieder ab dem 15. Oktober 1950 begonnen werden, um die laufenden Umstrukturierungsmaßnahmen bei der Wismut AG ungehindert abschließen zu können ${ }^{114}$. Zwar hatte die sowjetische Generaldirektion in einem kurz zuvor mit den Landesregierungen geschlossenen Vertrag zugesichert, einen "Werbebeitrag" von 10,- DM für jeden für den Erzbergbau geworbenen und eingestellten Arbeiter zu zahlen ${ }^{115}$, doch für die Arbeitsämter war mittlerweile die Versorgung der entlassenen Wismut-Arbeiter zur vordringlichen Aufgabe geworden. Im Zuge dieser Entlassungswelle gelangte ein Thema wieder auf die politische Agenda, das zuvor nicht geregelt worden war: die Ausgabe von einbehaltenen Personalausweisen. Hauptabteilungsleiter Litke teilte dem Ministerium des Innern mit, daß sich die Wismut AG dazu bereit erklärt habe, Ausweise von Personen, die nicht mehr bei ihr beschäftigt sind, an die Volkspolizeiämter des Erzbergbaugebietes auszuhändigen $^{116}$. Von dort sollten sie dann an die Volkspolizeiämter der Heimatkreise weitergeleitet werden. Strittig blieb dagegen die Frage, ob ehemaligen Wismut-Arbeitern Ersatzausweise ausgehändigt werden durften. Während die Arbeitsverwaltung diesen Schritt bejahte, um die entlassenen Arbeiter schnellstmöglich wie-

$110 \mathrm{BAB}, \mathrm{DQ} 2 / 903, \mathrm{Bl} .129$, Aktennotiz Steidles vom 24. 8. 1950.

11 BAB, DQ 2/2094, DWK-Hausmitteilung [sic] von der Abt. Arbeitskraftlenkung an Hauptabteilungsleiter Litke.

112 Ebenda, LDP-Parteileitung am 16. 8. 1950 an das Ministerium für Arbeit und Gesundheitswesen.

113 Ebenda, Huth am 25. 8. 1950 an die LDP-Parteileitung.

114 SächsHStA, Landesregierung Sachsen, Ministerium für Arbeit und Sozialfürsorge, Bd. 397, Ministerium für Arbeit und Gesundheitswesen am 5.10.1950 an das Ministerium für Arbeit und Aufbau in Dresden, S. 3.

115 Bei der Berechnung der Werbekosten sollten die bestätigten Transportlisten zugrundegelegt werden. BAB, DQ 2/2095, Ministerium für Arbeit und Gesundheitswesen Sachsen-Anhalt am 2. 11. 1950 an das Ministerium der Finanzen. Dagegen sprachen sich die Arbeitsamtsleiter in Mecklenburg dafür aus, daß die Wismut AG die gesamten Werbungskosten übernehmen sollte. BAB, DQ 2/2097, Ministerium für Arbeit und Sozialwesen Mecklenburg am 6.1.1951 an das Ministerium für Arbeit in Berlin.

116 BAB, DQ 2/1753, Litke am 10.11. 1950 an das MdI (Sekretariat des Staatssekretärs). 
der beruflich einsetzen zu können, sprach sich die Hauptverwaltung Deutsche Volkspolizei (HVDVP) kategorisch gegen den Vorschlag aus. Aus Gründen der Sicherheit - so der Chefinspekteur der Volkspolizei Lust - müsse darauf bestanden werden, daß die bei der Wismut AG abgegebenen Personalausweise der Volkspolizei zurückgegeben werden. Sicherheitspolitische Bedenken waren für die dem Innenministerium unterstehende Hauptverwaltung ausschlaggebend: „Ein doppelt ausgestellter Deutscher Personalausweis leistet den Agenten und Saboteuren Vorschub in ihrem verbrecherischen Treiben gegen die antifaschistisch-demokratische Ordnung." 117

Die Arbeitskräftelenkung im Bereich des Uranbergbaus blieb auch weiterhin gekennzeichnet von kurzfristig formulierten Zielen, die sich in erheblichem Ausmaße an den sowjetischen Interessen zu orientieren hatten. Während - wie bereits angesprochen - im September ein Einstellungsstopp erfolgt war und eine „Freisetzung" zahlreicher Bergarbeiter eingesetzt hatte, sah sich das Arbeitsministerium Ende 1950 mit einer erneuten Arbeitskräfteauflage konfrontiert. Diese für die Arbeitsverwaltung überraschend angemeldete Nachfrage resultierte daraus, $\mathrm{da} ß$ zum einen „ein bedeutender Teil“ der zwischen der Wismut AG und den Arbeitern abgeschlossenen Verträge auslief und zum anderen eine Produktionserhöhung für 1951 vorgesehen war. Arbeitsminister Chwalek wurde angewiesen, im I. Quartal 1951 zusätzlich 40000 Arbeitskräfte für den Uranbergbau zu vermitteln ${ }^{118}$. Chwalek leitete die sowjetische Anforderung eine Woche später an die Landesregierungen weiter ${ }^{119}$. In die anschließend einsetzende Werbekampagne sollten nicht nur die Massenorganisationen, sondern auch die Kammern der Wirtschaft eingebunden werden, die dagegen Einspruch erhoben. So wandte sich etwa die Industrie- und Handelskammer Sachsen-Anhalt gegen den Versuch der Arbeitsverwaltung, einzelnen IHK-Kreisgeschäftsstellen Aufgaben der Arbeitskräftewerbung für die Wismut AG zu übertragen 120 .

Die thüringische Landesregierung erwog kurzzeitig, beim Ministerium für Industrie und Aufbau eine Abteilung zu bilden, die sich ausschließlich mit Fragen der Plansollerfüllung für den Erzbergbau beschäftigen sollte ${ }^{121}$. Mit den neuen sowjetischen Arbeitskräfteanforderungen schien der Versuch des Berliner Arbeitsministeriums wieder gefährdet zu sein, einheitliche Richtlinien und Maßnahmen durchzusetzen. Statt dessen entwickelte jede Landesregierung eigene Lösungsansätze, um die jeweiligen Auflagen erfüllen zu können. Innerhalb des Ministeriums für Arbeit und Gesundheitswesen bestand rasch Einigkeit darüber, den Vorschlag Thüringens abzulehnen: „Wenn in Sachsen eine besondere ,Abteilung' nicht besteht und nicht geplant ist, wird sie sich auch für Thüringen erübrigen." ${ }^{122} \mathrm{Als} \mathrm{zu-}$

117 BAB, DQ 2/2097, HVDVP am 27. 11. 1950 an das Ministerium für Arbeit (HA Arbeit).

118 BAB, DQ 2/2095, Ministerpräsident Grotewohl am 8. 12. 1950 an Arbeitsminister Chwalek.

119 ThHStA, Land Thüringen, Büro des Ministerpräsidenten, Bd. 1685-1688, Bl. 47, Arbeitsminister Chwalek am 15.12. 1950 an den Ministerpräsidenten von Thüringen (Eggerath). Thüringen sollte demnach 8500 Arbeitskräfte stellen, davon 3000 im Januar 1951.

120 LA Magdeburg LHA, Rep. K MW, Nr. 9448, Bl. 118, IHK Sachsen-Anhalt am 8. 1. 1951 an das Ministerium für Wirtschaft (HA Arbeit) von Sachsen-Anhalt.

$121 \mathrm{BAB}, \mathrm{DQ} 2 / 721$, Ministerpräsident Eggerath am 15. 1. 1951 an Arbeitsminister Chwalek.

122 Ebenda, Hausmitteilung der Abt. Arbeitskraftlenkung vom 26. 1. 1951 an das Sekretariat des Ministers. Hauptabteilungsleiter Litke unterstrich die Position der Abt. Arbeitskraftlenkung. Vgl. BAB, DQ 2/721, Hausmitteilung Litkes vom 27. 1. 1951 an Minister Chwalek. 
sätzliches Argument wurde angeführt, daß kein Grund für eine Vergrößerung des Verwaltungsapparates bestehe. Ein entsprechendes Antwortschreiben sandte Minister Chwalek am 6. Februar 1951 an den thüringischen Ministerpräsidenten Werner Eggerath: „Es besteht die Gefahr, daß durch Schaffung einer solchen selbständigen Abteilung ein Nebeneinander in der Arbeitskraftlenkung eintritt, was unbedingt vermieden werden sollte, und zum anderen wird der Tendenz der Erhaltung bzw. Aufblähung des Verwaltungskörpers Vorschub geleistet.“"123

Nachdem die Arbeitskräftewerbung für den Uranbergbau wieder aufgenommen worden war, sahen sich die Landesverwaltungen rasch mit dem Problem konfrontiert, daß zahlreiche Betriebe die Mitarbeit verweigerten bzw. nicht bereit waren, sogenannte Betriebsaktivs zu bilden ${ }^{124}$. In solchen Fällen wurde das Berliner Arbeitsministerium eingeschaltet, das sich daraufhin an die zuständigen Industrieministerien oder Staatssekretariate wandte. Das bedeutete wiederum eine erhebliche zeitliche Verzögerung bei der Abdeckung des gemeldeten Bedarfs und einen erheblichen Verwaltungsaufwand für die Arbeitsverwaltung, dessen Nutzen zunehmend in Frage geriet. Den Betrieben gelang es in der Regel, das verhängte Plansoll deutlich zu reduzieren: Auf einer gemeinsamen Sitzung mit Mitarbeitern des Ministeriums für Industrie und Aufbau von Sachsen-Anhalt versuchte die Betriebsleitung des volkseigenen Betriebes Carl Zeiss (Jena) deutlich zu machen, daß die Anweisung des zuständigen Arbeitsamtes, 300 Arbeitskräfte zu stellen, zu hoch bemessen sei. Nach längerer Diskussion einigten sich beide Seiten auf ein Plansoll in Höhe von 120; gleichzeitig verpflichtete sich das Arbeitsamt Jena, für diese Personengruppe Ersatzarbeitskräfte zu gewinnen ${ }^{125}$. Die Arbeitskräftenachfrage beschränkte sich zunächst nur auf die Bergarbeiter, schloß aber bald die Baufacharbeiter mit ein. Hintergrund für diese Entwicklung war das Wiederaufleben des Wohnungsbauprogramms, das auf eine Initiative der Generaldirektion der Wismut AG zurückging. Dieses Programm sollte - so das ehrgeizige Ziel - mit dazu beitragen, die Fluktuation unter den Wismut-Arbeitern zu senken und langfristig eine Stammbelegschaft heranzubilden ${ }^{126}$. Die unzureichende wohnliche Unterbringung der Arbeiter, die neu angeworben worden waren, dauerte auch 1951 immer noch an. Der Familienzuzug in die Kreise des Erzbergbaus war nach wie vor nicht geregelt, was nicht selten dazu führte, daß zugewiesene Arbeitskräfte das Arbeitsverhältnis wieder auflösten, nachdem ihnen der Zuzug der Ehefrauen verweigert worden war ${ }^{127}$.

Die Bereitstellung von Arbeitskräften für die Wismut AG hinkte - wie bereits mehrfach betont - hinter den gesteckten Zielen her und erfüllte die Erwartungen der Arbeitsverwaltung nicht. So hatte Sachsen die gestellte Auflage Mitte Februar 1951 zu 70 Prozent erfüllt. Thüringen wies eine Quote von 55, Sachsen-Anhalt

$123 \mathrm{BAB}, \mathrm{DQ} 2 / 721$

$124 \mathrm{Vgl}$. BAB, DQ 2/2148, Ministerium für Wirtschaft von Sachsen-Anhalt am 9. 2. 1951 an das Ministerium für Arbeit (HA Arbeit).

$125 \mathrm{BAB}, \mathrm{DQ}$ 2/2147, Bericht der Abt. Arbeitskraftlenkung über die Sitzung am 10.2. 1951 im VEB Carl Zeiss Jena.

$126 \mathrm{BAB}, \mathrm{DQ}$ 2/2096, Hauptabteilungsleiter Litke am 14. 2. 1951 an das Ministerium für Industrie, Verkehr, Aufbau und Arbeit von Sachsen-Anhalt, S. 1.

$127 \mathrm{BAB}, \mathrm{DQ}$ 2/2131, Gunther R. aus Burow (Mecklenburg) am 15. 2. 1951 an das Arbeitsamt Parchim. 
und Mecklenburg eine Quote von 47 bzw. 45 Prozent auf; Schlußlicht war offenbar Brandenburg mit 27 Prozent ${ }^{128}$. Die Vertreter der Landesministerien wurden deshalb auf einer gemeinsamen Tagung aufgefordert, ihre Werbeaktivitäten zu verstärken ${ }^{129}$. Nachhaltigen Druck bekamen die Landesregierungen auch von der SKK zu spüren. Die brandenburgische Arbeitsverwaltung arbeitete deshalb einen Maßnahmenkatalog aus und räumte gleichzeitig ein, daß mit dem beginnenden Aufbau des Eisenhüttenkombinats Ost (EKO) ein Konkurrent auf der Nachfrageseite aufgetreten war. Die Wanderungsbewegung kehrte sich somit um: „Es geht bereits soweit, daß Arbeitskräfte bei der AG-Wismut die Arbeit niederlegten und beim Hüttenkombinat Ost versuchen, Arbeit zu bekommen. “130 Zur Unterstützung der Tätigkeit der Arbeitsämter waren in Sachsen-Anhalt ein Landesausschuß und zahlreiche Kreisausschüsse für Arbeitskraftlenkung gebildet worden, in denen sich Vertreter sämtlicher Parteien und Massenorganisationen befanden. Dennoch mußte das zuständige Landesministerium enttäuscht feststellen, daß diese Verwaltungsmaßnahme keine wesentliche Verbesserung mit sich brachte. Für die nach wie vor bestehende Diskrepanz zwischen Plansoll und Erfüllungsstand wurde nunmehr das „mangelnde Bewußtsein der Bevölkerung für den Aufbau [der] Grundstoffindustrie" verantwortlich gemacht ${ }^{131}$.

Mitarbeiter des Ministeriums für Arbeit und Gesundheitswesen unternahmen verstärkt Dienstreisen in das Uranbergbaugebiet und beanstandeten dabei die katastrophalen Verhältnisse in einzelnen Übernachtungsheimen. Diese seien „derartig schlecht, daß man es keinem Menschen zumuten könne, dort zu verweilen“"132. Darüber hinaus wurde die mangelhafte Organisation der Bergarbeitertransporte sowie deren Verteilung auf die einzelnen Schachtanlagen kritisiert. Ein Mitarbeiter kam in seinem Untersuchungsbericht zu dem Ergebnis: „Wenn aber jetzt schon ein so grundsätzliches Versagen festgestellt wird, dann wird bei den Ämtern für Arbeit die beste Werbung schließlich doch versagen. " 133 Im Laufe des Monats März häuften sich offensichtlich die Beschwerden, so daß schließlich auch der stellvertretende Ministerpräsident Walter Ulbricht eingeschaltet wurde, der wiederum eine ausführliche Berichterstattung über die Zustände im Kreis Aue in Auftrag gab ${ }^{134}$. Obwohl die Mißstände bereits zuvor bekannt gewesen waren, beschränkte sich die DDR-Staatsführung darauf, weitere Untersuchungen anzufordern. Auch die SED-Führung hielt sich zunächst auffallend zurück und überließ es der Arbeitsverwaltung, die Versorgungsschwierigkeiten zu beheben. Diese veranlaßte zwar die Durchführung von Ausbesserungsarbeiten im Durchgangslager

128 BAB, DQ 2/1761, Niederschrift über die Arbeitstagung am 20. 2. 1951, S. 7.

129 Ebenda.

130 BAB, DQ 2/2097, Leiter der HA Arbeit und Sozialfürsorge im brandenburgischen Ministerium für Wirtschaft und Arbeit am 23. 2. 1951 an die SKK (Planökonomische Abt.). Diesen Trend bestätigten auch spätere Berichte des Arbeitsministeriums. Vgl. BAB, DQ 2/721, Bericht der Abt. Arbeitskraftlenkung vom 21.8. 1951.

131 LA Magdeburg LHA, Rep. K MW, Nr. 9448, Bl. 128, Hauptabteilungsleiter Eifler am 19. 3. 1951 an die Landeskommission für Staatliche Kontrolle Sachsen-Anhalt, S. 1 f.

$132 \mathrm{BAB}, \mathrm{DQ} 2 / 2096$, Bericht über die am 27. 2. 1951 durchgeführte Dienstreise nach Aue, S. 1.

133 BAB, DQ 2/2097, Bericht Arndts vom 1. 3. 1951, S. 3.

13+ Vgl. BAB, DQ 2/2097, Abteilungsleiter Heisig am 21.3. 1951 an das Ministerium für Verkehr. Ein weiterer Bericht lag bereits am 28. 3. 1951 vor, der die ersten Eindrücke über das Auffanglager bestätigte. BAB, DQ 2/2097, Bericht der Abt. Arbeitskraftlenkung vom 28. 3. 1951. 
Auerhammer, so daß wieder ankommende Bergarbeiter vorübergehend untergebracht werden konnten. Gleichzeitig plädierte Hauptabteilungsleiter Litke dafür, die Generaldirektion der Wismut AG stärker in die Verantwortung zu nehmen und kündigte weitere Verhandlungen mit der sowjetischen Grubenleitung an ${ }^{135}$. Der stellvertretende Ministerpräsident Ulbricht wurde gebeten, seinerseits an General Malzew heranzutreten, um die Position des Arbeitsministeriums zu unterstützen ${ }^{136}$.

Die Bergarbeitertransporte für den sächsischen Erzbergbau wurden vorerst bis Ende Mai bzw. Anfang Juni ausgesetzt ${ }^{137}$. Diese Pause sollte offensichtlich dazu genutzt werden, um Fragen der Versorgung mit Wohnraum und der Arbeitsverhältnisse in den Gruben zu erörtern. Darüber hinaus waren die beschäftigungspolitischen Ziele der Wismut AG nach wie vor unklar: Die zuvor einsetzende Entlassungswelle erfaßte mittlerweile auch die Lehrlinge, was wiederum dazu führte, daß Bestrebungen der Staatlichen Plankommission und des Arbeitsministeriums, den Uranbergbau in den Nachwuchsplan 1951 aufzunehmen, gegenstandslos wurden ${ }^{138}$. Erneut waren die deutschen Verwaltungen vorab nicht informiert worden. Sie befanden sich in einer passiven Position, da sie auf die eigenmächtig getroffenen Entscheidungen der Wismut-Verwaltung nur verspätet und improvisiert reagieren konnten. Längerfristige Planungen von seiten der Arbeitsverwaltung waren somit kaum möglich. Zu diesem Zeitpunkt schätzte das Arbeitsministerium die Beschäftigungslage insgesamt eher pessimistisch ein: Durch die Entlassungen waren zunächst einmal die Zahlen der Arbeitsuchenden in Sachsen angestiegen ${ }^{139}$. Ein Blick auf die Gesamtentwicklung der Arbeitslosenzahlen, die im Jahr 1951 einen klaren Abwärtstrend aufwiesen (vgl. Tabelle 6, S. 271), legt jedoch die Vermutung nahe, daß es den Arbeitsämtern vergleichsweise rasch gelungen sein muß, in anderen Ländern die Arbeitslosenquote so zu senken, daß die Entlassung der Bergarbeiter der Wismut AG nicht zu einem Anstieg der Gesamtzahlen führte. In Sachsen konnten dagegen die entlassenen Wismut-Arbeiter „nur unwesentlich " in andere Wirtschaftszweige umgelenkt werden ${ }^{140}$.

Zur Verbesserung der Lage auf dem Wohnungsmarkt im Einzugsbereich der Wismut AG war sogar geplant, von der Emissionsbank der DDR Darlehen an Einzelpersonen auszahlen zu lassen, mit denen der individuelle Wohnungsbau gefördert werden sollte. Diese Fördermaßnahme, für die bereits in den letzten drei Quartalen des Jahres 195015 Millionen DM eingeplant worden waren, konnte sowohl von Arbeitern und Angestellten als auch von Mitgliedern der „technischen

${ }^{135} \mathrm{BAB}, \mathrm{DQ} 2 / 2096$, Litke am 12. 4. 1951 an das Sekretariat des stellv. Ministerpräsidenten Ulbricht, S. 3.

136 Ebenda, S. 4.

137 BAB, DQ 2/1721, Bericht der HA Arbeit der Landesregierung Sachsen-Anhalt vom 16. 4. 1951.

$138 \mathrm{BAB}, \mathrm{DQ} 2 / 2131$, Aktenvermerk der HA Arbeit vom 25. 4. 1951, S. 3. Die Landesregierung Sachsen meldete allein 300 entlassene Jugendliche, die auf andere volkseigene Betriebe verteilt wurden. Die Entlassungen erfolgten vor Abschluß des Lehrvertrages und wurden mit dem Hinweis auf Einsparungsmaßnahmen begründet. Die Umverteilung der Lehrlinge führte letztlich aber zur personellen Überbelegung der volkseigenen Betriebe.

139 BAB, DQ 2/1728, Abt. Arbeitskraftlenkung am 26.6. 1951 an den Org.-Instrukteur, S. 1. Während des 1 . Halbjahrs 1951 sollen insgesamt über 30000 Arbeiter entlassen worden sein. Roeling, Arbeiter im Uranbergbau, S. 125.

140 Ebenda, S. 5. 
Intelligenz" in Anspruch genommen werden ${ }^{141}$. Die Wohnraumversorgung wurde aber dadurch noch erschwert, daß in einigen Kreisen bereits belegte Unterkünfte für sowjetische Zivilbedienstete geräumt werden mußten. Bei Verhandlungen zwischen Vertretern der Wismut AG, dem Bürgermeister von Auerbach sowie betroffenen Familien kam es am 7. Juli zu „politischen Demonstrationen“ gegen die geplanten Räumungen, so Fritz Lange in einem kurzen Bericht an Walter Ulbricht ${ }^{142}$.

Im Frühsommer 1951 wurde der Einstellungsstopp aufgehoben, und der Arbeitskräftebedarf stieg wieder merklich an. Für den Zeitraum vom 1. bis zum 20. Juli benötigte der sächsische Erzbergbau 10000 Bergarbeiter, wobei dem Arbeitsministerium in Berlin die Auflage erst am 25. Juni mitgeteilt wurde ${ }^{143}$. Die Arbeitsverwaltung war über die rasch wechselnden sowjetischen Anordnungen sichtlich irritiert: Der Anfang 1951 erteilten Auflage von 40000 Arbeitskräften folgte im Frühjahr ein Einstellungsstopp, der wenige Wochen später durch eine erneute Auflage revidiert wurde. Während die Arbeitsämter von einem mittelund langfristigen Rückgang des Arbeitskräftebestandes bei der Wismut AG ausgingen, kündigte der Chef der Personal-Hauptverwaltung Schumilin an, daß der Bedarf noch weiter steigen werde ${ }^{144}$. Arbeitsminister Chwalek wandte sich hilfesuchend an die Ministerpräsidenten der Länder und bat um nachhaltige Unterstützung bei der Bereitstellung von Arbeitskräften für den Uranbergbau145. Die sowjetische Auflage wurde auf die einzelnen Länder folgendermaßen aufgeteilt: Sachsen hatte 3200 Arbeitskräfte zu stellen, Sachsen-Anhalt 1800, Thüringen 2000, Mecklenburg 1500 und Brandenburg 1000146. Während Thüringen seine zu stellenden Arbeitskräfte in die im eigenen Land liegenden Gruben der Wismut AG entsenden sollte, wurde die restliche Auflage für den sächsischen Erzbergbau benötigt. Auch einzelne Fachministerien wurden von Chwalek angesprochen und um Mithilfe gebeten: Dabei unterstrich er nochmals, daß nur bergbautaugliche Arbeitskräfte eingestellt werden könnten ${ }^{147}$. Die Zahl der Wirtschaftszweige bzw. Schwerpunktbetriebe, die von der Auflage nicht betroffen waren, vergrößerte sich. Neben dem Erz- und Steinkohlenbergbau sowie dem Eisenhüttenkombinat Ost nannte Chwalek unter anderem das Bauvorhaben "Südlicher Außenring“ ${ }^{148}$. Die angeschriebenen Ministerien kamen der Bitte des Arbeitsministers weitgehend nach. Der Minister für Leichtindustrie gab sogar mehrmals Dienstanweisungen an die Betriebsleiter der ihm unterstehenden Wirtschaftszweige weiter, in denen zur Bereitstellung von Arbeitskräften für die Wismut AG aufgerufen wurde ${ }^{149}$.

141 SAPMO, NY 4090/315, Bl. 98, Merkblatt (o.D., o.Verf.).

142 SAPMO, NY 4182/986, Bl. 162f., hier Bl. 162, Lange am 9. 7. 1951 an Ulbricht.

${ }^{143}$ Ebenda, Bl. 164-166, hier Bl. 164, Roman Chwalek am 9. 7. 1951 an Walter Ulbricht.

144 Ebenda, Bl. 166.

${ }^{145}$ ThHStA, Land Thüringen, Büro des Ministerpräsidenten, Bd. 1685-1688, Bl. 6, Fernschreiben Chwaleks vom 9.7.1951 an den Ministerpräsidenten des Landes Thüringen.

${ }^{146} \mathrm{BAB}, \mathrm{DQ} 2 / 2096$, Bericht des Ministeriums für Arbeit (Abt. Arbeitskraftlenkung) vom 18. 7. 1951, S. 2.

1+7 BAB, DQ 2/2099, Chwalek am 7. 8. 1951 an den Minister für Aufbau und stellvertretenden Ministerpräsidenten Lothar Bolz, S. 1 .

148 Ebenda, S. 2.

149 BAB, DQ 2/2100, Dienstanweisung Nr. 66 a vom 10. 8. 1951. 
Die Landesverwaltungen nahmen zwar ihre zuvor abgebrochenen Werbemaßnahmen wieder auf, doch war innerhalb der vorgegeben Zeit mit einem zufriedenstellenden Ergebnis nicht zu rechnen. Am 19. Juli, einen Tag vor Ablauf der Frist, waren erst 4381 Arbeitskräfte gestellt worden; der sogenannte Erfüllungsstand lag damit bei 46,1 Prozent ${ }^{150}$. Die Tatsache, daß die Leitung der Wismut AG für die Monate August und September einen weiteren Bedarf von insgesamt $20000 \mathrm{Ar}$ beitskräften anmeldete, trieb die Arbeitsverwaltung allmählich in die Enge. Daraufhin bat Minister Chwalek das Sekretariat des ZK, die 1. Sekretäre der Landesleitungen zusammenzurufen, "um sie über die Dringlichkeit und Notwendigkeit der Werbung von Arbeitskräften für den Erzbergbau zu informieren und ihnen die entsprechende Anleitung zur Führung der Werbekampagnen zu erteilen" 151. Darüber hinaus sollten nach den Vorstellungen des Arbeitsministers der FDGB und die Industriegewerkschaften in die Werbekampagnen eingebunden werden. Auch die Fachministerien wurden gebeten, in ihrem Zuständigkeitsbereich Arbeitskräfte für die Wismut AG zu werben. Bei einer gemeinsamen Besprechung am 23. Juli wies der Vertreter des Arbeitsministeriums Krüger darauf hin, daß "notfalls" auch Fachkräfte, sofern sie bergbautauglich sind, zur Verfügung gestellt werden müßten ${ }^{152}$. Nachdem die SED-Landesleitung von Sachsen-Anhalt einen Maßnahmenkatalog zur Unterstützung der Werbung für den sächsischen Erzbergbau beschlossen hatte ${ }^{153}$, befaßte sich Ende Juli auch das Sekretariat des ZK mit der Arbeitskräfteanforderung für die Wismut AG154. Dabei erhielt Otto Schön den Auftrag, die 1. Sekretäre der SED-Landesleitungen, die Fachminister und Staatssekretäre, das Sekretariat des FDGB-Bundesvorstandes und die 1. Vorsitzenden der Zentralvorstände der Industriegewerkschaften zu einer Beratung einzuladen, um ihnen dann entsprechende Anweisungen zu erteilen. Die Werbung sollte in allen Zweigen der volkseigenen und privaten Wirtschaft erfolgen; davon ausgenommen blieben nur der Erz- und Steinkohlenbergbau sowie das Eisenhüttenkombinat Ost. Nicht unwichtig war jedoch die Einschränkung, daß „sehr wichtige Schwerpunktbetriebe" von der Anweisung befreit werden konnten.

Ein Mitarbeiter des Berliner Arbeitsministeriums schlug nach Abschluß einer Dienstreise die Verlagerung der zuständigen Abteilung des Arbeitsamtes Aue in das Durchgangslager vor ${ }^{155}$. Da das Auffanglager in Auerhammer jedoch nicht über ausreichende Kapazitäten verfügte, hätte in diesem Falle ein größeres Lager erst noch errichtet werden müssen. Auf diese Weise sollte die Organisation der Bergarbeitertransporte und vor allem die zügige Verteilung der Neuankömmlinge auf die einzelnen Schachtanlagen optimiert werden. Eine gewisse Verbesserung war vermutlich schon dadurch eingetreten, daß ein Vertreter der Hauptpersonal-

150 BAB, DQ 2/721, Chwalek am 20.7. 1951 an das Sekretariat des ZK (Schön), S. 2.

151 Ebenda, S. 3.

152 BAB, DQ 2/721, Bericht der Abt. Arbeitskraftlenkung vom 23. 7. 1951, S. 2.

153 SAPMO, NY 4182/986, Bl. 2-8, Bericht der Org.-Instrukteur-Abt. (Sektor Parteiinformation) vom 28. 7. 1951.

154 SAPMO, DY 30/J IV 2/3/219, Bl. 1 f., Protokoll der Sitzung des Sekretariats des ZK vom 30. 7. 1951.

155 BAB, DQ 2/2099, Bericht von Werner Ahrens über die Dienstreise (7.-14.8. 1951), S. 3. Die Dienstreise hatte ihn zum Arbeitsamt Aue, zur Hauptverwaltung der Wismut AG und zur sächsischen Landesregierung in Dresden geführt. 
stelle der Wismut AG im Arbeitsamt Aue tätig war, der wiederum für eine effiziente Verteilung der Arbeitskräfte Sorge tragen sollte und durch seine Tätigkeit eine direkte Verbindung zwischen Arbeitsverwaltung und Grubenleitung herzustellen vermochte ${ }^{156}$. Die Hauptverwaltung der Wismut AG lehnte allerdings den Neubau eines solchen Lagers aus finanziellen Gründen $a b$ und sprach sich dafür aus, das zuständige Arbeitsamt zu einem Auffanglager umzugestalten ${ }^{157}$. Die dabei anfallenden Kosten wollte die sowjetische Leitung übernehmen. Sowohl die Kommunalverwaltung als auch die sächsische Landesregierung zeigten sich über diesen Vorschlag wenig begeistert.

Bereits vor der DDR-Gründung hatte sich rasch herauskristallisiert, daß das Land Sachsen letztlich die Hauptlast bei der Arbeitskräftezuteilung für den Uranbergbau leisten mußte. Das hing zunächst einmal mit den Auflagen zusammen, die stets höher angesetzt waren als bei den übrigen Ländern. Darüber hinaus lag auch der tatsächliche Erfüllungsstand überdurchschnittlich hoch, was vermutlich auf die räumliche Nähe zur Hauptverwaltung der Wismut AG zurückzuführen war, die sich häufig anschickte, bei der Landesregierung zu intervenieren oder auch selber Arbeitskräfte von sächsischen Betrieben zum Teil eigenmächtig abzog. Die Landesregierung in Dresden hatte sich frühzeitig bemüht, die Lasten bei der Gewinnung von Bergarbeitern auf alle Länder gleichmäßig zu verteilen. Das Ministerium für Arbeit in Berlin erkannte zwar die Notwendigkeit dieser Maßnahme an, mußte aber des öfteren feststellen, daß die übrigen Landesverwaltungen entweder nicht willens oder nicht in der Lage waren, ihren Anforderungen nachzukommen. Das Schlußlicht bildete in dieser Frage oft das nördlichste Land der DDR, das primär agrarisch geprägte Mecklenburg. Mitarbeiter von Arbeitsminister Chwalek unternahmen in unregelmäßigen Abständen Dienstreisen, um die mecklenburgische Landesverwaltung an die Einhaltung der Plansollziffern nachdrücklich zu erinnern ${ }^{158}$.

Die SED-Führung schaltete sich relativ spät in die Diskussion über die Lebensund Arbeitsbedingungen im Erzbergbau ein. Sie hatte zwar des öfteren Informationsberichte erhalten, verhielt sich aber eher passiv und überließ die Problemlösung in erster Linie der Arbeitsverwaltung. Sicherheitspolitische Überlegungen weckten jedoch bald das Interesse des Politbüros: Als sich Mitte August 1951 Krawalle zwischen Arbeitern und Angehörigen der Volkspolizei in der thüringischen Stadt Saalfeld zu einem größeren Protest auszuweiten drohten ${ }^{159}$, gab das Politbüro vermutlich auch auf sowjetische Anweisung hin seine Zurückhaltung

156 Ebenda, S. 1 f.

157 Ebenda, S. 5.

158 So unternahm etwa Hauptreferent Krüger (Abt. Arbeitskraftlenkung) Mitte August 1951 eine Dienstreise nach Mecklenburg. Dabei wies er auf das schlechte Ergebnis der laufenden Werbemaßnahmen im Lande hin: Demzufolge war die Auflage im Juli nur zu 30 Prozent erfüllt worden. Vgl. $\mathrm{BAB}, \mathrm{DQ} 2 / 2152$, Bericht der Abt. Arbeitskraftlenkung über die Dienstreise nach Mecklenburg (14.-16. 8. 1951), S. 2.

$159 \mathrm{Vgl}$. zu den Vorfällen, auf die hier nicht im einzelnen eingegangen werden kann: Port, When workers rumbled; Roth/Diedrich, Wir sind Kumpel - uns kann keiner, S. $236 \mathrm{f}$.; Weber, Justiz und Diktatur, S. 343-347. Kurze Erwähnung bei Karlsch, Allein bezahlt?, S. 144. Eine Einbettung in einen größeren Kontext bietet Port, The „Grumble Gesellschaft“. Ein ausführlicher Bericht - vermutlich von der SED-Landesleitung - liegt ebenfalls vor. Vgl. SAPMO, NY 4182/986, Bl. 19-27, Bericht vom 20. 8. 1951. 
etwas auf. Zunächst wurde die SED-Landesleitung beauftragt, einen ausführlichen Bericht zu liefern, der Ende August schließlich vorlag. Darin wurde selbstkritisch festgehalten, daß die Partei ,innerhalb der Wismut AG in keiner Weise als führende Kraft in Erscheinung tritt" ${ }^{160}$. Dies war angesichts der sowjetischen Dominanz im sächsischen und thüringischen Erzbergbaugebiet, die eine Mitarbeit deutscher Stellen nahezu ausschloß, nicht weiter verwunderlich. Die vorgeschlagenen Maßnahmen beschränkten sich jedoch auf den Auf- und Ausbau der Parteiorganisation sowie eine Intensivierung der Kaderpolitik im Bereich der staatlichen Verwaltung im Wismut-Gebiet; dagegen blieben die Vorschläge zur Verbesserung der sozialen Lage sehr allgemein ${ }^{161}$. Das Politbüro nahm die eingehenden Berichte zur Kenntnis und beauftragte den Chef der Volkspolizei, „eine entsprechende Verstärkung der Volkspolizei in diesem Gebiet vorzunehmen"162. Die Unruhen in Saalfeld waren auch Thema der folgenden Sitzungen des Politbüros, auf denen jedoch keine weiteren Beschlüsse gefaßt wurden ${ }^{163}$. Auf Veranlassung des Politbüros setzte das Sekretariat des ZK auf seiner Sitzung am 17. September 1951 eine Kommission ein, dessen Aufgaben jedoch unklar blieben ${ }^{164}$. Ein an den SEDVorsitzenden Otto Grotewohl gerichteter Bericht unterstrich nochmals die soziale Sprengkraft, die sich in einigen Kreisen des Wismut-Gebietes angesammelt hatte. Ausgangspunkt der Analyse war die Bevölkerungsexplosion: So war in 13 Städten des Kreises Aue die Bevölkerungszahl zwischen 1946 und Juli 1951 von 110000 auf 212000 angestiegen ${ }^{165}$. In einzelnen Städten hatte sich die Bevölkerung im selben Zeitraum sogar vervierfacht bzw. versechsfacht: in Niederschlemma von 2538 auf 9500 und in Johanngeorgenstadt von 6293 auf 38300 . Der Bericht listete zwar Mängel bei der Wohnraumversorgung auf, zog daraus jedoch keine konkreten Schlußfolgerungen. Im Zentrum des Untersuchungsberichtes stand vielmehr die unzureichende Sicherheitslage, der durch eine personelle Verstärkung der Polizeieinheiten und des Ministeriums für Staatssicherheit im Uranbergbaugebiet begegnet werden sollte ${ }^{166}$. Außerdem wurde eine Verbesserung der „ideologisch-politischen Arbeit" der SED-Parteiorganisation gefordert ${ }^{167}$. Auch die SKK unterbreitete offensichtlich Vorschläge zur Neustrukturierung der Parteiorganisation Wismut, denen sich das Politbüro am 13. November 1951 grundsätzlich anschloß168. Darüber hinaus sprach sich das Politbüro dafür aus, bei der

160 SAPMO, NY 4182/986, Bl. 9-27, hier Bl. 9, Bericht der Org.-Instrukteur Abt. (Sektor Parteiinformation) vom 29.8. 1951. Dieser zusammenfassende Bericht basierte auf Informationen der SED-Landesleitung Thüringen vom 22.8 .

161 Ebenda, Bl. 18.

162 SAPMO, DY 30/IV 2/2/163, Bl. 1 f., Protokoll der Sitzung des Politbüros am 28. 8. 1951. Über die Politbürositzung informierte Otto Grotewohl einen Tag später den SKK-Vorsitzenden Tschuikow. Vgl. SAPMO, NY 4090/306, Bl. 1.

163 SAPMO, DY 30/IV 2/2/164, Bl. 2, Protokoll der Sitzung des Politbüros am 4. 9. 1951; SAPMO, DY 30/IV 2/2/165, Bl. 11, Protokoll der Sitzung des Politbüros am 11. 9. 1951.

164 Laut Beschlußprotokoll sollte die Kommission eine Vorlage über die Wismut AG ausarbeiten und dabei auch Fragen der „Umsiedlung“ behandeln. SAPMO, DY 30/J IV 2/3/233, Bl. 8.

165 SAPMO, NY 4182/986, Bl. 33-37, hier Bl. 33, Bericht vom 10.11. 1951 (o.Verf.).

166 Ebenda, Bl. 36.

167 Ebenda, Bl. 35. Der Gebietsparteiorganisation der SED wurde in einem weiteren ausführlichen Bericht vorgehalten, die Entwicklung in Saalfeld unterschätzt zu haben. Vgl. SAPMO, NY 4182/ 986, Bl. 38-63, Bericht (o.D., o.Verf.).

168 SAPMO, DY 30/IV 2/2/176, Bl. 37. Die Vorschläge der „Sowjetorgane“ sind jedoch nicht überliefert. Die Wismut AG und die Vorfälle in Saalfeld waren erneut Gegenstand einer Besprechung in 
Generaldirektion eine deutsche Abteilung für Arbeitskräftelenkung zu schaffen, in der „politisch überprüfte Genossen“ tätig sein sollten ${ }^{169}$. Dieser - wie auch die zuvor gemachten Vorschläge - waren aber letztlich von der sowjetischen Zustimmung abhängig.

Die Ereignisse von Saalfeld hatten keine unmittelbaren Folgen für die Arbeitskräftelenkung. Während die SED bemüht war, die sicherheitspolitisch bedenkliche Situation wieder in den Griff zu bekommen, setzte die Arbeitsverwaltung in Thüringen ihre Werbetätigkeit fort ${ }^{170}$. Nach Mitteilung der SED-Landesleitung hatte sich allerdings der Schwerpunkt der Werbung verschoben: Dieser liege nunmehr "auf dem persönlichen und individuellen Ansprechen der bergbautauglichen Kollegen, da man erkannt hat, daß die Massenwerbung nicht die Erfolg versprechendste ist" ${ }^{171}$. Darüber hinaus wurden die Anforderungen bei der ärztlichen Überprüfung offenbar auch auf Betreiben der sowjetischen Seite verschärft ${ }^{172}$. Es sollte von vornherein verhindert werden, daß zugewiesene Arbeiter, die nicht bergbautauglich waren, auf ihre Rückführung warten mußten und zu einer Belastung für die Kommunalverwaltungen wurden. Im Oktober 1951 luden einige Landesministerien die Leiter der neu geschaffenen Abteilungen für Arbeit bei den Bezirksverwaltungen zu gemeinsamen Tagungen ein, an denen auch Vertreter des Arbeitsministeriums in Berlin teilnahmen und auf denen unter anderem die Arbeitskräftewerbung für den Erzbergbau erörtert wurde. Dabei beklagten sich Tagungsteilnehmer über das bestehende Desinteresse zahlreicher Betriebsleiter an der Erfüllung des Plansolls ${ }^{173}$. In der Tat erhielten die Landesämter sowie die Kommunalverwaltungen immer häufiger Absagen einzelner Betriebe, die sich nicht in der Lage sahen, Arbeitskräfte für den Uranbergbau zur Verfügung zu stellen. Dabei handelte es sich unter anderem um Betriebe des Braunkohlenbergbaus $^{174}$, der Energiewirtschaft ${ }^{175}$ sowie der Textilindustrie ${ }^{176}$. Zur Begründung

Karlshorst am 15. 11. 1951. Die Pieck-Notizen enthalten dazu jedoch keine weiteren konkreten Angaben. Vgl. Badstübner/Loth, Wilhelm Pieck, S. 379.

169 SAPMO, DY 30/IV 2/2/176, Bl. 40-53, hier Bl. 49, Stellungnahme des Politbüros des ZK der SED über die Maßnahmen zur Verbesserung der Parteiarbeit und der Arbeit auf allen Gebieten in der Wismut.

170 Vgl. ThHStA, Land Thüringen, Büro des Ministerpräsidenten, Bd. 1685-1688, Bl. 26f., Minister für Wirtschaft und Arbeit Walter Strampfer am 21.9. 1951 an das Büro des Ministerpräsidenten.

171 ThHStA, Land Thüringen, Büro des Ministerpräsidenten, Bd. 1683-1684, Bl. 261 f., hier Bl. 261.

172 BAB, DQ 2/2100, Chefarzt Dr. W. der Bergbau-Poliklinik Oberschlemma am 14.9. 1951 an die SVK Wismut (Arztabt.); ebenda, Chefarzt Dr. R. von der Bergbau-Poliklinik Antonsthal am 15. 9. 1951 an Dr. B. in Chemnitz.

173 BAB, DQ 2/2152, Bericht Krügers vom 23. 10. 1951 über die Tagung in Dresden, S. 3. Weitere Tagungen gab es mit leitenden Mitarbeitern der Arbeitsverwaltung in Mecklenburg, aber auch in der dortigen Warnow-Werft Warnemünde, der Volkswerft Stralsund sowie mit dem Forstamt Schuenhagen bei Stralsund. Für das Berliner Arbeitsministerium blieb Mecklenburg das Sorgenkind: Hier betrug der Erfüllungsstand im Landesdurchschnitt im Oktober 1951 nur 17\%. BAB, DQ 2/2152, Bericht der Abt. Arbeitskraftlenkung über die Tagung der Leiter der Abteilungen für Arbeit des Landes Mecklenburg am 16.10.1951, S. 1.

${ }^{174}$ SächsHStA, Landesregierung Sachsen, Ministerium für Wirtschaft, Bd. 1193, Bl. 83, Braunkohlenverwaltung Welzow (Werk Hirschfelde) am 25.10. 1951 an den Rat des Landkreises Zittau (Abt. für Arbeit).

175 Ebenda, Bl. 85, VVB Energiebezirk Ost (Kraftwerk Zittau) am 19. 10. 1951 an das Ministerium für Wirtschaft und Arbeit in Dresden.

176 Ebenda, Bl. $80 \mathrm{f}$., VEB Mechanische Weberei Zittau am 25. 10. 1951 an den Rat des Landkreises Zittau (Abt. für Arbeit). 
wurde vor allem auf die angespannte Arbeitskräftelage im jeweiligen Werk hingewiesen. Darüber hinaus mußten die Betriebsleitungen Rücksicht nehmen auf die Belange der Belegschaft: Daher sprachen die mangelhaften Unterbringungsmöglichkeiten im Erzgebirge, die zum Teil ungelösten Fragen der Entlohnung, aber auch die Trennung von den Familien gegen eine Entsendung in die Gruben der Wismut AG. Insofern deckten sich in dieser Frage die Interessen der angesprochenen Betriebe mit denen der betroffenen Beschäftigten. Einzelne Betriebe gingen sogar noch einen Schritt weiter und stellten den Antrag, von der Auflage, Arbeitskräfte für die Wismut AG abzustellen, für einen bestimmten Zeitraum befreit zu werden 177 .

Die SED war bestrebt, arbeitsrechtliche Konflikte bereits im Vorfeld zu entschärfen. Dazu erhielten die Gebietsparteileitung Wismut und der FDGB den Auftrag, eingegangene Beschwerden individuell zu bearbeiten. In dem Zusammenhang wurde am 24. August 1951 beim Zentralvorstand der IG Wismut eine Beschwerdestelle eingerichtet, die Verbindung zum zuständigen Arbeitsgericht aufnehmen sollte ${ }^{178}$. Dort gingen innerhalb von zwei Monaten 205 Beschwerdeschreiben ein, von denen 109 geklärt werden konnten. Die SED-Gebietsleitung mußte dennoch einräumen, daß einige Beschwerden beim Arbeitsgericht eingereicht wurden. Die Klagen bezogen sich häufig auf Schwierigkeiten bei der Entlassung aus dem Arbeitsverhältnis sowie die Aushändigung von Entlassungspapieren. Dies verdeutlicht zum einen, daß Einstellung und Entlassung nach wie vor nicht konfliktfrei verliefen und Unmut unter den Beschäftigten hervorriefen. Zum anderen übernahm die Parteigliederung der SED in zunehmendem Maße Aufgaben, die entweder der Arbeitsverwaltung oder den Gewerkschaften oblagen. Allerdings mußte sich erst noch zeigen, ob die Mitarbeit der Hegemonialpartei bei der arbeitsrechtlichen Schlichtung eine Entlastung mit sich brachte. Das Grundproblem bestand schließlich darin, daß die Generaldirektion der Wismut AG bisher nicht bereit gewesen war, deutschen Stellen Kompetenzen auf diesem Gebiet zu übertragen. Gespräche zwischen Wilhelm Pieck und führenden SKK-Vertretern über den Uranbergbau blieben eher von den Vorkommnissen in Saalfeld und damit von sicherheitspolitischen Überlegungen geprägt: Deshalb ging es bei den verabredeten Maßnahmen primär um die Verstärkung des Sicherheitsapparates und die Verbesserung der Kaderarbeit. Es hat den Anschein, als ob bei den Besprechungen in Karlshorst Fragen der Wohnraumversorgung eher von nachgeordneter Bedeutung waren ${ }^{179}$.

Ende 1951 erhielt das Ministerium für Arbeit von der Hauptverwaltung Personal der Wismut AG die Anweisung, alles zu unternehmen, um den Arbeitskräftebedarf für den Uranbergbau doch noch abzudecken. Der kommissarische Hauptabteilungsleiter Heisig versuchte diesen neuerlichen Vorstoß abzuwehren und wies darauf hin, daß „seitens der zu Werbenden im allgemeinen keine Neigung be-

$177 \mathrm{BAB}, \mathrm{DQ} 2 / 2100$, VVB Elektro-Maschinenbau Berlin am 27.10. 1951 an das Ministerium für Arbeit.

178 Das geht aus einem Schreiben der SED-Gebietsparteileitung Wismut vom 26.10.1951 an das ZK der SED (Paul Verner) hervor. Vgl. SAPMO, NY 4182/986, Bl. 171-174, hier Bl. 174.

179 Die kurz gehaltene Notiz von Pieck über die Besprechung am 5.11. 1951 enthält einen Maßnahmenkatalog, der an vorletzter Stelle die Wohnraumfrage thematisiert („Wohnfläche für Familien vergrößern“). Vgl. Badstübner/Loth, Wilhelm Pieck, S. $378 \mathrm{f}$. 
steht, unmittelbar vor den Feiertagen den Heimatort zu verlassen, um die Arbeit im Erzbergbaugebiet aufzunehmen"180. Gleichzeitig entsandte das Arbeitsministerium Instrukteure in die Länder, „um mit aller Eindringlichkeit auf den unbefriedigenden Stand der Arbeitskräftewerbung hinzuweisen"181. Durch eine bessere Anleitung der Betriebe sollte die Auflage - so das von Minister Chwalek formulierte Ziel - noch erfüllt werden. Auch die Generaldirektion der Wismut AG stellte eigene Instrukteure zur Verfügung, die aber nicht verhindern konnten, daß die Erfüllung des Plansolls für Dezember nur schleppend voranging. Ministerpräsident Grotewohl wurde in dem Zusammenhang gebeten, die Fachminister und Staatssekretäre, soweit ihnen volkseigene Betriebe unterstanden, „einmal eindeutig auf die Unterstützung der Betriebsleiter, Techniker und Meister bei der Werbung von Arbeitskräften für die Grundstoffindustrie Sachsen und Thüringen“ hinzuweisen ${ }^{182}$. Aufgrund des akuten Arbeitskräftemangels gab es anscheinend Überlegungen, die bisherige Praxis zu lockern, nach der Personen mit Westkontakten bzw. Westgefangenschaft die Arbeitsaufnahme im Uranbergbau verweigert wird. In dieser Frage setzte sich allerdings eine widersprüchliche Politik durch. So wurde etwa am Rande der V. Gebietsdelegiertenkonferenz der Parteiorganisation Wismut, an der unter anderem Walter Ulbricht teilnahm, festgelegt, daß „alle Personen, die aus dem Westen in das Wismutgebiet eingereist sind, sofort aus dem Gebiet der Wismut zu entfernen sind “183. Diesem sicherheitspolitischen Kurs, der lange zuvor prägend gewesen war, standen nunmehr arbeitsmarktpolitische Überlegungen gegenüber. Es ist bemerkenswert, daß ausgerechnet der russische Hauptpersonalleiter Andrejew behauptete, es gäbe bei der Wismut AG keinen Befehl, "der besagt, daß Personen, die sich in westlicher Gefangenschaft befanden oder im Westen Verwandte haben, nicht eingestellt werden dürfen" 184 . Es bestehen begründete Zweifel, daß die Meinungsäußerung Andrejews repräsentativ für die sowjetische Position insgesamt war.

Die Hauptverwaltung der Wismut AG plante offenbar zum Jahreswechsel 1951/52, das ehemalige Arbeitsamt Chemnitz als zentrale Leitstelle zur Lenkung der zugewiesenen Bergarbeiter auszubauen ${ }^{185}$. Im einzelnen war vorgesehen, daß dort ein Durchgangslager mit Tagesräumen und Gaststättenbetrieb sowie Übernachtungsmöglichkeiten für etwa 500 Personen errichtet und „in den freien Räumen" die Abteilung Arbeitskraftlenkung untergebracht wurde. Das Durchgangslager sollte bereits zum 1. Januar 1952 fertiggestellt und vom bisherigen Leiter der

180 BAB, DQ 2/2106, Aktenvermerk Heisigs vom 11. 12. 1951, S. 1.

$181 \mathrm{BAB}, \mathrm{DQ}$ 2/721, Arbeitsminister Chwalek am 13.12. 1951 an Ministerpräsident Grotewohl, S. 1.

182 Ebenda, S. 3. Darüber hinaus nahm das Arbeitsministerium Kontakt zu einzelnen Fachministerien auf, um in bilateralen Gesprächen Fortschritte bei der Bereitstellung von männlichen Arbeitskräften für den Uranbergbau zu erreichen. Vgl. BAB, DQ 2/2146, Protokoll der Besprechung zwischen dem Ministerium für Arbeit und dem Ministerium für Post- und Fernmeldewesen am 30. 1. 1952. Auch hierbei stellten sich aber keine nennenswerten Erfolge ein: So hatte etwa die Landesregierung Sachsen der Oberpostdirektion Leipzig zugestanden, daß sie wegen Personalmangels von der Werbung ausgenommen wurde.

183 SAPMO, NY 4090/306, Bl. 49-58, hier Bl. 53, Protokoll einer Besprechung während der V. Gebietsdelegiertenkonferenz am 15. 12.1951.

$184 \mathrm{BAB}, \mathrm{DQ} 2$ 2/2152, Bericht der Abt. Arbeitskraftlenkung vom 28. 12. 1951, S. 2.

185 Ebenda, Bericht der Abt. Arbeitskraftlenkung vom 28. 12. 1951 über die Dienstreise nach Dresden zum Ministerium für Wirtschaft und Arbeit und nach Chemnitz zur Hauptpersonalabteilung der Wismut AG am 21./22. 12. 1951, S. 3. 
Abteilung für Arbeit Aue, Wenzel, geleitet werden. Der Vorschlag war sowohl mit der SKK als auch mit der SED-Führung abgestimmt worden ${ }^{186}$, so daß mit der Verwirklichung rasch begonnen und kurz darauf das Durchgangslager Chemnitz eröffnet werden konnte ${ }^{187}$. Während das Arbeitsministerium und die Generaldirektion der Wismut AG davon ausgingen, die organisatorischen Voraussetzungen für eine effiziente Arbeitskräftegewinnung und -lenkung geschaffen zu haben, zeigte sich in der Folgezeit, daß die eigentlichen Hindernisse nach wie vor auf der kommunalen und betrieblichen Ebene bestanden. Aus diesem Grunde versuchte etwa die SED-Landesleitung Thüringen das Interesse Ulbrichts und der Arbeitsverwaltung auf die Kleinstädte zu lenken, in denen eine überdurchschnittlich hohe Arbeitslosenquote registriert wurde ${ }^{188}$. Hier schien der Erfolg der Werbemaßnahmen für die Wismut AG noch am größten zu sein. Dabei wurden mitunter gegenläufige Interessenlagen deutlich: So sprach sich der Bürgermeister in Oberweißbach (Kreis Rudolstadt) für den Aufbau einer neuen Industrie in der Stadt aus, die Arbeitsplätze anbieten sollte, während die SED-Landesleitung und die Landesregierung dafür plädierten, die registrierten Arbeitslosen der Wismut AG zuzuweisen. Das Ministerium für Wirtschaft und Arbeit erhoffte sich von dieser Maßnahme einen Anstoß für die Betriebe, „die innerbetriebliche Arbeitskräftelenkung zu organisieren, um Schwerbeschädigte und ortsgebundene Frauen an Stelle von einsatzfähigen männlichen und weiblichen Arbeitskräften einzusetzen" 189 .

Das Ministerium für Arbeit versuchte in der Folgezeit, die Fachministerien in die Arbeitskräftegewinnung für den Uranbergbau stärker einzubeziehen. So wurde etwa am 5. Februar 1952 mit dem Ministerium für Leichtindustrie und Vertretern der Landesregierungen vereinbart, daß die Hauptverwaltungen des Ministeriums für Leichtindustrie den Landesregierungen die Betriebe nennen, "die für die Beauflagung [...] in Frage kommen"190. An eine direkte Beteiligung der Vereinigungen der volkseigenen Betriebe (VVB) war zunächst nicht gedacht. Das Ministerium für Leichtindustrie beanstandete dies und wies darauf hin, daß so eine Kontrolle „mit der nötigen Genauigkeit und Sorgfalt" nicht durchgeführt werden könne ${ }^{191}$. Das Ministerium für Arbeit wurde daher gebeten, „die Aufschlüsselung des Auflagensolls auf die einzelnen Betriebe nur in Zusammenarbeit mit den einzelnen VVB'en vorzunehmen." Gegen die Einbindung der Fachministerien hatte beispielsweise die sächsische Landesregierung prinzipiell nichts einzuwenden, sie betonte allerdings, daß vor einer "Beauflagung" der jeweiligen Betriebe der Stellenplan mit der eigens dafür geschaffenen zentralen Stellenplankommission festgelegt werden müsse ${ }^{192}$. Daher könnten die vom Ministerium für

186 Dies geht aus einem Schreiben Chwaleks vom 17.1. 1952 an Leuschner (SPK) hervor. Vgl. BAB, DQ 2/2106.

$187 \mathrm{BAB}, \mathrm{DQ} 2 / 2106$, Bericht der Abt. Arbeitskraftlenkung vom 3. 3. 1952 über die Eröffnung des Durchgangslagers Chemnitz.

188 SAPMO, NY 4182/952, Bl. 85, SED-Landesleitung Thüringen (Sekretariat Mückenberger) am 10. 3. 1952 an Generalsekretär Walter Ulbricht.

189 BAB, DQ 2/1719, Bericht Hans Peschels vom 10. 3. 1952.

$190 \mathrm{BAB}, \mathrm{DQ}$ 2/2127, Ministerium für Leichtindustrie (Zentrale Abt. Arbeitskraft) am 10. 3. 1952 an das sächsische Ministerium für Wirtschaft und Arbeit (Abt. Arbeitskräftelenkung).

191 Ebenda, Ministerium für Leichtindustrie am 20.3. 1952 an das Ministerium für Arbeit.

192 Ebenda, Ministerium für Wirtschaft und Arbeit des Landes Sachsen am 28. 3. 1952 an das Ministerium für Arbeit. 
Leichtindustrie übersandten Listen der Betriebe, die Arbeitskräfte für die Grundstoffindustrie bereitstellen sollten, zunächst nicht berücksichtigt werden. Gleichzeitig versprach das Ministerium für Wirtschaft und Arbeit in Dresden, den Hinweis über die Betriebe mit einem Arbeitskräfteüberhang "entsprechend" auszuwerten. Nachdem das Ministerium für Leichtindustrie eine ausführliche Berichterstattung über den bisherigen Verlauf der Arbeitskräftegewinnung angemahnt hatte, wandte sich das sächsische Ministerium für Wirtschaft und Arbeit an das Arbeitsministerium in Berlin und betonte, daß eine entsprechende Anweisung nicht bekannt sei ${ }^{193}$. Das Ministerium für Arbeit wurde aufgefordert, die „Angelegenheit" mit dem Ministerium für Leichtindustrie zu klären. Dieser Vorgang zeigte, daß mit der Einbeziehung weiterer Akteure die Arbeitskräftelenkung nicht übersichtlicher und effizienter geworden war. $\mathrm{Zu}$ unterschiedlich waren die Interessen von Betrieben, Landesregierungen, Fachministerien und Arbeitsverwaltung. Diese Entwicklung konnte zudem leicht Irritationen auslösen: So wurde der volkseigene Betrieb Turmalin-Strumpfwerke Thurm von der Kommunalverwaltung und von der VVB getrennt aufgefordert, Arbeitskräfte zu stellen ${ }^{194}$. Das Arbeitsministerium in Berlin wurde aufgrund der somit verhängten doppelten Auflage um „baldigste Stellungnahme“ gebeten ${ }^{195}$, die jedoch ausblieb. Die $\mathrm{Zu}$ sammenarbeit mit den Fachministerien verlief auch weiterhin nicht reibungslos: Aus Sicht der Arbeitsverwaltung unternahmen diese nämlich zu wenig Anstrengungen, damit die ihnen unterstehenden Betriebe die Arbeitskräfteanforderungen erfüllten. Eine engagierte Werbung zugunsten des Uranbergbaus konnte nicht festgestellt werden. Darüber hinaus leiteten die Fachministerien Anträge einzelner Firmen, die von der Auflage befreit werden wollten, ohne weitere Beantwortung an das Ministerium für Arbeit weiter ${ }^{196}$. Im Sommer 1952 häuften sich die Meldungen der Landesarbeitsämter über eine zunehmende Ablehnung gegenüber Arbeitskräfteauflagen der Wismut AG, die mittlerweile auch die SED erfaßt hatte. So untersagte etwa ein ZK-Beauftragter Mitarbeitern des Arbeitsamtes, im Industriewerk Ludwigsfelde (Kreis Teltow) für die Grundstoffindustrie zu werben ${ }^{197}$.

Bei der Erfüllung der Arbeitskräfteanforderungen ergaben sich Konflikte nicht nur zwischen dem Ministerium für Arbeit und einzelnen Betrieben, die von der

193 Ebenda, Ministerium für Leichtindustrie am 14.5. 1952 an das Ministerium für Wirtschaft und Arbeit des Landes Sachsen; ebenda, Ministerium für Wirtschaft und Arbeit des Landes Sachsen am 28. 5. 1952 an das Ministerium für Arbeit.

194 Ebenda, Turmalin-Strumpfwerke Thurm am 8.4. 1952 an den Rat des Landkreises Glauchau (Abt. Arbeit).

195 Ebenda, Ministerium für Wirtschaft und Arbeit Sachsen am 10.4. 1952 an das Ministerium für Arbeit.

196 Vgl. BAB, DQ 2/2126, Ministerium für Wirtschaft und Arbeit Sachsen am 29. 5. 1952 an das Ministerium für Arbeit. Eine solche Befreiung konnte grundsätzlich nur das Ministerium für Arbeit aussprechen, das dieses Recht auch gegenüber anderen Ministerien oder Staatssekretariaten durchzusetzen suchte. Vgl. BAB, DQ 2/2127, Abt. Arbeitskraftlenkung am 7. und am 22.7.1952 an das Staatssekretariat für Chemie, Steine und Erden. Das Ministerium für Arbeit erneuerte diesen Anspruch auch später noch. Vgl. BAB, DQ 2/2103, Minister Chwalek am 27. 1. 1953 an alle Bezirke. $\mathrm{Zu}$ diesem Zeitpunkt waren nur die Betriebe des Steinkohlenbergbaus, das Mansfeld-Kombinat "Wilhelm Pieck“ und das Eisenhüttenkombinat Ost - allerdings ohne die dort eingesetzte Bauunion - von entsprechenden Auflagen befreit.

197 BAB, DQ 2/2127, Ministerium für Wirtschaft und Arbeit Brandenburg am 15. 7. 1952 an das Ministerium für Arbeit. Der ZK-Beauftragte berief sich dabei auf eine Anordnung, die angeblich der Minister für Schwerindustrie Ziller erlassen hatte. 
Auflage entbunden werden wollten, sondern auch zu anderen staatlichen Verwaltungen, die ein Abwandern von Arbeitskräften aus ihrem Zuständigkeitsbereich zu verhindern suchten. Das Ministerium für Arbeit verteidigte die vorgenommene Aufteilung des Plansolls und scheute sich nicht, eine stark ideologisch gefärbte Begründung abzugeben: Gegenüber der Staatlichen Geologischen Kommission wurde die Befreiung eines volkseigenen Betriebes in Nordhausen von der Arbeitskräfteauflage abgelehnt, „weil im Kampf um den Frieden die Produktion der Grundstoffindustrie und die Erfüllung ihrer Pläne das Primäre" sei ${ }^{198}$. Nachdem das zuständige Landesministerium in Erfurt eine Einzelprüfung vorgenommen hatte, kam Hauptabteilungsleiter Heisig zu dem Ergebnis, daß die Beauflagung im vorliegenden Fall keine Produktionsstörung verursacht habe. Die Staatliche Geologische Kommission gab sich jedoch mit diesem Beschluß nicht zufrieden und stellte einige Wochen später erneut den Antrag, den Betrieb von der Verpflichtung auszunehmen, Arbeitskräfte abgeben zu müssen ${ }^{199}$. Mitarbeiter des Ministeriums für Arbeit unternahmen im Frühjahr 1952 Dienstreisen in einige Kreise der DDR, um die Werbung von Arbeitskräften vor Ort zu überprüfen. Dabei wurden oftmals die größten Betriebe ausgesucht: Im Kreis Cottbus betraf das etwa die ansässige Textilindustrie ${ }^{200}$, in Meißen unter anderem die Staatliche Porzellanmanufaktur ${ }^{201}$.

Kommunikationsprobleme zwischen deutschen und sowjetischen Stellen erschwerten die ohnehin schleppende Bautätigkeit im Uranbergbaugebiet, die auch 1952 im Mittelpunkt der Kritik stand. Zwar mußte Walter Ulbricht einräumen, daß aufgrund von Fehlern der Staatlichen Plankommission und der Baukommission geplante Investitionen nicht durchgeführt werden konnten. Ein grundsätzliches Problem bestand seiner Meinung nach allerdings schon darin, daß inhaltliche Aussprachen zwischen dem zuständigen Vertreter der Wismut AG Bogdanow und dem Leiter des Sonderbaustabes Robert Siewert noch nicht stattgefunden hatten 202. Diese müßten konkrete Absprachen treffen über die Dringlichkeit der einzelnen Baumaßnahmen, da bisher eine einheitliche Position auf sowjetischer Seite nicht erkennbar gewesen wäre. Ein solches Treffen fand schließlich am 2. April statt, das noch einmal die unzureichende Informationslage Bogdanows deutlich machte 203 . Da einzelne Bauvorhaben stets mit einem Vertreter der Hauptverwaltung der Wismut AG abgestimmt worden waren, muß davon ausgegangen werden, daß der Informationsaustausch zwischen den jeweiligen sowjetischen Abteilungen völlig unzureichend war. Bogdanow und Siewert kamen überein, monatlich eine Besprechung durchzuführen. Dazu kam es jedoch nicht: Vereinbarte Termine wurden auf sowjetische Veranlassung hin zunächst verschoben.

198 BAB, DQ 2/2099, Abt. Arbeitskraftlenkung am 14.3. 1952 an die Staatliche Geologische Kommission (HA Plandurchführung).

199 Ebenda, Staatliche Geologische Kommission am 23. 5. 1952 an Minister Chwalek.

$200 \mathrm{BAB}, \mathrm{DQ} 2 / 2152$, Bericht der Abt. Arbeitskraftlenkung vom 24. 3. 1952 über die Dienstreise im Kreis Cottbus (18.-21.3. 1952).

201 Ebenda, Bericht vom 15. 3. 1952 über Dienstreise nach Meißen (25.-28. 2. 1952).

202 SAPMO, NY 4182/986, Bl. 239f., Ulbricht am 26. 3. 1952 an Kobulow.

${ }^{203}$ Ebenda, Bl. 251-253, Leiter des Sonderbaustabes „Erzbergbau“ Siewert am 8. 4. 1952 an Ulbricht. Der Sonderbaustab unterstand formell dem Staatssekretariat für Bauwirtschaft. 
Trotz mehrerer Anläufe gelang es dem Leiter des Sonderbaustabes nicht, einen regelmäßigen Kontakt zum sowjetischen Vertreter aufzubauen ${ }^{204}$.

Obwohl der sowjetische Bedarf stetig zurückgegangen war, hatte die Arbeitsverwaltung Ende 1952 erneut Probleme, die angeforderten Arbeitskräfte bereit zu stellen, da der Gesamtbestand an verfügbaren und vor allem bergbautauglichen Arbeitern erheblich gesunken war. Von den 6000 Arbeitskräften, die im November zur zentralen Leitstelle nach Chemnitz zu entsenden waren, konnten innerhalb von zehn Tagen nur 917 Personen gewonnen werden ${ }^{205}$. Damit zeichnete sich $a b$, daß der Erfüllungsstand sehr niedrig liegen würde. Als weitere Ursache für diese Entwicklung nannte die Abteilung Arbeitskraftlenkung aber noch die Auflösung der Länder im Sommer 1952 und die damit zusammenhängende Abschaffung der Landesregierungen, welche die Werbung von Arbeitskräften trotz der kurzfristigen und nach wie vor unberechenbaren Auflagen letztlich „befriedigend" durchgeführt hätten 206. Durch die „Demokratisierung der Verwaltungen“" seien zahlreiche neue Mitarbeiter bei den Abteilungen für Arbeit und Berufsausbildung der Bezirke und Kreise eingestellt worden, denen die „Methode der Werbung und Lenkung von Arbeitskräften" noch nicht geläufig sei. Ministerpräsident Grotewohl warf der Arbeitsverwaltung vor, zu spät Gegenmaßnahmen ergriffen zu haben, um ein Absinken des Erfüllungsstandes zu verhindern ${ }^{207}$. Die leitenden Mitarbeiter sollten daher unter der persönlichen Anleitung Chwaleks die Werbetätigkeit in den Bezirken und Kreisen anleiten und tatkräftig unterstützen, so daß „bis spätestens 15.1. 1953 die angeforderten Arbeitskräfte im vollen Umfang bereitstehen." Doch auch diese Terminfestsetzung war illusorisch: In einem ausführlich gehaltenen Antwortschreiben wies der Arbeitsminister darauf hin, daß zu diesem Zeitpunkt die bereits reduzierte Auflage (5530 statt 6000 Arbeitskräfte) erst zu 48,3 Prozent erfüllt werden konnte 208 . Chwalek räumte durchaus selbstkritisch ein: „Wir haben nicht rechtzeitig berücksichtigt, daß bei dem Übergang der Aufgaben der Werbung von den Landesregierungen auf die neu gebildeten Bezirke auch die bisherige Organisation der Werbung entsprechend neu aufgebaut werden mußte" 209 . Die zunehmenden Schwierigkeiten bei der Gewinnung von Arbeitskräften für den Uranbergbau hingen aber nicht ausschließlich mit der angeblich unzureichenden Werbung bzw. mit der Verwaltungsumstrukturierung zusammen, sondern hatten ihre tiefere Ursache vielmehr darin, daß mit dem Anlaufen des 1. Fünfjahrplanes andere Wirtschaftsbranchen zu wirtschaftlichen Schwerpunkten erklärt worden waren. Eine Folge dieser struktur- und wirtschaftspolitischen Maßnahme war ein Ansteigen der Löhne und Gehälter in der Stahlindustrie, die sich somit für die Wismut AG zu einem Konkurrenten auf der Angebotsseite entwickelte ${ }^{210}$. Nicht umsonst hatten zahl-

204 Ebenda, Bl. 252 (Rückseite).

$205 \mathrm{BAB}, \mathrm{DQ} 2 / 721$, Disposition des Ministeriums für Arbeit (Abt. Arbeitskraftlenkung) vom 15. 11. 1952, S. 1 .

206 Ebenda, S. 2.

207 SAPMO, NY 4090/359, Bl. 39, Grotewohl am 5. 1. 1953 an Minister Chwalek.

208 Ebenda, Bl. 40-42, hier Bl. 41, Chwalek am 17. 1. 1953 an Grotewohl.

209 Ebenda, Bl. 40.

210 So betonte auch Arbeitsminister Chwalek, daß der „materielle Anreiz zur Arbeitsaufnahme in der Grundstoffindustrie nicht mehr in dem bisherigen Umfang vorhanden“ sei. Ebenda, Bl. 42. 
reiche Berichte der Landesämter schon zuvor darauf aufmerksam gemacht, daß etwa Wismut-Arbeiter zum Eisenhüttenkombinat Ost abwanderten, weil sie dort eine längerfristige berufliche Perspektive erwarteten. Dabei kam auch der Umstand der befristeten Arbeitsverträge bei der Wismut AG zum Tragen, die ursprünglich eingeführt worden waren, um die körperlich schwere und zum Teil auch gefährliche Arbeit untertage nur für einen begrenzten Zeitraum durchführen zu lassen.

Nach Mitteilung des Ministeriums für Arbeit hatte die ehemalige Landesverwaltung Thüringen ein Konzept zur Arbeitskräftewerbung entwickelt, das als vorbildlich angesehen wurde und offenbar den Bezirken der DDR zur Nachahmung empfohlen werden sollte211. Demzufolge sollten bei den Räten der Bezirke und Kreise Werbekommissionen gebildet werden, die sich aus Mitgliedern der Parteien und Massenorganisationen zusammensetzten. Außerdem waren auf betrieblicher Ebene sogenannte Werbeaktivs zu bilden, denen die „direkte, individuelle Werbung der Arbeitskräfte" anvertraut werden sollte. Anleitung, Unterstützung aber auch Kontrolle der Tätigkeiten dieser Betriebskommissionen oblag den Kreiskommissionen, die ihrerseits von den Bezirkskommissionen angewiesen wurden. Nur bei den industriellen Schwerpunktbetrieben konnte sich die Kreiskommission „entscheidend" einschalten. An der Spitze stand wiederum das Ministerium für Arbeit. Die Abteilung Arbeitskraftlenkung war sich über den Erfolg der Kommissionsbildung und deren Hierarchisierung sicher: „Wenn wir die Werbung vom Ministerium bis zum letzten Mann im Betrieb durchorganisieren, werden wir der politischen und wirtschaftlichen Bedeutung der Grundstoffindustrie gerecht werden und die geforderten Arbeitskräfte zu diesen Betrieben lenken. ${ }^{\text {"212 }}$ Arbeitsminister Chwalek machte das Sekretariat des ZK auf den „alarmierenden Zustand in der Arbeit der Arbeitskräftegestellung für die Grundstoffindustrie“ aufmerksam und bat darum, die SED-Bezirks- und Kreisleitungen auf diese zentrale Aufgabe hinzuweisen ${ }^{213}$. Bis zu ihrer Auflösung hätten sich die Landesleitungen ,in gewissen Abständen“ über den Ablauf der Werbemaßnahmen informieren lassen "und durch ihre Autorität die Genossen in den Verwaltungen zur Erfüllung ihrer Pflichten" angehalten. Diese Maßnahme sei - so Chwalek - dringend erforderlich, da die Hauptverwaltung der Wismut AG für den Monat Dezember eine neue Auflage von 6000 Arbeitskräften angekündigt hätte und mit einer Bedarfssteigerung im übrigen wieder zu rechnen sei. Das Ministerium für Arbeit gab am 11. Dezember 1952 eine Richtlinie über die Durchführung der Werbung und Lenkung von Arbeitskräften für den Erzbergbau heraus, die sich inhaltlich sehr stark am thüringischen Konzept der Werbekommissionen orientierte $^{214}$.

Arbeitsminister Chwalek versuchte, die Vorsitzenden der Räte der Bezirke dazu zu bewegen, in Kooperation mit den SED-Bezirksleitungen Konferenzen abzuhalten, auf denen den Betriebsleitungen nochmals die Bedeutung der Ar-

211 Zum folgenden: BAB, DQ 2/721, Disposition des Ministeriums für Arbeit (Abt. Arbeitskraftlenkung) vom 15. 11. 1952, S. 2 f.

212 Ebenda, S. 3.

${ }^{213}$ BAB, DQ 2/721, Chwalek am 28. 11. 1952 an das Sekretariat des ZK (Schön).

$214 \mathrm{BAB}, \mathrm{DQ} 2 / 1761$. 
beitskräftewerbung für die Wismut AG deutlich gemacht werden sollte. Darüber hinaus erteilte Chwalek den Abteilungen für Arbeit und Berufsausbildung den Auftrag, dem Ministerium täglich über den Stand der Werbemaßnahmen zu berichten - eine Aufgabe, welche die früheren Landesregierungen wahrgenommen hatten ${ }^{215}$. Da zahlreiche volkseigene Betriebe nicht mehr in der Lage waren, Arbeitskräfte abzugeben, begannen einzelne Bezirksverwaltungen damit, ihre Werbemaßnahmen verstärkt auf die private Wirtschaft zu konzentrieren, die bisher verschont geblieben war. So teilte der Vorsitzende des Rates des Bezirkes Frankfurt/Oder mit, daß er verantwortliche Mitarbeiter der Industrie- und Handelskammer, der Handwerkskammer und den FDGB für diese Aufgabe gewonnen habe216. Erste Berichte der Bezirksverwaltungen trafen Anfang Januar 1953 in Berlin ein: Diese waren durchweg selbstkritisch gehalten und machten gleichzeitig deutlich, daß die Bildung neuer Kommissionen nicht zwangsläufig den erhofften Erfolg bei der Arbeitskräftegewinnung mit sich brachte ${ }^{217}$.

Abschließend sei nochmals darauf hingewiesen, daß eine genaue quantitative Darstellung des Beschäftigtenstandes der Wismut AG über einen längeren Zeitraum hinweg nicht möglich ist. Diese müßte sowohl die Einstellungen als auch die Entlassungen gleichermaßen berücksichtigen. Entsprechende Unterlagen konnten jedoch nur für das Jahr 1950 ermittelt werden: Demzufolge waren etwa im 1. Halbjahr 1950 insgesamt 64245 Personen eingestellt worden; dem standen 27833 Entlassungen gegenüber ${ }^{218}$. Im vierten Quartal 1950 wurden 11486 Einstellungen und 27497 Entlassungen registriert ${ }^{219}$. Meldungen der Abteilung Arbeitskraftlenkung in Berlin ist zu entnehmen, daß im Zeitraum vom 1. September 1951 bis zum 20. Juli 1952 insgesamt 62336 Arbeitskräfte für die Wismut AG in Sachsen und Thüringen gewonnen wurden ${ }^{220}$. An den Monatszahlen läßt sich der allmähliche Rückgang der sowjetischen Nachfrage ablesen: So wurden im September 195110968 Arbeiter zugewiesen, einen Monat später 8046 und im Dezember 4123. Die Angaben stiegen nochmals im Februar und März 1952 auf 7869 bzw. 6283 Arbeitskräfte. In der Folgezeit reduzierte sich die Zahl der zugewiesenen Bergarbeiter deutlich und lag zwischen 1644 (Mai) und 2160 (Juli). Für die Gesamtbeurteilung ist allerdings die Höhe der Anforderungen entscheidend, die an der prozentualen Erfüllungsquote festgemacht werden kann. Auch hier schwankten die Werte beträchtlich. Konnten die Arbeitsämter im September 1951 73,1 Prozent der angeforderten Arbeitskräfte zuweisen, so sank die Rate im folgenden Monat auf 53,6 und stieg im November auf 126 Prozent. Dagegen lag sie im Dezember 1951 nur bei 45,8 Prozent. Diese Berg- und Talfahrt setzte sich auch im 1. Halbjahr 1952 fort. Auffallend dabei ist jedoch die insgesamt gesehen stetige

215 BAB, DQ 2/721, Rundschreiben Chwaleks vom 10.12. 1952.

216 BAB, DQ 2/2127, Vorsitzender des Rates des Bezirkes Frankfurt/Oder am 20.12. 1952 an Arbeitsminister Chwalek.

$217 \mathrm{Vgl}$. BAB, DQ 2/2127, Rat des Bezirks Suhl (Abt. Arbeit und Berufsausbildung) am 3. 1. 1953 an das Ministerium für Arbeit (Abt. Arbeitskraftlenkung).

218 BAB, DQ 2/2095, Statistik des Ministeriums für Arbeit und Aufbau Sachsen vom 4. 7. 1950.

219 Ebenda, Statistik des Ministeriums für Industrie, Arbeit und Aufbau Sachsen vom 22. 12. 1950.

220 BAB, DQ 2/1646. Die monatlichen Kurzberichte waren für Minister Chwalek und Staatssekretärin Malter angefertigt worden. 
Abnahme der monatlichen Auflagenhöhe. Erwähnenswert ist noch die bereits bekannte Tatsache, daß Sachsen seine Auflagen überdurchschnittlich gut zu erfüllen vermochte 221 . Der Arbeitskräftebedarf nahm auch 1952 weiter ab, bis er gegen Jahresende wieder etwas anstieg, ohne aber die Höhe vom Jahresanfang zu erreichen. Deutlich erkennbar sind außerdem die beträchtlichen Schwankungen bei der Erfüllung des Plansolls.

Tabelle 11: Erfüllung der Auflagen für die Wismut AG 1952

\begin{tabular}{lccc}
\hline Monat & Auflage & Erfüllung & in Prozent \\
\hline Januar & 12000 & 10017 & 84 \\
Februar & 7800 & 7869 & 100 \\
März & 5000 & 6283 & 126 \\
April & 2000 & 4159 & 208 \\
Mai & - & 1644 & - \\
Juni & 1150 & 1776 & 156 \\
Juli & 2150 & 2734 & 127 \\
August & 900 & 1241 & 138 \\
September & 2090 & 1459 & 70 \\
Oktober & 2700 & 3028 & 112 \\
November & 6000 & 2347 & 39 \\
Dezember & 6000 & 2376 & 39,6 \\
\hline
\end{tabular}

Quelle: SAPMO, NY 4090/359, Bl. 36-38, Minister Chwalek am 30.12. 1952 an die Planökonomische Abteilung der SKK (Chomjakow).

Eine differenzierte Analyse nach regionalen Gesichtspunkten verdeutlicht noch einmal die starke Belastung des Landes Sachsen bzw. ab Sommer 1952 des Bezirkes Karl-Marx-Stadt bei der Bereitstellung von Arbeitskräften für die Wismut AG.

${ }^{221}$ Die sächsische Landesregierung meldete, daß im Verlauf des Jahres 195142850 Arbeitskräfte angefordert worden seien. Es konnten insgesamt 37854 Personen zugewiesen werden, von denen 36367 eingestellt wurden (85\%). Damit war die Fehlvermittlungsquote im Vergleich zu den anderen Ländern sehr niedrig. BAB, DQ 2/1755, Ministerium für Wirtschaft und Arbeit des Landes Sachsen am 25. 2. 1952 an das Ministerium für Arbeit. In Sachsen-Anhalt lag die durchschnittliche Erfüllungsquote in der Zeit 1.1.-30.11. 1951 bei 65,8\%. BAB, DQ 2/1755, Ministerium für Wirtschaft (HA Arbeit) der Landesregierung Sachsen-Anhalt am 10.12. 1951 an den Minister für Arbeit Chwalek, S. 1. Die mecklenburgische Landesregierung bezifferte den Erfüllungsstand für das Jahr 1951 auf 40,7\% (Untertagearbeiter) bzw. 31\% (Ubertagearbeiter). Vgl. BAB, DQ 2/1755, Ministerium für Wirtschaft und Arbeit Mecklenburg am 31.3. 1952 an das Ministerium für Arbeit, S. 1. 
Tabelle 12: Bereitstellung von Arbeitskräften für die Wismut $A G$ durch die Bezirke November 1952-August 1953

\begin{tabular}{lrrrrrrrrrr}
\hline & Nov. & Dez. & Januar & Februar & März & April & Mai & Juni & Juli & August \\
& 1952 & 1952 & 1953 & 1953 & 1953 & 1953 & 1953 & 1953 & 1953 & 1953 \\
\hline Frankf./Oder & 4 & 38 & 55 & 11 & 21 & & & & & 1 \\
Leipzig & 186 & 171 & 525 & 232 & 279 & 54 & 146 & 193 & 108 & 185 \\
Karl-Marx- & 1368 & 1019 & 1548 & 1148 & 958 & 1099 & 1159 & 903 & 1324 & 1288 \\
Stadt & & & & & & & & & & \\
Dresden & 123 & 307 & 589 & 256 & 207 & 15 & 159 & 23 & 117 & 140 \\
Erfurt & 117 & 135 & 388 & 216 & 181 & 102 & 145 & 4 & 103 & 16 \\
Gera & 90 & 183 & 265 & 312 & 200 & 176 & 132 & 273 & 24 & 54 \\
Suhl & 24 & 66 & 149 & 78 & 119 & 56 & & & 1 & \\
Magdeburg & 71 & 88 & 207 & 61 & 61 & 13 & 60 & & 21 & 11 \\
Halle & 221 & 232 & 420 & 171 & 211 & 113 & 166 & 74 & 124 & 77 \\
Potsdam & 59 & 61 & 117 & 35 & 33 & 1 & 17 & 1 & 8 & 9 \\
Cottbus & 21 & 46 & 96 & 19 & 37 & 5 & 24 & 2 & 15 & 21 \\
Rostock & 29 & 21 & 78 & 40 & 46 & 5 & 23 & 2 & 4 & 1 \\
Schwerin & 16 & 43 & 120 & 19 & 38 & & 25 & & 7 & \\
Neubg. & 18 & 10 & 42 & 31 & 29 & & 20 & & 2 & 1 \\
Insg. & 2347 & 2420 & 4599 & 2626 & 2420 & 1639 & 2076 & 1480 & 1858 & 1804 \\
Auflage & 6000 & 6000 & 5530 &. & 2070 & 600 & 700 & & & 1300 \\
\hline
\end{tabular}

Quelle: BAB, DQ 2/2101, Aktenvermerke der Abt. Arbeitskraftlenkung (o.D.).

\section{Steinkoblenbergbau}

Es blieb zunächst der sächsischen Landesregierung überlassen, den Arbeitskräftebedarf für den Steinkohlenbergbau selber abzudecken. Aufgrund der Binnenwanderung sowie der beginnenden Abwanderung zum Uranbergbau, der unter anderem auch die Gruben des Steinkohlenbergbaus erfaßt hatte, sah sich jedoch das zuständige Ministerium für Arbeit und Sozialwesen in Dresden dazu nicht mehr in der Lage. Die VVB Steinkohlenverwaltung Zwickau entsandte ihrerseits Werber in das Heimkehrerlager Gronenfelde, um den drohenden Arbeitskräftemangel einigermaßen ausgleichen zu können. Ohne Zustimmung des Berliner Arbeitsministeriums durften jedoch die Arbeitskräftewerber ihre Tätigkeit nicht aufnehmen. Das sächsische Ministerium, das die Vorgehensweise der Grubenverwaltung ausdrücklich billigte, stellte deshalb einen offiziellen Antrag222, der allerdings abgewiesen wurde. Ein Mitarbeiter des Ministeriums begründete die Ablehnung mit dem Hinweis, daß „den nach langen Jahren der Abwesenheit in ihre Heimat zurückkehrenden ehemaligen Kriegsgefangenen nach dem Betreten deutschen Bodens während des nur höchstens 24 Stunden währenden Durchschleusens im Lager aus psychologischen und politischen Gründen die durch eine Werbung bedingte Belastung unbedingt" erspart werden solle223. Für das Ministerium für

$222 \mathrm{BAB}, \mathrm{DQ} 2 / 2134, \mathrm{Bl}$. 28, Ministerium für Arbeit und Sozialwesen Sachsen am 12.11. 1949 an das Ministerium für Arbeit und Gesundheitswesen.

${ }^{223}$ Ebenda, Bl. 29, Ministerium für Arbeit und Gesundheitswesen (Donau) am 25.11. 1949 an das Ministerium für Arbeit und Sozialwesen Sachsen. 
Arbeit und Gesundheitswesen dürfte jedoch ausschlaggebend gewesen sein, daß grundsätzlich an der zentralisierten Arbeitskräfteplanung und -lenkung festgehalten werden sollte. Insofern mußte einzelnen Betrieben oder Wirtschaftsverwaltungen zwangsläufig untersagt werden, selbständig Arbeitskräfte anzuwerben. Damit besaß die einmal getroffene Entscheidung auch prinzipiellen Charakter und war aus Sicht der Arbeitsverwaltung durchaus nachvollziehbar. Für die betroffenen Betriebe und die jeweiligen Landesverwaltungen stellte dies andererseits eine erhebliche Einschränkung der eigenen Handlungsfähigkeit dar: Sie hatten für die Abdeckung des Arbeitskräftebedarfs zu sorgen, durften sich aber einiger zentraler Instrumente staatlicher Arbeitsmarktpolitik nicht bedienen. Statt dessen erklärte sich das Arbeitsministerium in Berlin bereit, den Ländern Auflagen zu erteilen, Arbeitskräfte für den Steinkohlenbergbau zu gewinnen ${ }^{224}$. Nach Angaben des Ministeriums für Industrie hatte die Steinkohlenverwaltung Zwickau für den Monat März einen Gesamtbedarf von 1740 Bergarbeitern, 18 Steigern, zehn Grubenschlossern und fünf Elektrikern angemeldet. Zugleich wurde vorgeschlagen, die Werbung auf die gesamte DDR auszuweiten und die Arbeitsämter, die sich auf dem Gebiet des Steinkohlenbergbaus befanden (Zwickau, Glauchau und Lugau), von den Auflagen zur Bereitstellung von Arbeitskräften für den Uranbergbau zu befreien 225 .

Die Arbeitsämter erhielten den Auftrag, die geworbenen Arbeitskräfte durch Beratungsärzte auf ihre Bergbautauglichkeit überprüfen zu lassen. Diese Bestimmung galt sowohl für den Uranbergbau als auch für den Steinkohlenbergbau, wurde jedoch Ende der vierziger Jahre bzw. Anfang der fünfziger Jahre nicht konsequent praktiziert, so daß die Zahl der „Fehllenkungen“ sprunghaft anstieg. Die sächsische Landesregierung kritisierte in dem Zusammenhang, daß die ärztlichen Untersuchungen oftmals „zu großzügig“ durchgeführt würden ${ }^{226}$. Bei nochmaliger Kontrolle durch Beratungsärzte der Steinkohlenverwaltung seien nämlich zahlreiche zugewiesene Bergarbeiter wieder entlassen worden. Die Arbeitsämter wurden deshalb gebeten, die Tauglichkeitsprüfungen sorgfältig durchführen zu lassen, um die Zahl der „Fehllenkungen“ so gering wie möglich zu halten. $\mathrm{Zu}$ gleich durfte jedoch das Ziel der Planerfüllung nicht gefährdet werden: Die SKK, die einen Rückgang der Steinkohlenförderung befürchtete, schlug dem Minister für Industrie Selbmann am 27. Mai 1950 Maßnahmen „zur Verbesserung der Arbeit der Kohlenindustrie“" vor 227 . So sollten unter anderem im zweiten Quartal 1950 im Steinkohlengebiet Zwickau-Ölsnitz 1000 Arbeiter zusätzlich eingestellt und im laufenden Jahr weitere 1000 Hauer ausgebildet werden 228 . Des weiteren regte die sowjetische Besatzungsmacht die Verbesserung einiger materieller Anreize an, etwa die Erhöhung von Prämienzahlungen und Lohnsätzen für einzelne Bergarbeitergruppen. Ein ausführlicher Bericht des Arbeitsamtes Zwickau schien

$224 \mathrm{Vgl}$. BAB, DQ 2/2132, Ministerium für Arbeit und Gesundheitswesen Sachsen am 11.3. 1950 an die Landesregierungen in Erfurt, Potsdam, Schwerin und Halle.

225 Ebenda, Ministerium für Industrie (HA Kohle) am 15.3. 1950 an das Ministerium für Arbeit und Gesundheitswesen (Abt. Arbeitskraftlenkung).

226 Ebenda, Ministerium für Arbeit und Gesundheitswesen Sachsen am 16.5. 1950 an das Ministerium für Arbeit und Gesundheitswesen.

227 SAPMO, NY 4182/1194, Bl. 113-116.

228 Ebenda, Bl. 114. 
die sowjetischen Befürchtungen zu bestätigen: Die Anzahl der Grubenarbeiter war innerhalb von fünf Monaten zwar nur geringfügig von 12722 auf 12714 zurückgegangen ${ }^{229}$. Die angestrebte Steigerung der Produktionsmenge wurde jedoch als unrealistisch eingeschätzt, zumal eine Abwanderungswelle zur Wismut AG eingesetzt hatte. Das Arbeitsamt $Z$ wickau äußerte die Vermutung, daß die Fluktuation zum Uranbergbau noch weiter zunehmen werde, da die Entlohnung bei der Wismut AG wesentlich besser sei. Das Ministerium für Arbeit und Gesundheitswesen schloß sich dieser Einschätzung allerdings nicht an und behauptete, daß für die Nichterfüllung der Pläne nicht der Arbeitskräftemangel verantwortlich sei, sondern vielmehr die mangelnde Arbeitseinstellung von Betriebsleitung und Belegschaft ${ }^{230}$.

Auf seiten der SED nahm sich auch der sächsische Landesvorstand der Thematik an und besprach mit Vertretern der Landesregierung Maßnahmen zur Zurückdrängung der Fluktuation und damit langfristig zur Steigerung der Steinkohlengewinnung, die jedoch allgemein gehalten waren und wenig Neues enthielten ${ }^{231}$. Zu diesem Zeitpunkt diskutierte die SED-Führung bereits die Verabschiedung einer Verordnung „über die Stellung der Bergarbeiter", die nicht nur dem Steinkohlenbergbau zugute kommen sollte. Vielmehr ging es allgemein um eine Aufwertung des Bergbaus, die sich auch in entsprechenden Lohnverbesserungen niederschlagen sollte. Erstmals befaßte sich das Sekretariat des ZK auf seiner Sitzung am 10. und 11. Mai 1950 mit dem Arbeitsvorhaben und berief eine Kommission, die bis zum 10. Juni einen ersten Entwurf ausarbeiten sollte232. Zwei Monate später stimmte das Politbüro, dem der Verordnungsentwurf vorgelegt worden war, "Richtlinien zur Ausarbeitung eines solchen Gesetzes" zu und berief Fritz Selbmann als weiteres Mitglied in die Kommission ${ }^{233}$. Nach den Vorstellungen der SED-Führung sollte die geplante Verordnung die zukünftige Lohnpolitik für den Bergbau in den Grundzügen festlegen. Dabei müsse berücksichtigt werden, daß der Bergbau „von erstrangiger Bedeutung“ für die Gesamtwirtschaft sei234. Diese Forderung war bereits in den Jahren zuvor mehrmals erhoben worden. Aufgrund der anhaltenden Abwanderungsbewegung sah sich aber das Politbüro offensichtlich gezwungen, das Instrument der Lohnpolitik nicht mehr ausschließlich nur als Anreizfunktion, sondern auch dezidiert zur Regulierung der Fluktuation einzusetzen. Während es zuvor um die Gewinnung neuer Arbeitskräfte gegangen war, stand nunmehr die Beschränkung der zwischenbetrieblichen Wanderung im Vordergrund. Zum vorgeschlagenen Maßnahmenbündel gehörten außerdem die Verbesserung des Wohnungsbaus, die Ausgabe von Arbeitskleidung und der Ausbau der betrieblichen Gesundheitsfürsorge zur Senkung des Krankenstandes. Auch

${ }^{229} \mathrm{BAB}, \mathrm{DQ} 2 / 2132$, Arbeitsamt Zwickau am 19.6. 1950 an das Ministerium für Arbeit und Gesundheitswesen, S. 1.

230 Ebenda, Abt. Arbeitskraftlenkung am 29.6. 1950 an Hauptabteilungsleiter Litke.

${ }^{231}$ SächsHStA, Landesregierung Sachsen, Ministerium für Arbeit und Sozialfürsorge, Bd. 402, Protokoll über die Besprechung des SED-Landesvorstandes am 27.7. 1950, S. $7 \mathrm{f}$.

232 SAPMO, DY 30/J IV 2/3/106, Bl. 10. Der Kommission gehörten an: Max Herm, Hanisch, Gustav Sobottka, Fritsche und der stellvertretende Vorsitzende der IG Bergbau.

${ }^{233}$ SAPMO, DY 30/IV 2/2/97, Bl. 87, Protokoll der Sitzung des Politbüros am 11. 7. 1950.

${ }^{234}$ Ebenda, Bl. 164, Grundlage eines Entwurfs für eine Verordnung über die Stellung der Bergarbeiter. 
diese Maßnahmen bewegten sich in den altbekannten Bahnen der bisherigen Arbeitsmarktpolitik. Das gilt genauso für die Forderung nach Intensivierung der Nachwuchsausbildung. Kurz zuvor hatte das Sekretariat des ZK seine grundsätzliche Zustimmung gegeben und die Meinung vertreten, daß gleichzeitig eine Regelung der Gehälter des bergbautechnischen Personals vorgenommen werden müsse ${ }^{235}$. Nach nochmaliger Überarbeitung und Beratung verabschiedete das Politbüro den Verordnungsentwurf schließlich am 8. August 1950236, so daß er elf Tage später im Gesetzblatt veröffentlicht werden konnte ${ }^{237}$. Die Erhöhung der tariflichen Löhne und Gehälter für die im Bergbau Beschäftigten wurde durch die Verordnung „über die Verbesserung der Entlohnung der Arbeiter und Angestellten in den volkseigenen und ihnen gleichgestellten Betrieben" geregelt ${ }^{238}$.

Rasche Erfolge waren allerdings von der in Kraft getretenen Verordnung nicht zu erwarten. Der Steinkohlenbergbau befand sich bereits zuvor im Schatten des Erzbergbaus - das belegen die Beschäftigtenzahlen (vgl. Tabelle 13). Dabei wird deutlich, daß der Erzbergbau zwischen November 1949 und Mai 1950 den größten Beschäftigtenzuwachs zu verzeichnen hatte, während die übrigen $Z$ weige des Bergbaus eher stagnierten. Abteilungsleiter Huth warnte vor übertriebenen Hoffnungen und wies noch auf andere Hindernisse hin, die einer spürbaren Erhöhung der Steinkohlenmenge im Wege standen: $\mathrm{Da}$ bei den vorgenommenen Tiefbohrungen noch keine neuen Kohlevorkommen erschlossen werden konnten, war an eine Erhöhung der Fördermenge nicht zu denken ${ }^{239}$. Darüber hinaus gab es einen Bedarf an Facharbeitern in den Zuliefererbetrieben, die Bohrmaschinen für den Bergbau herstellten ${ }^{240}$. Diese Nachfrage konnte auch nicht durch ein verbessertes Lohnsystem befriedigt werden, sondern erforderte entsprechende berufsausbildende Programme über einen mehrjährigen Zeitraum hinweg.

Das Ministerium für Arbeit beklagte ein halbes Jahr nach Inkrafttreten der Verordnung vom 10. August 1950, daß die Probleme bei der Versorgung des Steinkohlenbergbaus mit Arbeitskräften „nur zum geringen Teil behoben“ seien²4. So konnte zwar die Abwanderung abgebremst, die Fluktuation der Arbeitskräfte jedoch nicht entscheidend eingeschränkt werden. Die zuständige Abteilung

${ }^{235}$ SAPMO, DY 30/J IV 2/3/122, Bl. 1, Protokoll der Sitzung des Sekretariats des ZK am 29. 6. 1950.

${ }^{236}$ SAPMO, DY 30/IV 2/2/103, Bl. 82 und 91-97.

${ }_{237}$ Verordnung zur Verbesserung der Lage der Bergarbeiter, des ingenieurtechnischen und kaufmännischen Personals sowie der Produktionsverhältnisse im Bergbau der DDR, in: Gesetzblatt des DDR 1950, S. 832-834.

${ }^{238}$ Ebenda, S. 839-843. Die Lohnerhöhung war letztlich abhängig vom Wirtschaftszweig und der Einstufung in die Lohngruppen 1 bis 8 . Im Stein- und Braunkohlenbergbau bewegte sich die Erhöhung zwischen 8 und 50 Prozent und lag damit - mit Ausnahme der beiden unteren Lohngruppen - deutlich über den Werten der übrigen Wirtschaftszweige.

$239 \mathrm{BAB}, \mathrm{DQ} 2 / 2125$, Huth am 20. 10. 1950 an Hauptabteilungsleiter Litke. Die Steinkohlenvorräte blieben in der DDR stark begrenzt: Das Staatssekretariat für Kohle und Energie ging Mitte 1952 von einer Lebensdauer der einzelnen Schachtanlagen von zwei (Freitaler Schächte) bis maximal neun Jahren (Karl-Marx-Schächte) aus. Die Kohlenvorräte betrugen demzufolge insgesamt 39663800 t. Vgl. BAB, DQ 2/2130, Staatssekretariat für Kohle und Energie am 12.6. 1952 an das Ministerium für Arbeit (Heinze), S. 2.

${ }^{240} \mathrm{BAB}, \mathrm{DQ} 2 / 2145$, Ministerium für Industrie (HA Kohle) am 17. 11. 1950 an das Ministerium für Arbeit und Gesundheitswesen.

${ }^{241} \mathrm{BAB}, \mathrm{DQ}$ 2/717, Hausmitteilung der Abt. Arbeitskraftlenkung vom 16.2.1951 an das Sekretariat des Ministers, $\mathbf{S} .1$. 
Tabelle 13: Übersicht über die unselbständig Beschäftigten im Bergban 1949/50

\begin{tabular}{|c|c|c|c|c|c|c|}
\hline & $\begin{array}{l}\text { Stand: } \\
\text { Männer }\end{array}$ & $\begin{array}{l}10.11 .1 \\
\text { Frauen }\end{array}$ & $\begin{array}{l}949 \\
\text { Insgesamt }\end{array}$ & $\begin{array}{l}\text { Stand: } \\
\text { Männer }\end{array}$ & $\begin{array}{l}\text { 10.5.1950 } \\
\text { Frauen }\end{array}$ & Insgesamt \\
\hline Steinkohle & 21190 & 844 & 22034 & 21472 & 969 & 22441 \\
\hline Braunkohle & 111745 & 11117 & 122862 & 111234 & 12224 & 123458 \\
\hline Erzbergbau & 185365 & 25824 & 211189 & 217265 & 35222 & 252487 \\
\hline Salzbergbau & 22555 & 940 & 23495 & 23295 & 981 & 24276 \\
\hline
\end{tabular}

Quelle: BAB, DQ 2/2125, Statistik des Ministeriums für Arbeit (Abt. Planung und Statistik); handschriftlich: 6. 12. 1950.

Arbeitskraftlenkung registrierte mit Befriedigung, daß die Zahl der Zugänge die der Abgänge mittlerweile übersteige. So seien im Zeitraum vom 1. August bis zum 22. Dezember 1950 insgesamt 2175 Grubenarbeiter zugewiesen und auch eingestellt worden; demgegenüber verzeichneten die Arbeitsämter im gleichen Zeitraum einen Abgang von nur 1416 Beschäftigten. Die Abteilung Arbeitskraftlenkung wies zugleich darauf hin, daß nach wie vor eine nicht unerhebliche Abwanderung zum Erzbergbau bestehe. Als Gründe wurden die niedrigere Entlohnung im Steinkohlenbergbau sowie schlechte Wohnverhältnisse für die Bergarbeiter genannt. Die Arbeitsämter erhielten deshalb die Anweisung, Entlassungen aus dem Steinkohlenbergbau nicht mehr zuzustimmen, und es erfolgten andererseits auch keine gezielten Abwerbungen zum Uranbergbau ${ }^{242}$. Das Ausmaß der Fluktuation läßt sich für das Jahr $1950 \mathrm{am}$ Beispiel eines zentralen Steinkohlenreviers sehr anschaulich nachzeichnen (vgl. Tabelle 14).

Tabelle 14: Belegschaftswechsel über das Arbeitsamt im Steinkoblenrevier Zwickau 1950

\begin{tabular}{lccrrrr}
\hline & Arbeiter & & \multicolumn{2}{c}{ Angestellte } & \multicolumn{2}{c}{ Insgesamt } \\
& Zugang & Abgang & Zugang & Abgang & Zugang & Abgang \\
\hline Januar & 364 & 248 & 5 & 18 & 369 & 266 \\
Februar & 364 & 206 & 11 & 6 & 375 & 212 \\
März & 308 & 251 & 14 & 10 & 322 & 261 \\
April & 219 & 283 & 7 & 9 & 226 & 292 \\
Mai & 138 & 278 & 11 & 6 & 149 & 284 \\
Juni & 123 & 487 & 10 & 12 & 133 & 499 \\
Juli & 215 & 655 & 6 & 18 & 221 & 673 \\
August & 510 & 458 & 19 & 15 & 529 & 473 \\
September & 1020 & 386 & 17 & 6 & 1037 & 392 \\
Oktober & 742 & 399 & 19 & 11 & 761 & 410 \\
November & 469 & 342 & 6 & 8 & 475 & 350 \\
Dezember & 302 & 262 & 8 & 5 & 310 & 267 \\
Insgesamt & 4774 & 4255 & 123 & 124 & 4907 & 4379 \\
\hline
\end{tabular}

Quelle: BAB, DQ 2/717, Statistischer Überblick des Ministeriums für Industrie (HV Kohle).

${ }^{242}$ Ebenda, Minister Chwalek am 24. 2. 1951 an Ministerpräsident Grotewohl, S. 1. 
Da die Bereitstellung von Arbeitskräften für den Steinkohlenbergbau nicht in dem erhofften Maße gesichert werden konnte, nahm die Arbeitsverwaltung Kontakt zum Ministerium der Justiz auf, um Strafgefangene für den Arbeitseinsatz zu gewinnen. Beide Ministerien konnten sich grundsätzlich darauf einigen, „künftig auch Bewährungsarbeiter im Steinkohlenbergbau anzusetzen "243. Da sich mittlerweile auch die FDJ bereit erklärt hatte, Arbeitskräfte in ihren Reihen zu werben, verringerte sich die Anzahl der einzusetzenden Strafgefangenen. Es kann somit festgehalten werden, daß es in dieser Phase der akuten Arbeitskräftenachfrage einen verstärkten Einsatz von sogenannten Bewährungsarbeitern in diesem Wirtschaftszweig gab, wobei das quantitative Ausmaß nicht genau zu ermitteln ist. Die SED-Führung schaltete sich offensichtlich in diese Diskussion nicht ein, sondern begnügte sich mit allgemein gehaltenen Beschlüssen und Appellen. So beriet etwa das Sekretariat des ZK mehrmals über die Situation im Steinkohlenbergbau ${ }^{244}$ und setzte Kommissionen ein, die entsprechende Maßnahmen ausarbeiten und vorlegen sollten ${ }^{245}$. Der Arbeitsverwaltung und den einzelnen Grubenleitungen gelang es auch in der Folgezeit nicht, die Fluktuationsrate auf ein erträgliches Maß zu senken. Nach Angaben der Steinkohlenverwaltung Zwickau hatten in der Zeit vom 1. bis zum 10. April 1952 insgesamt 270 Beschäftigte die einzelnen Gruben des Steinkohlenbergbaus verlassen; dem standen nur 195 Zugänge gegenüber ${ }^{246}$. Bei einer Gesamtbelegschaft von 23639247 war zwar die Anzahl der Abgänge auf den ersten Blick verschwindend gering. $\mathrm{Da}$ es sich jedoch um eine konstante Größe handelte, war die Arbeitsverwaltung gezwungen, regelmäßig Arbeitskräfte in diesen Wirtschaftszweig zu entsenden. Ähnlich wie beim Uranbergbau mußte auch hier der Arbeitsplatzwechsel einzelner Bergarbeiter bei der Arbeitskräfteplanung und -lenkung berücksichtigt werden: Die Zahl der Zuweisungen mußte daher immer über der Zahl der Abgänge liegen, um den Beschäftigtenstand halten zu können.

Da bei der Arbeitskräftegewinnung für den Steinkohlenbergbau stets der vordringliche Bedarf der Wismut AG in Rechnung gestellt werden mußte, kam es häufig zu improvisierten Maßnahmen, bei denen sich die Arbeitsverwaltung von der monatlichen Auflagenhöhe in beiden Bergbaubereichen leiten ließ. Anfang Juni stand der Arbeitskräftebedarf für den Uranbergbau in Sachsen und Thüringen noch nicht fest, so daß die sächsische Landesverwaltung angewiesen wurde, „auf die für die Grundstoffindustrie bereitstehenden Kräfte zurückzugreifen und [zu] versuchen, diese für den Einsatz im Steinkohlenbergbau zu gewinnen" 248 . Darüber hinaus wurde erneut die Senkung der Fluktuationsrate gefordert. Dazu vereinbarten Vertreter des Arbeitsministeriums in Berlin und Dresden, des Staats-

${ }^{243}$ BAB, DQ 2/2132, Aktenvermerk der Abt. Arbeitskraftlenkung vom 5. 3. 1951.

${ }_{244}$ Erstmals auf der Sitzung am 8. 12. 1950. Vgl. SAPMO, DY 30/J IV 2/3/158, Bl. 2.

245 SAPMO, DY 30/J IV 2/3/229, Bl. 6f., Protokoll der Sitzung des Sekretariat des ZK am 3. 9. 1951; SAPMO, DY 30/J IV 2/3/238, Bl. 9, Protokoll der Sitzung des Sekretariats des ZK am 4. 10. 1951.

246 SächsHStA, VVB Steinkohle Zwickau, Bd. 1771, Bl. 272, Steinkohlenverwaltung Zwickau am 16. 4. 1952 an die HV Kohle in Berlin.

247 Darunter befanden sich 522 Bewährungsarbeiter aus dem Lager Oelsnitz und der Strafvollzugsanstalt Zwickau. Ebenda.

248 BAB, DQ 2/2130, Abt. Arbeitskraftlenkung am 3.6. 1952 an das Ministerium für Wirtschaft und Arbeit (HA Arbeit) in Dresden. 
sekretariats für Kohle und Energie sowie der Steinkohlenverwaltung, einen Plan aufzustellen, ,in dem Maßnahmen, durch die die Fluktuation eingedämmt werden kann, aufgeführt werden" ${ }^{249}$. Erste Vorschläge reichten von ideologisch-politischer Arbeit unter den Bergleuten bis hin zu Fragen des Gesundheitsschutzes, der Sozialversicherung und des Wohnungsbaus. Der Plan sollte vom Staatssekretariat für Kohle und Energie in enger Zusammenarbeit mit den Grubenleitungen ausgearbeitet werden und lag dem Ministerium für Arbeit termingerecht am 12. Juni vor ${ }^{250}$. Hauptabteilungsleiterin Heinze vertrat den Standpunkt, daß zunächst einmal die Grubenleitungen Maßnahmen zu treffen hätten, um beispielsweise den Krankenstand zu senken und dadurch den Beschäftigtenbestand besser auszuschöpfen ${ }^{251}$. Eine Erhöhung der Lohnsätze in den Lohngruppen 5 bis 8 werde dagegen nicht die bestehenden Probleme lösen, da ein Großteil der abwandernden Arbeitskräfte nicht qualifizierte Arbeiter seien, führte Heinze weiter aus. Damit hatte sie deutlich gemacht, daß das Arbeitsministerium nicht willens und nicht in der Lage war, Lohnverbesserungen vorzunehmen oder zusätzliche Prämienzahlungen einzuführen, um die Bergarbeiter zum Verbleiben im Steinkohlenbergbau zu bewegen. Während die Angleichung der Lebensmittelkarten noch verschoben werden mußte, da dies eine Erhöhung für alle Bergarbeiter bedeutet hätte, schlug ein Vertreter des Ministeriums für Handel und Versorgung die Verbesserung der Werksküchenverpflegung vor ${ }^{252}$, worauf sich die beteiligten Verwaltungsstellen offensichtlich einigen konnten. Da weitere Investitionsmittel für den Wohnungsbau nicht zur Verfügung gestellt wurden, war an eine Entspannung auf dem Wohnungsmarkt im Einzugsbereich der Steinkohlengruben nicht zu denken. Letztendlich diskutierte die Arbeitsverwaltung mit den Landesverwaltungen sowie den Grubenleitungen häufig die hohen Fluktuationsraten und deren Ursachen, konnte jedoch keine konkreten sozialpolitischen Maßnahmen einleiten, da entsprechende Finanzmittel nicht vorhanden waren. Das Ministerium für Arbeit wälzte die Federführung hinsichtlich der Ausarbeitung weiterer Vorschläge zur Beseitigung der Fluktuation auf das Staatssekretariat für Kohle und Energie ab und wollte nur noch die „Anleitung und Kontrolle“ ausüben ${ }^{253}$. Gleichzeitig nahm das Arbeitsministerium den „Kampf gegen das Bummelantentum" wieder auf - eine Maßnahme zur Senkung des Krankenstandes, die bereits zuvor mit stark eingeschränktem Erfolg angewendet worden war. In dem Zusammenhang erhielt das Ministerium für Gesundheitswesen den Auftrag, in einzelnen Schächten hauptamtlich tätige Betriebsärzte einzusetzen ${ }^{254}$, welche die Krankmeldungen zu überprüfen hatten. Auf der anderen Seite sollte die Verstärkung des betrieblichen Gesundheitsschutzes dazu beitragen, die neu zugeteilten Arbeitskräfte auf ihre Bergbautauglichkeit zu überprüfen ${ }^{25}$. Senkung des Krankenstandes und der

${ }^{249} \mathrm{BAB}, \mathrm{DQ} 2 / 718$, Aktenvermerk der HA Arbeit vom 4. 6. 1952, S. 2.

$250 \mathrm{BAB}, \mathrm{DQ} 2 / 2130$, Plan über Maßnahmen zur Beseitigung der Fluktuation im Steinkohlenbergbau.

251 Ebenda, Heinze am 17.6. 1952 an das ZK der SED (Abt. Planung und Finanzen).

$252 \mathrm{BAB}, \mathrm{DE} 1 / 8813, \mathrm{Bl}$. 11-15, hier Bl. 13, Protokoll der Abt. Arbeitskraftlenkung über eine Besprechung im Ministerium für Arbeit am 14. 7. 1952.

253 Ebenda, Bl. 14.

${ }^{254} \mathrm{BAB}, \mathrm{DQ}$ 2/2130, Ministerium für Arbeit am 15.7. 1952 an das ZK der SED (Gurgeit).

${ }^{255}$ Ebenda, stellv. Abteilungsleiterin Arndt (Abt. Arbeitskraftlenkung) am 5. 8. 1952 an die Pressestelle. 
Fehlvermittlungen waren somit für die Arbeitsverwaltung zwei eng miteinander verknüpfte Ziele256. Darüber hinaus rief das Ministerium für Arbeit die Bezirksverwaltungen auch weiterhin dazu auf, dem Steinkohlenbergbau bergbautaugliche Arbeitskräfte zur Verfügung zu stellen 257 .

Das Sekretariat des ZK befaßte sich Mitte August 1952 erneut mit der Lage im Steinkohlenbergbau, nachdem dem SED-Führungsgremium eine entsprechende Beschlußvorlage unterbreitet worden war ${ }^{258}$. Der vom Arbeitsministerium und dem Staatssekretariat für Kohle und Energie ausgearbeitete Maßnahmenkatalog wurde allerdings dilatorisch behandelt und wiederholt mit der Aufforderung zurückgereicht, über die bisher durchgeführten Beschlüsse des Politbüros und des Sekretariats zu berichten ${ }^{259}$. Einen Monat später wurde eine weitere Kommission eingesetzt, die eine Direktive ausarbeiten sollte, „wie die Betriebe des Steinkohlenbergbaus, die Werksleitungen, die Hauptverwaltung Kohle ihre Arbeit grundlegend verbessern" 260 können. Der Beschluß enthielt allerdings auch dieses Mal keine konkreten inhaltlichen Vorgaben zur Tätigkeit der Kommission. Einzige Ausnahme war eine sicherheits- bzw. kaderpolitische Anweisung: Die Kommission wurde bevollmächtigt, Maßnahmen zu ergreifen, „um feindliche und unzuverlässige Elemente aus leitenden Funktionen des Steinkohlenbergbaus zu entfernen und an ihrer Stelle zuverlässige Fachleute einzusetzen“. Auch in der Folgezeit waren die Entscheidungen der SED-Führung ausschließlich von kaderpolitischen Überlegungen geprägt ${ }^{261}$. Es hat den Anschein, als ob sozialpolitische Aspekte in diesen Führungszirkeln kaum eine Rolle gespielt haben. Das Sekretariat des ZK beriet abschließend über den Steinkohlenbergbau am 2. Februar 1953 und legte dem Politbüro eine entsprechende Beschlußvorlage vor ${ }^{262}$. Bereits einen Tag später billigte das Politbüro die Vorlage, die sich unter anderem mit der bisherigen Beschäftigungspolitik im Steinkohlenbergbau kritisch auseinandersetzte: „Es besteht ein großes Mißverhältnis zwischen der Zahl der unter Tage Arbeitenden zu den Beschäftigten über Tage, schon gar nicht zu reden von dem schlechten Verhältnis der Zahl der Produktionsarbeiter zu der Zahl der Verwaltungsangestellten." ${ }^{263}$ Der Gesamtbestand an Häuern sei weder ergänzt noch vergrößert wor-

256 Auch die einzelnen Grubenleitungen führten Krankenkontrollen durch. Dabei wurden hauptamtliche „Krankenbesucher“ eingesetzt, wobei unklar ist, ob es sich um Ärzte oder Mitarbeiter der Grubenverwaltung handelte. Nach Angaben der zuständigen VVB Steinkohle Zwickau bestand ein direkter Zusammenhang zwischen der Tätigkeit dieser Kontrolleure und der Senkung des Krankenstandes. Vgl. SächsHStA, VVB Steinkohle Zwickau, Bd. 1771, Bl. 4 f. Niederschrift über die am 27. 11. 1952 stattgefundene Besprechung der Arbeitskräftelenker der VVB.

257 BAB, DQ 2/2130, Abt. Arbeitskraftlenkung am 21. 8. 1952 an die Räte der Bezirke.

258 SAPMO, DY 30/J IV 2/3/317, Bl. 1 f., Protokoll der Sitzung des Sekretariats des ZK am 18.8. 1952.

${ }^{259}$ SAPMO, DY 30/J IV 2/3/330, Bl.7, Protokoll der Sitzung des Sekretariats des ZK vom 9. 10. 1952.

260 SAPMO, DY 30/J IV 2/3/340, Bl. 1 f., Protokoll der Sitzung des Sekretariats des ZK am 13. 11. 1952.

$26 !$ Vgl. SAPMO, DY 30/J IV 2/3/356, Bl. 1-3, Protokoll der Sitzung des Sekretariats des ZK am 19. 1. 1953. Auf dieser Sitzung wurde unter anderem beschlossen, alle Mitarbeiter im Staatssekretariat für Kohle und Energie zu überprüfen. Außerdem sollten die „sowjetischen Genossen“ gebeten werden, für die Hauptverwaltung Steinkohle zwei "qualifizierte Funktionäre" der Wismut AG zur Verfügung zu stellen.

262 SAPMO, DY 30/J IV 2/3/359, Bl. 1.

${ }^{263}$ SAPMO, DY 30/J IV 2/2/260, Bl. 23-26, hier Bl. 24. 
den, während die Zahl der in der Verwaltung Beschäftigten angestiegen sei und die dafür anfallende Lohnsumme die ursprünglichen Planungen weit überschritten habe. Die Fluktuation habe - so das Politbüro in seiner Analyse - in erster Linie neu angeworbene Bergleute erfaßt und sei auf die unzureichende soziale und kulturelle Betreuung derselben zurückzuführen. Damit bestätigte sich der bisherige sozial- und vor allem lohnpolitische Kurs: Die Verbesserung der materiellen Anreize in Form von Lohnerhöhungen und Prämienzahlungen wurde nicht in Erwägung gezogen. Aufgrund des geringen Stellenwertes, den der Steinkohlenbergbau für die SED und für die Gesamtwirtschaft de facto einnahm, war dies auch nicht weiter verwunderlich, zumal dieser Bereich des Bergbaus infolge der rasch sinkenden Steinkohlenvorräte weiter an Bedeutung verlieren sollte. Da der Arbeitskräftebedarf stagnierte bzw. leicht rückläufig war, bestand für die Grubenleitungen keine Notwendigkeit mehr, die Werbebüros weiterhin bestehen zu lassen. Diese wurden Anfang 1953 sukzessive aufgelöst ${ }^{264}$. Der Leiter der VVB Steinkohle Zwickau wies am 2. April 1953 gegenüber den Abteilungen Arbeit und Berufsausbildung bei den Räten der Bezirke darauf hin, daß der Arbeitskräftebedarf gedeckt sei „bzw. aus Zugängen aus den eigenen Kreisen gedeckt“ werden könne ${ }^{265}$. Deshalb wurde die Tätigkeit der VVB-Abteilung Zentrale Arbeitskräftelenkung mit Wirkung vom 1. April beendet. Die einzige Aufgabe der Arbeitsverwaltung und der VVB Steinkohle bestand nunmehr darin, die nach wie vor bestehende Fluktuationsrate niedrig zu halten und in unregelmäßigen Abständen die Gesamtbelegschaft mit neuen Arbeitskräften aufzufrischen.

\section{Mansfelder Kupferbergbau}

Unter der bevorzugten Zuteilung von Arbeitskräften für die Wismut AG litt auch der Mansfelder Kupferbergbau. Die VVB Mansfeld beabsichtigte, die Werbung von Bergarbeitern nicht nur auf das Land Sachsen-Anhalt zu konzentrieren, sondern auf Mecklenburg und Brandenburg auszudehnen. Das Ministerium für Arbeit wurde gebeten, entsprechende Ausweise für die Arbeitskräftewerber auszustellen, damit diese Einsicht in die Karteien der betreffenden Arbeitsämter nehmen konnten ${ }^{266}$. Die Werbung sollte also mit Unterstützung der Arbeitsverwaltung zielgerichtet durchgeführt werden. Das Ministerium für Arbeit und Gesundheitswesen erklärte sich zwar grundsätzlich bereit, die Gewinnung von Arbeitskräften für den Untertagebau in Mansfeld zu unterstützen, vertrat allerdings den Standpunkt, daß „die individuelle Werbung in dem verhältnismäßig kleinen Rahmen, der hier [von der VVB Mansfeld] vorgeschlagen wird, zu keinem günstigen Ergebnis führen kann “"267. Der zuständige Sachbearbeiter Donau ging auf die Pläne der VVB Mansfeld nicht weiter ein und schlug seinerseits vor, die Werbung im Rundfunk zu intensivieren und die Arbeitsämter mit entsprechenden

264 SächsHStA, VVB Steinkohle, Bd. 1771, Bl. 1 f. Niederschrift über die Besprechung mit den Werbeorganen und Arbeitskräftelenkern am 24.1. 1953 in der VVB.

${ }^{265}$ Dies geht aus einem Brief des Staatssekretariats für Kohle und Energie vom 11.4. 1953 an das Ministerium für Arbeit hervor, in dem das entsprechende Schreiben des Leiters der VVB wörtlich zitiert wird. Vgl. BAB, DQ 2/2130.

266 BAB, DQ 2/2132, VVB Mansfeld am 10. 11. 1949 an Minister Steidle.

267 Ebenda, Ministerium für Arbeit und Gesundheitswesen am 11.11. 1949 an die VVB Mansfeld. 
Werbeplakaten zu beliefern. Auch die Blockparteien beteiligten sich an der Debatte über die Wege, neue Arbeitskräfte für den Kupferbergbau zu gewinnen. So warf etwa der 1. Vorsitzende des CDU-Landesverbandes Mecklenburg Reinhold Lobedanz gegenüber der Hauptgeschäftsstelle seiner Partei die Frage auf, ob der Einsatz der neu eingestellten Arbeiter "nicht zu unvermittelt" erfolge. Diese seien nämlich „sofort" einer Arbeitsschicht zugeteilt worden und müßten bereits „die volle Arbeit“ verrichten. $\mathrm{Da}$ „Körper und Geist der aus anderen Berufen Zugewanderten [...] doch eine erhebliche Umstellung auf die neue Arbeit erfordern“ würden, schlug er eine „schrittweise Einführung“ in Form von betrieblichen Vorbereitungskursen vor ${ }^{268}$.

Ein ausführlich gehaltener Bericht der VVB Mansfeld versuchte Mitte 1950 die angespannte Arbeitskräftelage deutlich zu machen: Die Nichterfüllung der Produktionsauflagen wurde unter anderem auf den Mangel an bergbautauglichem Facharbeiterpersonal zurückgeführt ${ }^{269}$. Statt der für die vorgesehene Schiefergewinnung erforderlichen Beschäftigtenzahl von 3200 seien de facto nur $2710 \mathrm{Ar}$ beiter im Einsatz, so der Leiter der Hauptabteilung Arbeit und Sozialwesen der VVB. Der Bedarf werde 1951 auf insgesamt 4430 Arbeitskräfte ansteigen; bei Nichterfüllung könne die im Wirtschaftsplan vorgesehene Produktionsmenge von 1,2 Millionen $t$ im Jahr nicht erreicht werden ${ }^{270}$. Gleichzeitig war die Fluktuationsrate außerordentlich hoch: Von den 2788 Arbeitskräften, die im ersten Halbjahr 1950 gewonnen werden konnten, verließen offensichtlich rund 74 Prozent den Kupferbergbau "teilweise schon nach wenigen Tagen" 271 . Zu den Ursachen zählten nach Einschätzung des Leiters der VVB-Hauptabteilung der zurückgebliebene Wohnungsbau, die langen An- und Abfahrtswege zu den Gruben, die unzureichende soziale Betreuung sowie die Lohn- und Arbeitsbedingungen. So verdiene ein Häuer im Steinkohlenbergbau durchschnittlich zwischen 15 und $17 \mathrm{DM}$ pro Schicht, im Braunkohlenbergbau 17 bis $18 \mathrm{DM}$ und im Kupferbergbau nur rund $12 \mathrm{DM}^{272}$. Damit lag der Durchschnittslohn in Mansfeld um bis zu 50 Prozent niedriger als in den anderen Bergbauzweigen, ganz zu schweigen vom Uranbergbau mit seiner überdurchschnittlich guten Entlohnung. Insofern war es nicht verwunderlich, wenn auch der Kupferbergbau Abgänge zur Wismut AG registrieren mußte. Das verdeutlichte erneut, daß die Lohn- und Gehaltshöhe zum Verbleiben oder Wechsel des Arbeitsplatzes entscheidend beitragen konnte.

Die Tatsache, daß der Mansfelder Kupferbergbau erst nach Vorlage des kritischen Berichtes der zuständigen VVB zu einem Schwerpunktgebiet der Arbeitskräftelenkung erklärt worden war, zeigte die vorherige Planlosigkeit bzw. die Überforderung der Arbeitsverwaltung, die zur Verfügung stehenden Arbeitskräfte angemessen auf die einzelnen Wirtschaftsbereiche zu verteilen. Der Kupfer-

268 ACDP, VII, 013, 2066, 1. Vorsitzender des CDU-Landesverbandes Mecklenburg Lobedanz am 12. 6. 1950 an die CDU-Hauptgeschäftsstelle.

$269 \mathrm{BAB}, \mathrm{DQ} 2 / 2132$, Bericht Hubert Hölters vom 31. 7. 1950 an die LKK (Kästner), S. 1. Die Zuweisung von fachlich ungeeigneten Arbeitskräften ließ den Krankenstand im Juni 1950 auf $9,14 \%$ ansteigen. Vgl. BAB, DQ 2/2132, Zentralvorstand der Sozialversicherung am 16.8. 1950 an das Ministerium für Arbeit und Gesundheitswesen (HA Arbeit).

$270 \mathrm{BAB}, \mathrm{DQ} 2 / 2132$, Bericht Hölters vom 31. 7. 1950 an die LKK, S. 2.

271 Ebenda, S. 5.

272 Ebenda, S. 13. 
bergbau als Bestandteil des Erzbergbaus zählte zwar von Anfang an zu den sogenannten Schwerpunkten der Wirtschaft, doch erst im Laufe des Spätsommers 1950 nahm sich das Arbeitsministerium in Berlin dieser Aufgabe an. Die Arbeitsämter in Sachsen-Anhalt mußten auf die Dringlichkeit der Arbeitskräftezuteilung für Mansfeld hingewiesen werden, da einige Ämter ,interessierten bergbautauglichen Kräften" freistellte, sich zum Uranbergbau nach Sachsen zu melden oder in den Kupferbergbau zu gehen. Angesichts der bereits angesprochenen geringeren Entlohnung war die Anziehungskraft des sächsischen Erzbergbaus in der Regel weitaus größer. Darüber hinaus waren die Arbeitsämter bereits seit geraumer Zeit mit der Erfüllung der ihnen zugeteilten Auflagen beschäftigt und betrachteten den Kupferbergbau zwangsläufig nicht als vorrangige Aufgabe. Das Arbeitsministerium registrierte diese Entwicklung und ging dazu über, einige Arbeitsamtsbezirke von der Wismut-Auflage zu befreien und ihnen statt dessen die Anweisung zu erteilen, „, in allererster Linie“ Arbeitskräfte für die VVB Mansfeld zu stellen"273. Das betraf die Arbeitsämter Sangerhausen, Eisleben und Hettstedt, in deren Zuständigkeitsbereich sich der Mansfelder Kupferbergbau befand. Abteilungsleiter Huth ging bei seiner Gesamteinschätzung sogar noch einen Schritt weiter: „Jede gestellte Kraft für den Erzbergbau [Uranbergbau] seitens dieser 3 Ämter kann nicht als Erfolg, sondern muß in Zukunft vielmehr als Mißerfolg gewertet werden." 274

Im Herbst schien sich eine gewisse Entspannung abzuzeichnen, als die monatlich geforderten 200 Arbeitskräfte für den Untertagebergbau termingerecht gestellt werden konnten ${ }^{275}$. Dagegen gelang es der Arbeitsverwaltung offenbar nicht, die Fluktuationsrate auf einem konstant niedrigen Niveau zu halten und vor allem für eine angemessene Unterbringung der von auswärts angeworbenen Arbeiter zu sorgen ${ }^{276}$. Arbeitsplatzwechsel und Wohnraumversorgung blieben somit auch im Kupferbergbau ein drängendes Problem Anfang der fünfziger Jahre. Die Arbeitskräftelage in Mansfeld gestaltete sich in der Folgezeit noch etwas günstiger, da die Bergarbeitertransporte für die Wismut AG bis Ende Mai zurückgestellt worden waren. Auf diese Weise erhielt der Kupferschieferbergbau im ersten Quartal 1951 etwa 800 Arbeitskräfte mehr als ursprünglich vorgesehen war $^{277}$. Der Bedarf konnte somit abgedeckt werden, und es mußte im April sogar eine vorläufige Einstellungssperre verhängt werden. Während die Versorgung mit Bergarbeitern zufriedenstellend verlief und damit die Produktion aufrecht erhalten werden konnte, traten auf einem anderen Sektor akute Planungschwierigkeiten auf. Die VVB Mansfeld teilte am 26. April mit, daß die im Investitionsplan 1951 vorgesehenen und von der Bauunion Magdeburg begonnenen Bauten nicht fertiggestellt werden könnten, da weitere „Unterlagen“ und vor allem „Fachkräfte" fehlten ${ }^{278}$. Dadurch drohte die Entlassung von mehreren 100 Bauarbei-

${ }^{273} \mathrm{BAB}, \mathrm{DQ} 2 / 2132$, Abteilungsleiter Huth am 21. 8. 1950 an das Ministerium für Arbeit und Gesundheitswesen in Halle, S. 2 .

274 Ebenda.

$275 \mathrm{BAB}, \mathrm{DQ} 2 / 2125$, Abteilungsleiter Huth am 20. 10. 1950 an Hauptabteilungsleiter Litke.

276 Vgl. BAB, DQ 2/2132, Niederschrift über die am 18.1. 1951 bei der VVB Mansfeld und im Arbeitsamt Eisleben durchgeführte Besprechung.

277 BAB, DQ 2/1721, Bericht des Ministeriums für Wirtschaft (Abt. Arbeitskraftlenkung) des Landes Sachsen-Änhalt vom 16. 4. 1951.

278 BAB, DQ 2/717, Telegramm der VVB Mansfeld vom 26. 4. 1951 an das Ministerium für Arbeit. 
tern. Das Arbeitsministerium versuchte daraufhin, den Bedarf an technischem Fachpersonal (zwei Statiker, zwei Architekten, sechs Bauingenieure und vier bis sechs technische Zeichner) schnellstmöglich abzudecken, was offensichtlich aber nicht gelang279. Dieses Beispiel veranschaulicht, daß die regionale Beschäftigungspolitik zu diesem Zeitpunkt keineswegs in geordneten Bahnen verlief, sondern durch Pannen im Zentralverwaltungsapparat oder durch unvorhersehbare Entwicklungen auf den Teilarbeitsmärkten rasch unter neuen Handlungsdruck geraten konnte. Auch Ende 1951 klagte das zuständige Ministerium für Wirtschaft in Halle (Saale), daß der Arbeitskräftebedarf durch die anhaltende Abwanderung nach wie vor sehr hoch sei280. Mit der Kombinatsleitung wurde deshalb vereinbart, "die hohe Fluktuation durch genaue Analysierung der Abgänge zu unterbinden“. Auf diese Weise sollten bereits innerhalb des Betriebes „Ansatzpunkte“ gefunden werden, um dieses Problem besser in den Griff zu bekommen.

Das Sekretariat des ZK begegnete den geschilderten Schwierigkeiten im Kupferbergbau in erster Linie mit organisationspolitischen Maßnahmen. So erhielt die Parteiorganisation im Mansfelder Kombinat „Wilhelm Pieck“ die Rechte einer Kreisleitung und wurde der SED-Landesleitung direkt unterstellt ${ }^{281}$. Zusätzlich wurde der Generaldirektor der Hauptverwaltung Wismut gebeten, Ingenieure für die Verbesserung der Arbeit in Mansfeld zur Verfügung zu stellen ${ }^{282}$. Es hat den Anschein, als ob die SED-Führung keine eigenen arbeitsmarktpolitischen Konzepte für den Kupferbergbau entwickelt bzw. angeregt hat. Dies hatte im übrigen auch für den Steinkohlenbergbau gegolten und es überrascht nicht weiter, daß die Arbeitsverwaltung bei der Sicherung des Beschäftigtenstandes auf sich alleine gestellt blieb. Die Abteilung Arbeitskraftlenkung des Berliner Arbeitsministeriums unternahm des öfteren Dienstreisen nach Eisleben, um sich einen Eindruck über die konkrete Arbeitskräftelage im Mansfelder Kombinat zu verschaffen, wobei die Entwicklung der Fluktuationsrate im Mittelpunkt der gemeinsamen Gespräche mit der Landesverwaltung und der Kombinatsleitung standen. Hier lagen nach wie vor starke Schwankungen vor, so daß eine planvolle und vor allem längerfristige Arbeitskräftelenkung nicht möglich war: Im vierten Quartal 1951 standen 1622 Zugängen 1235 Abgänge gegenüber; im ersten Quartal 1952 war das Verhältnis noch ungünstiger (1353 zu 1493)283. Als zusätzliche Belastung kamen die sogenannten Fehlschichten (infolge von Krankheit und „Bummelantentum“) hinzu, die zeitweise bis zu 24 Prozent der gefahrenen Schichten betrugen. Große Anziehungskraft genoß bei zahlreichen Bergarbeitern im Kupferbergbau immer noch die Wismut AG, obwohl die Werbung im Mansfelder Revier ganz eingestellt worden war, wie die Vertreter des Arbeitsministeriums in ihrem Bericht resigniert

279 Ebenda, Abt. Arbeitskraftlenkung am 10.5. 1951 an das Sekretariat des Ministers, S. 1.

${ }^{280} \mathrm{BAB}, \mathrm{DQ} 2 / 1755$, Bericht des Ministeriums für Wirtschaft von Sachsen-Anhalt an das Ministerium für Ârbeit am 10. 12. 1951, S. 2.

281 SAPMO, DY 30/J IV 2/3/291, Bl. 11, Protokoll der Sitzung des Sekretariats des ZK am 21. 5. 1952.

282 SAPMO, DY 30/J IV 2/3/312, Bl. 7, Protokoll der Sitzung des Sekretariats des ZK am 31. 7.1952.

283 BAB, DQ 2/2152, Bericht der Abt. Arbeitskraftlenkung über Dienstreise nach Eisleben (20./21. 5. 1952), S. 2. Das Mansfelder Kombinat hatte am 30. 4. 1952 insgesamt 19070 Beschäftigte, darunter 10455 im Bergbau und 8615 im Hüttenbetrieb sowie in sonstigen Betriebsteilen. Für 1952 sah der Arbeitskräfteplan eine Steigerung um weitere 1556 Arbeitskräfte vor. Vgl. BAB, DQ 2/2125, Vermerk der Abt. Arbeitskraftlenkung vom 15. 7. 1952. 
feststellen mußten 284 . Dabei spielte jedoch nicht mehr die bessere Bezahlung die ausschlaggebende Rolle, sondern die mittlerweile verbesserten Wohnverhältnisse im Erzgebirge.

Bei der Arbeitskräftewerbung und -gewinnung blieb der Kupferbergbau auch weiterhin dem Uranbergbau eindeutig untergeordnet. Dies bestätigte ausdrücklich das Arbeitsministerium in Berlin, das damit eingestand, gegen die fortlaufende berufliche Binnenwanderung zur Wismut AG nahezu machtlos zu sein ${ }^{285}$. Das nach dem DDR-Präsidenten benannte Kombinat entwickelte im Sommer 1952 Richtlinien für die Werbung von Arbeitskräften, die vermutlich an die Arbeitsämter verteilt wurden ${ }^{286}$. Diese enthielten detaillierte Angaben zur medizinischen Untersuchung der gewonnenen Arbeitskräfte, zum Transport nach Eisleben sowie zu den festgelegten Arbeits- und Lebensbedingungen (z.B. Entlohnung, Prämien, Verpflegung, Wohnungen ${ }^{287}$ ). Nach dem Vorbild des Steinkohlenbergbaus wurde die Kombinatsleitung durch einen Ministerratsbeschluß vom 7. August verpflichtet, Werbebüros auf bezirklicher Ebene einzurichten ${ }^{288}$. Wenige Monate später erhielt die Zentrale Kommission für Staatliche Kontrolle von der SED-Führung den Auftrag, die Durchführung des Ministerratsbeschlusses zu überprüfen. Der ausführlich gehaltene Bericht, der Ende Dezember 1952 vorlag, übte heftige Kritik an der Vorgehensweise des Ministeriums für Hüttenwesen und Erzbergbau sowie der Leitung des Kombinats „Wilhelm Pieck“289. Im einzelnen wurde beanstandet, daß der geplante Ausbau der Produktionsanlagen nur sehr langsam voranschritt: Vor allem die Mechanisierung und die Modernisierung des Maschinenparks blieb offensichtlich weit hinter den Erwartungen des Ministerrates zurück. Darüber hinaus wurde auch die Tätigkeit der Werbebüros, die bis zum 15. Oktober 1952 in neun Bezirken der DDR eingerichtet worden waren und vom Mansfeld Kombinat personell besetzt wurden, kritisch beleuchtet. So hätten die Arbeitskräftewerber den Arbeitern „Zusagen für sofort zu beziehende Wohnungen und für die Entlohnung gemacht, die nicht eingehalten werden konnten“290. Die ZKSK führte die Fluktuation der Arbeitskräfte zum einen auf die „irreführenden Versprechungen" und zum anderen auf die falsche Einordnung von Arbeitern in untere Lohngruppen zurück. Erst nach Eingreifen der ZKSK habe der Arbeitsdirektor des Werkes nach Absprache mit dem Ministerium für Arbeit die Eingruppierung von Facharbeitern, die Ende Oktober die Kupferhütte verlassen wollten, in eine höhere Lohngruppe rückwirkend vorgenommen ${ }^{291}$.

${ }^{284} \mathrm{BAB}, \mathrm{DQ} 2 / 2152$, Bericht der Abt. Arbeitskraftlenkung über Dienstreise nach Eisleben (20./21. 5 . 1952), S. 2.

285 Vgl. BAB, DQ 2/2125, Vermerk der Abt. Arbeitskraftlenkung vom 15. 7. 1952.

$286 \mathrm{BAB}, \mathrm{DQ} 2 / 2125$, Richtlinien des Hauptdirektors Gutjahr vom 19. 8. 1952.

287 Mitte 1952 bestand offenbar ein großer Mangel an verfügbarem Wohnraum. Nach Angaben der Kombinatsleitung fehlten 6845 Wohnungen und etwa 1200 Wohnplätze in Bergarbeiterwohnheimen. Vgl. BAB, DQ 2/2125, Anlage V zum Schreiben des Mansfeld Kombinats "Wilhelm Pieck“ vom 21. 8. 1952 an das Ministerium für Arbeit (Heinze).

288 Vgl. BAB, DQ 2/2125, Mansfeld Kombinat "Wilhelm Pieck“ am 21.8. 1952 an das Ministerium für Arbeit (Heinze).

289 SAPMO, NY 4182/1093, Bl. 94-119, Bericht der ZKSK vom 16. 12. 1952. Der Bericht wurde dem Generalsekretär der SED, Walter Ulbricht, am 22.12. übersandt.

290 Ebenda, Bl. 102.

291 Ebenda, Bl. 106. 
Tabelle 15: Stand der Arbeitskräftewerbung im Kombinat Mansfeld (1. Halbjabr 1952)

\begin{tabular}{lrrrrrrr}
\hline & $\begin{array}{c}\text { Stand: } \\
\text { 31. 12.51 }\end{array}$ & Bedarf & $\begin{array}{c}\text { neu } \\
\text { gewonnen }\end{array}$ & $\begin{array}{c}\text { Fluktua- } \\
\text { tion }\end{array}$ & $\begin{array}{r}\text { effektiver } \\
\text { Zugang }\end{array}$ & $\begin{array}{c}\text { Stand: } \\
30.6 .52\end{array}$ & $\begin{array}{c}\text { Fluktua- } \\
\text { tion in \% }\end{array}$ \\
\hline Bergbau & 9740 & 666 & 1746 & 1908 & -162 & 9147 & 16,5 \\
Hüttenwerk & 2725 & 263 & 526 & 447 & 79 & 2866 & 13,7 \\
Insgesamt & 12465 & 929 & 2272 & 2355 & -83 & 12013 & 15,9 \\
\hline
\end{tabular}

Quelle: BAB, DQ 2/2125, Statistik des Mansfeld Kombinats „Wilhelm Pieck“ (Zentrale Arbeitskräftewerbung).

Nachdem sich allem Anschein nach die SKK mit der Situation im Kupferbergbau beschäftigt und entsprechende Untersuchungen eingeleitet hatte ${ }^{292}$, stand auch die SED-Führung unter gewissem Handlungsdruck: Das Sekretariat des ZK stellte auf seiner Sitzung am 19. Januar 1953 eine Inspektionsbrigade aus Mitgliedern des ZK-Apparates und der SED-Bezirksleitung Halle zusammen. Diese erhielt die Aufgabe, die Untersuchungen der „sowjetischen Genossen“ zu unterstützen und anschließend auszuwerten. Von sowjetischer Seite kam bald der Vorschlag, aus dem bestehenden Kombinat zwei selbständige Betriebe mit eigenen Werksleitern zu bilden, und zwar für den Bereich Bergbau und Hüttenwerk ${ }^{293}$. Die Verbesserungsvorschläge betrafen jedoch nicht nur die organisatorische Neugliederung, sondern auch die Besetzung leitender Positionen durch neue Kader. Der Bericht der eingesetzten Brigade wurde am 19. Februar erneut im Sekretariat des ZK diskutiert $^{294}$, das eine Beschlußvorlage für das Politbüro ausarbeiten wollte ${ }^{295}$. Kurz darauf war es offenbar gelungen, die Abwanderung vom Kupferbergbau nicht nur einzudämmen, sondern sogar die Zuwanderung stärker zu erhöhen. Mittlerweile war die Wohnraumversorgung im Mansfelder Gebiet so weit gesichert, daß anliegende Landkreise gegenüber dem Ministerium für Arbeit auf die neu entstandene Anreizfunktion ausdrücklich aufmerksam machten. So seien etwa vom Walzwerk in Hettstedt zahlreiche Arbeitskräfte zum Kombinat „Wilhelm Pieck“ abgewandert, „weil ihnen dort eher die Möglichkeit auf Wohnraum geboten“ werde ${ }^{296}$.

\section{Exkurs: bayerische Arbeiter im thüringischen Schieferbergbau}

Mit dem Aufkommen des „Kalten Krieges“ erfolgte bekanntlich die forcierte Einbettung der drei Westzonen bzw. der Bundesrepublik und der SBZ/DDR in zwei sich immer stärker herausbildende Blocksysteme. Dieser langfristige Prozeß, dessen tiefere Ursachen hier nicht weiter thematisiert werden können, vollzog sich in

292 Das geht aus dem Protokoll der Sitzung des Sekretariats des ZK vom 19.1. 1953 hervor. SAPMO, DY $30 / \mathrm{J}$ IV $2 / 3 / 356, \mathrm{Bl} .3$.

${ }^{293}$ SAPMO, NY 4182/986, Bl. 131 f., hier Bl. 132, SED-Hausmitteilung von Hengst für Ulbricht vom 4. 2. 1953.

294 SAPMO, DY 30/J IV 2/3/364, Bl. 1 f.

295 Das Politbüro befaßte sich auf seiner Sitzung am 24. 2. 1953 mit der Angelegenheit und stimmte den einzelnen Vorlagen letztlich zu. Vgl. SAPMO, DY 30/J IV 2/2/264, Bl. 3 und 8-36.

296 BAB, DQ 2/2146, Rat des Landkreises Hettstedt am 5. 3. 1953 an das Ministerium für Arbeit (Abt. Kollektivverträge und Lohnkontrolle). 
politischer, wirtschaftlicher und militärischer Hinsicht. Für die weitere ökonomische Entwicklung Deutschlands war entscheidend, daß die noch nach Kriegsende weiter existierenden Handelsbeziehungen sukzessive abbrachen. Während die Bundesrepublik sich stärker in Richtung Westeuropa und Nordamerika orientierte, ließ sich die DDR in das primär osteuropäisch ausgerichtete Wirtschaftssystem integrieren. Nicht nur der Außenhandel wurde auf diese Weise jeweils neu ausgerichtet, sondern auch Zulieferungen innerhalb der früheren vier Besatzungszonen brachen immer mehr ab. So gab es seit 1950 ein westdeutsches Stahlembargo $^{297}$, das aus Sicht der SED-Führung sowie der Wirtschaftsverwaltung den raschen Auf- und Ausbau einer heimischen Stahlindustrie noch dringender machte. Dagegen blieb die Binnenwanderung von Arbeitskräften über die Demarkationslinie hinweg auch weiterhin noch möglich, zumindest bis zur Verschärfung des "Grenzregimes" im Frühsommer 1952.

Die Beschäftigung von Arbeitern, die ihren Wohnsitz in der Bundesrepublik hatten und täglich zu ihrem Arbeitsplatz in die grenznahen DDR-Kreise pendelten, diente letztlich auch der Abdeckung des Facharbeiterbedarfs. Beispielhaft dafür erscheint der thüringische Schieferbergbau: Hier bestand seit dem 24. Januar 1950 eine Vereinbarung zwischen den Ländern Thüringen und Bayern, die am 27. April 1951 nochmals verlängert wurde und die Beschäftigung dieser Personengruppe und deren Bezahlung in westdeutscher Währung genau regelte298. Bereits im März 1951 wurde die Abteilung Arbeitskraftlenkung des Ministeriums für Arbeit eingeschaltet, um zu überprüfen, ob die bayerischen Arbeiter nicht durch "geeignete Kräfte aus Thüringen" ersetzt werden können ${ }^{299}$. Während jedoch die thüringische Landesregierung auf den Einsatz der rund 230 westdeutschen Arbeitskräfte ${ }^{300}$ zunächst noch nicht vollständig verzichten wollte, sprachen sich Mitarbeiter des Ministeriums der Finanzen und des Ministeriums für innerdeutschen und Außenhandel frühzeitig gegen eine Verlängerung der Vereinbarung aus ${ }^{301}$. Sowohl das Ministerium für Schwerindustrie als auch die VVB Schiefer unterstützten die Position Thüringens und wiesen übereinstimmend darauf hin, daß „ohne die Facharbeiter aus dem Westen die Produktion der VVB Schiefer Steinach gefährdet" sei ${ }^{302}$. Neben der Überlegung, die laufende Schieferproduktion somit absichern zu können, spielten am Rande wohl auch deutschlandpolitische Ziele eine Rolle: Es würde „auf die Kollegen im Westen im Zeichen des Kampfes um die Wiederherstellung der Einheit Deutschlands einen sehr schlechten Eindruck machen [...], wenn sie [die bayerischen Arbeiter] jetzt gekündigt

297 Heyl, Der innerdeutsche Handel mit Eisen und Stahl, S. 54-69.

298 BAB, DQ 2/2132, Vereinbarung zwischen dem Land Thüringen und dem Land Bayern vom 27. 4. 1951. Artikel 1 legte fest, daß „Zwecks Durchführung der Entlohnung der in Bayern ansässigen und in den Schiefergruben des Landes Thüringen [...] beschäftigten Facharbeiter [...] die VVB Schiefer an das Land Bayern monatlich ca. 250 To. Lehestener Dach- und Wandschiefer bezw. Schiefergriffel zu den jeweils geltenden Marktpreisen im Währungsgebiet der DM-West “ lieferte. Aus dem Erlös dieser Lieferung wurden die westdeutschen Arbeitskräfte entlohnt. Vgl. hierzu auch: Fässler, Westarbeiter in der DDR.

${ }^{299} \mathrm{BAB}, \mathrm{DQ}$ 2/2132, Abt. Sozialversicherung am 19.3. 1951 an Abt. Arbeitskraftlenkung.

300 Anfang April 1951 waren insgesamt 224 bayerische Schieferarbeiter in Thüringen beschäftigt. Vgl. $\mathrm{BAB}, \mathrm{DQ}$ 2/2132, Bescheinigung Stampfers vom 3. 4. 1951.

301 Ebenda, Aktenvermerk der Abt. Sozialversicherung vom 19. 3. 1951, S. 1 f.

302 Ebenda, Aktenvermerk der Abt. Arbeitskraftlenkung vom 2. 4. 1951. 
bekommen und arbeitslos werden“"303. Alle beteiligten Stellen konnten sich offenbar darauf verständigen, die bis zum Jahresende 1951 geltende Vereinbarung bestehen zu lassen und im September nochmals zu prüfen, inwieweit die westdeutschen Fachkräfte 1952 durch eigene Nachwuchskräfte zu ersetzen sind. Das thüringische Ministerium für Wirtschaft und Arbeit befand sich in der Zwangslage, einerseits für die Aufrechterhaltung der Schiefergewinnung zu sorgen und andererseits einen Facharbeiteraustausch durchzuführen ${ }^{304}$. Die Ausbildung von Bergarbeitern für den Schieferbergbau ließ sich jedoch nicht kurzfristig realisieren. Deswegen konnte auf den vorübergehenden Einsatz der bayerischen Fachkräfte auch nicht verzichtet werden. Für das Arbeitsministerium in Berlin stand bereits frühzeitig fest, daß eine weitere Verlängerung der Vereinbarung über den 1. Januar 1952 hinaus nicht in Frage kam ${ }^{305}$. Diese Position vertrat auch Staatssekretärin Friedel Malter gegenüber dem Ministerium für Schwerindustrie, das für eine Weiterbeschäftigung der westdeutschen Arbeiter eingetreten war ${ }^{306}$.

\section{Eisenhüttenkombinat Ost (EKO)}

Der Auf- und Ausbau der Schwerindustrie stand im Mittelpunkt des ersten Fünfjahrplanes. Erklärtes Ziel war die Produktionssteigerung der metallurgischen Industrie, was wiederum die Errichtung neuer Hütten- und Walzwerke nach sich zog. Walter Ulbricht kündigte auf dem III. Parteitag der SED am 22. Juli 1950 den Aufbau eines neuen Hüttenkombinats an der Oder an: Die Planungsarbeiten seien bereits abgeschlossen und „schon in wenigen Wochen" könne dort mit den ersten Arbeiten begonnen werden ${ }^{307}$. Im Gegensatz zu anderen Werken, die unmittelbar nach Kriegsende ihre Produktion wieder aufgenommen hatten, handelte es sich beim EKO um die komplette Neuerrichtung eines industriellen Standortes. Als erstes mußte die ganze Infrastruktur aufgebaut werden: Das betraf sowohl den Bau eines Verkehrsnetzes als auch Unterbringungsmöglichkeiten für die Arbeiter mit ihren Familien ${ }^{308}$. Darüber hinaus sollten die Produktionsanlagen innerhalb kürzester Zeit errichtet werden. Dieses Konzept zog einen entsprechend großen Bedarf an Baufacharbeitern automatisch nach sich. Das Ministerium für Industrie informierte Mitte August das Ministerium für Arbeit und Gesundheitswesen über die Planungen und bat darum, einen Mitarbeiter des Ministeriums als Ansprech-

${ }^{303}$ Ebenda.

${ }^{304}$ ThHStA, Land Thüringen, Büro des Ministerpräsidenten, Bd. 1683-1684, Bl. 270, Ministerium für Wirtschaft und Arbeit des Landes Thüringen am 7.7.1951 an Ministerpräsident Werner Eggerath. Zur Beschleunigung des Arbeitskräfteaustausches hatte der Minister für Wirtschaft und Arbeit Walter Strampfer sogar die Verkürzung der Ausbildungszeiten bei ausgewählten Jugendlichen von drei auf zwei Jahre vorgeschlagen. Vgl. ebenda, Bl. 268f., Minister Strampfer am 11.7. 1951 an Ministerpräsident Eggerath.

${ }^{305}$ BAB, DQ 2/2132, Aktennotiz von Hauptreferent Krüger vom 14. 9. 1951.

${ }_{306}$ BAB, DQ 2/2132, Malter am 23. 10. 1951 an das Ministerium für Schwcrindustrie.

307 Protokoll des III. Parteitages, Bd. 1, S. 356.

${ }^{308}$ Das Politbüro hatte am 14. 11. 1950 den Standort der neuen Industriestadt festgelegt, die insgesamt 30000 Einwohner haben sollte. SAPMO, DY 30/IV 2/2/118, Bl. 105. Kurz darauf gab das Sekretariat des ZK die Anweisung zum Baubeginn in Fürstenberg. Darüber hinaus wurde das Ministerium für Aufbau beauftragt, einen Entwurf für den Bau eines „Ledigenheimes für ca. 300 Werktätige“" zu erstellen. SAPMO, DY 30/J IV 2/3/156, Bl. 11, Protokoll der Sitzung des Sekretariats des ZK am 27. 11. 1950. 
partner für die beteiligten Ministerien und Verwaltungsstellen zu benennen ${ }^{309}$. Die Bauarbeiten gingen insgesamt nur sehr schleppend voran: Ende Januar 1951 waren zwar 2313 Arbeitskräfte (1906 Männer, 407 Frauen) beschäftigt, doch deren wohnliche Unterbringung und Versorgung ließ sehr zu wünschen übrig, wie Mitarbeiter des Arbeitsministeriums anläßlich einer Dienstreise zu den Baustellen an der Oder feststellen mußten ${ }^{310}$. Auch das Sekretariat des FDGB-Bundesvorstandes entsandte eine Kommission nach Fürstenberg, um die dortige Gewerkschaftsarbeit kritisch zu überprüfen ${ }^{311}$.

In der Folgezeit rückte die Wohnungsfrage immer stärker in den Mittelpunkt der Aktivitäten des Ministeriums für Arbeit. Weil die neu eingestellten Bauarbeiter zunächst nur provisorisch, d.h. in Baracken untergebracht werden konnten, mußte nunmehr eine langfristige Lösung erarbeitet werden. Bereits bei den Heimkehrer- und „Umsiedler“-Lagern waren die Arbeitsämter und die SED-Führung Ende der vierziger Jahre rasch zu der Erkenntnis gelangt, daß die wohnliche Unterbringung in Lagern nur eine Ad-hoc-Maßnahme darstellte. Um die Ausbreitung von Seuchen zu verhindern sowie den sozialen Frieden innerhalb der betroffenen Personengruppe zu wahren, mußten entsprechende Wohnungsbauprogramme gestartet werden. Angesichts der engen finanziellen Handlungsspielräume war dies jedoch ein schwieriges Unterfangen. Darüber hinaus wurden die Planungsarbeiten stellenweise unkoordiniert durchgeführt, was zur Folge hatte, daß die Errichtung der Wohnanlagen in unmittelbarer Nähe zum Kombinat merklich ins Stocken geriet. So waren die Erdarbeiten Mitte Februar 1951 noch nicht abgeschlossen und mußten nach Beendigung der Frostperiode wieder aufgenommen werden. Gleichzeitig seien allerdings für $460000,-D M$ genormte Türen und Fenster angekauft worden, die - so Staatssekretärin Malter - „in dieser Menge vorerst noch auf lange Zeit nicht benötigt werden" ${ }^{312}$. Vertreter des FDGB beklagten daraufhin bei einer Sitzung am 1. März, zu der die zuständigen Ministerien eingeladen worden waren, daß es ,keine Zusammenarbeit zwischen den gesellschaftlichen Massenorganisationen und den Betriebsleitungen" gebe ${ }^{313}$. Der Direktor des Stahlwerkes Brandenburg Greif, der ebenfalls an der Sitzung teilnahm, schlug die Aufstellung von Brigaden vor, die sich aus Mitarbeitern der bereits bestehenden Stahl- und Walzwerke zusammensetzen sollten. Diese könnten dem EKO aufgrund ihrer gewonnenen Erfahrungen behilflich sein. Außerdem sprach er sich - vor dem Hintergrund eigener Probleme in Brandenburg - für eine klare Kompetenzverlagerung zugunsten der Betriebsleitung aus: „Ein Betrieb ist kein Parlament, sondern eine Produktionsstätte. Es geht nicht an, daß am Tage 3 Kommissionen mit dem ehrlichen Willen zu helfen erscheinen, die aber nur den Ablauf hemmen, da man an einem Tag nicht einen Betrieb so eingehend studieren

$309 \mathrm{BAB}, \mathrm{DQ} 2 / 2152$, Ministerium für Industrie (Alders) am 15. 8. 1950 an das Ministerium für Arbeit und Gesundheitswesen.

$310 \mathrm{BAB}, \mathrm{DQ} 2 / 3810$, Reisebericht der Abt. Arbeitsschutz über Dienstreise nach Fürstenberg zum EKO am 2. 2. 1951 , S. 1 .

311 Ebenda, Bericht der Org.-Instrukteur-Abt. vom 14. 2. 1951.

312 Ebenda, Aktennotiz Malters vom 28. 2. 1951, S. $1 \mathrm{f}$.

313 Ebenda, Bericht der HA Arbeitsschutz vom 3. 3. 1951, S. 1. Trotz Einladung war kein Vertreter der Staatlichen Plankommission erschienen. Vgl. ebenda, Pressemitteilung des FDGB vom 7.3. 1951. 
kann, um operative Anleitungen zu geben, sondern es entstehen nur entstellte Berichte.“314 Grundsätzliche Entscheidungen über die Intensivierung des Wohnungsbaus in Fürstenberg und über die Bereitstellung zusätzlicher Finanzmittel wurden jedoch in Berlin nicht getroffen, so daß die Kommunalverwaltung weiterhin auf sich alleine gestellt blieb ${ }^{315}$.

Die nur langsam anlaufenden Bauarbeiten verzögerten letztlich den für 1951 vorgesehenen Produktionsbeginn. Die Arbeitsverwaltung sah sich gezwungen, verstärkt Arbeitskräfte in der eigens gebildeten VVB Bauunion Fürstenberg einzusetzen. Diese Schwerpunktsetzung schlug sich auch in der Beschäftigtenstatistik nieder, die allerdings in dieser Frühphase äußerst unzureichend war. Demnach waren am 7. April insgesamt 3365 Arbeiter bei der VVB Bauunion beschäftigt und nur 308 beim Eisenhüttenkombinat ${ }^{316}$. Das für das EKO zuständige Arbeitsamt in Fürstenberg führte zunächst einzelne Untersuchungen in Betrieben der örtlichen Leicht- und Konsumgüterindustrie durch, um den konkreten Arbeitskräfteüberhang und die generellen Möglichkeiten zum Beschäftigtenaustausch festzustellen. Nachdem auf diese Weise einige Arbeiter gewonnen werden konnten, vereinbarten der Leiter des Kreisarbeitsamtes sowie die beiden Vertreter des EKO bzw. der Bauunion, die umliegenden Betriebe beschleunigt und systematisch zu "durchkämmen" 317 . Auch wenn über den Erfolg dieser Aktion keine Angaben zu machen sind, so bleibt doch festzuhalten, daß die Leitung des neuen Hüttenkombinats in enger Kooperation mit der Arbeitsverwaltung des Kreises die Initiative ergriff und die Bereitstellung von Arbeitskräften nicht dem Arbeitsministerium in Berlin überließ. Darüber hinaus schlugen die beteiligten Stellen zur Verbesserung der Wohnraumversorgung die Erstellung eines Wohnraumbedarfsplanes vor, der sich am Arbeitskräftebedarfsplan orientieren sollte ${ }^{318}$. Dazu mußte jedoch zunächst einmal die Zusammenarbeit zwischen Betriebsleitung und Arbeitsverwaltung verbessert werden. Das Ministerium für Arbeit sah sich mit dieser Aufgabe offensichtlich überfordert und wies die Verantwortung der Leitung des EKO zu. Das Gesetz der Arbeit - so die zuständige Abteilung Wohnraumlenkung - lege fest, daß der Betrieb „für die Schaffung von Wohnraum verantwortlich“ sei und die "nötige Anzahl von Wohnungen bei der Verplanung für die Jahre 1952-1955 anzumelden" habe ${ }^{319}$.

Das Politbüro der SED versuchte im Frühjahr 1951 den Bau der Produktionsanlagen im Eisenhüttenkombinat voranzutreiben. Diesem Ziel diente der Beschluß, die ersten zwei Batterien für die Kokereianlage noch in das laufende Investitionsprogramm aufzunehmen ${ }^{320}$. Der Ministerrat wurde angewiesen, die dafür

314 Ebenda, Bericht der HA Arbeitsschutz vom 3. 3. 1951, S. 4.

315 Ebenda, KWU Fürstenberg am 5. 3. 1951 an Staatssekretärin Malter.

316 Ebenda, Statistik (o.D.). Die Statistik war Bestandteil eines Gesamtberichts über die Arbeitskräftesituation beim EKO, die vom kommissarischen Leiter des Kreisarbeitsamtes und jeweils einem Mitarbeiter des EKO und der Bauunion zusammengestellt worden war. Der Bericht bildete wiederum die Grundlage für eine Untersuchung des MdI. Vgl. BAB, DQ 1/8/150, Bl. 20-61, Bericht des MdI vom 1. 5. 1951.

317 BAB, DQ 2/3810, Bericht zur Statistik.

318 Ebenda.

319 BAB, DQ 2/3810, Aktenvermerk der Abt. Wohnraumlenkung vom 3. 4. 1951 für Staatssekretärin Malter.

320 SAPMO, DY 30/IV 2/2/144, Bl. 18 f., Protokoll der Sitzung des Politbüros am 25. 4. 1951. 
benötigten „materiellen und finanziellen Fonds“ bereitzustellen. Gleichzeitig erhielt Bruno Leuschner den Auftrag, die für den Bau der Kokereianlage notwendigen Lieferungen aus SAG-Betrieben mit der sowjetischen Leitung in Weißensee zu besprechen. Dagegen blieben die beiden drängenden Probleme - Wohnraumversorgung und Arbeitskräftegewinnung - weiterhin ungelöst. Da das EKO noch nicht viele Beschäftigte hatte, stellte deren Unterbringung keine große Schwierigkeit für die Wohnungs- und Arbeitsämter dar. Sehr viel problematischer war dagegen die Versorgung der zahlreichen Baufacharbeiter mit Wohnraum. Das Arbeitsministerium beklagte in dem Zusammenhang, daß die Bauunion "selbst nichts für die wohnliche Versorgung ihrer Betriebsangehörigen " unternehme und sogar Maßnahmen treffe, "die einen beträchtlichen Verlust an Wohnraum bedeuten" würden ${ }^{321}$. So plante die Bauunion offenbar die Verlegung ihrer Verwaltung nach Fürstenberg, obwohl ihr in Frankfurt/Oder Geschäftsräume angeboten worden waren. Angesichts der Wohnungsknappheit befürchtete das Arbeitsministerium nicht zu Unrecht eine Verschlechterung der Situation durch dieses Vorhaben. Das Ministerium für Arbeit beabsichtigte - auf der Grundlage eines Ministerratsbeschlusses vom 29. März - die Stadt Fürstenberg sowie die umliegenden Gemeinden zu „Brennpunkten des Wohnungsbedarfs“ zu erklären. Die Kreisverwaltung sollte ermächtigt werden, für die betroffenen Gemeinden Zuzugsverbote verhängen zu können, um eine weitere Verschlechterung der Wohnraumversorgung zu vermeiden. Darüber hinaus war vorgesehen, die „Benutzung von Wohnraum für andere Zwecke grundsätzlich" $\mathrm{zu}$ untersagen und Ausnahmen nur gesondert zu genehmigen ${ }^{322}$. Der Versuch, die Verteilungskonflikte auf dem Wohnungsmarkt dadurch zu entschärfen, daß „nicht ortsgebundene Personen“ umgesiedelt wurden, hatte wenig Aussicht auf Erfolg. Die staatlich angeregte und gesteuerte Binnenwanderung betraf in diesem Fall vor allem Rentner, die ihre Wohnungen für die neu eintreffenden Arbeitskräfte aufgeben sollten. SED-Führung und Arbeitsverwaltung waren allerdings darauf bedacht, daß diese Maßnahme nur mit Zustimmung der Betroffenen durchgeführt wurde. Im Stahlwerk Hennigsdorf kam es sogar vor, daß Arbeiter sich weigerten, Wohnungen zu beziehen, die alte und nicht mehr berufstätige Personen räumen mußten ${ }^{323}$.

Die Zuweisung von Arbeitskräften zur Bau-Union Fürstenberg und deren Versorgung blieb auch in der Folgezeit das zentrale Problem für die Arbeitsverwaltung. Nachdem zunächst das Arbeitsministerium in Berlin auf die Mangelsituation hingewiesen hatte, nahm sich das zuständige Landesministerium in Potsdam der Thematik an. Ein Sachbearbeiter des brandenburgischen Ministeriums für Wirtschaft und Arbeit bestätigte die bisherige kritische Einschätzung und stellte während einer Dienstreise fest, daß der „Stand der inneren Organisation der Arbeitskräfteplanung und innerbetrieblichen Arbeitskräftelenkung [...] alarmierend" sei324. Die Personalabteilung der Bau-Union sei der zahlenmäßig großen Zuweisung von Arbeitskräften letztlich nicht gewachsen: So würden die zugewie-

321 BAB, DQ 2/3810, Bericht des Ministeriums für Arbeit vom 4. 5. 1951, S. 2.

322 Ebenda, S. 3.

${ }^{323} \mathrm{BAB}, \mathrm{DQ} 2 / 3810$, Abt. Wohnraumlenkung (Jagodzinski) am 7. 6. 1951 an Staatssekretärin Malter, S. 3.

${ }^{324} \mathrm{BAB}, \mathrm{DQ}$ 2/2152, Lagebericht Gürtelers vom 5. 6. 1951, S. 1. 
senen Arbeitskräfte „stundenlang, ja oft den ganzen Tag auf ,Abfertigung ““ warten und könnten häufig „erst am folgenden Tag oder noch später einem Arbeitsplatz zugeführt werden" 325 . Außerdem erfasse die Werksverpflegung nicht die wartenden Arbeitskräfte, obwohl diese „doch praktisch so gut wie als [sic] eingestellt gelten". Bemängelt wurde des weiteren die nur sehr schleppend anlaufende Erstattung der Fahrtkosten: Zahlreiche Arbeiter beklagten sich darüber, daß sie „oft länger als 4 Wochen die Fahrtkosten selber bestreiten“ müßten. Nach Einschätzung des Sachbearbeiters war die Verwaltung der Bau-Union - insgesamt gesehen - mit den anstehenden Aufgaben der Arbeitskräftelenkung überfordert. Facharbeiter seien etwa als ungelernte Arbeiter und ungelernte Arbeiter als Elektromonteure eingestellt worden. Und weiter: "Jedenfalls ist hinsichtlich berufsrichtiger Lenkung der eingeschleusten Kräfte wenig System erkennbar. “326

Ein erkennbares und längerfristiges Konzept zur Sicherung des Facharbeiterbedarfs war nicht vorhanden bzw. konnte angesichts der engen finanziellen Spielräume, die der erste Fünfjahrplan gesetzt hatte, nicht entwickelt werden. Gleichzeitig fehlte es aber offensichtlich auch an inhaltlichen Absprachen zwischen der Betriebsleitung und der Arbeitsverwaltung. Beide Seiten beschränkten sich darauf, Ad-hoc-Maßnahmen zu beschließen. Die Leitung der Bau-Union verfügte zunächst einen zeitlich befristeten Einstellungsstopp für Baufacharbeiter, während das Berliner Arbeitsministerium eine nachträgliche Erhöhung bei der Ortsklasseneinstufung unter Hinweis auf die "finanziellen Auswirkungen“ ablehnte ${ }^{327}$. Mitte Juni hob das Ministerium für Arbeit den Einstellungsstopp wieder auf und ordnete die Zuteilung von Facharbeitern und Bauhilfsarbeitern für die Bau-Union in Fürstenberg wieder an ${ }^{328}$. Das Amt für Arbeit und Sozialfürsorge Frankfurt/Oder wies umgehend darauf hin, daß die Bereitstellung der angeforderten Arbeitskräfte nur durch eine Intensivierung des zwischen- und überbezirklichen Ausgleichs möglich sein könnte, der wiederum von den zur Verfügung stehenden Unterbringungsmöglichkeiten abhängig war ${ }^{329}$. Der Sachbearbeiter im brandenburgischen Ministerium für Wirtschaft und Arbeit unterstrich, daß „die Inanspruchnahme des Länderausgleichs [...] in jedem Falle abzulehnen [sei], solange nicht die Wohnbaracken nahe dem Werksgelände erstellt werden“ 330 . Gleichzeitig sollten die übrigen Länder bei der Gewinnung von Arbeitskräften für das Bauvorhaben an der Oder stärker herangezogen werden. Das Arbeitsministerium in Berlin hatte etwa die mecklenburgische Landesregierung gebeten, sich an dieser Aufgabe zu beteiligen. Da kurz zuvor Arbeiter der Werftenindustrie entlassen worden waren, schien sich hier die Möglichkeit eines überbezirklichen Ausgleichs anzubahnen. Ähnliches war wohl auch für Thüringen vorgesehen, wo

325 Ebenda, S. 2.

326 Ebenda, S. 3.

327 BAB, DQ 2/3810, komm. Leiter der Abt. Kollektivverträge und Lohnkontrollen am 8. 6. 1951 an Staatssekrctärin Malter.

328 Vgl. BAB, DQ 2/2152, Minister für Wirtschaft und Arbeit der Landesregierung Brandenburg am 14.6. 1951 an das Ministerium für Arbeit.

${ }^{329}$ Ebenda, Bericht des Amtes für Arbeit und Sozialfürsorge Frankfurt/Oder am 14.6. 1951 an das Ministerium für Arbeit.

330 Ebenda, Lagebericht Gürtelers vom 28. 6. 1951, S. 7 f. 
geplante Bauvorhaben nicht starten konnten und somit „eine wesentliche Zahl von Baufachkräften freigesetzt" wurde ${ }^{331}$.

Die Bau-Union Fürstenberg wurde sowohl für die Mängel bei der Arbeitskräftesteuerung als auch für die fehlenden Unterbringungsmöglichkeiten verantwortlich gemacht. Sie rückte damit immer mehr ins Zentrum der Kritik. Es hat jedoch den Anschein, als ob die Arbeitsverwaltung in Berlin und Potsdam der Betriebsleitung Fehler zuordnete, für die sie nicht alleine verantwortlich sein konnte. Entscheidend für die krisenhafte Zuspitzung der Arbeitskräfte- und Versorgungslage in Fürstenberg war vielmehr die von oben erteilte Anweisung, den industriellen Standort an der Oder in relativ kurzer Frist fertigzustellen. Die damit zusammenhängenden Folgen waren offenbar von den staatlichen Planungsverwaltungen weder vorhergesehen noch eingeplant worden. Die Feststellung der Arbeitsverwaltung war sicherlich zutreffend, daß aufgrund der schlechten Zuteilung und Einweisung der Arbeitskräfte ein Ansteigen der Fluktuationsrate zu befürchten war ${ }^{332}$. Die Personalverwaltung der Bau-Union wurde daher angewiesen, den organisatorischen Ablauf zu verbessern. Darüber hinaus schien es dem Arbeitsministerium „ratsam und dringend erforderlich" zu sein, die Nebenstelle Fürstenberg des Amtes für Arbeit und Sozialfürsorge in unmittelbare Nähe zum Werk zu verlegen ${ }^{333}$.

Staatssekretärin Malter berichtete dem Minister für Schwerindustrie Selbmann ausführlich über die bestehenden Mängel der innerbetrieblichen Arbeitskräftelenkung bei der Bau-Union und bat ihn, „durch notwendige Anweisungen zur Überwindung der Schwierigkeiten beizutragen " 334 . Neben den bereits bekannten Problemen der Wohnraum- und Lebensmittelversorgung wies Malter auf das unzureichende Verkehrsnetz im Raum Fürstenberg hin, das einen zügigen Transport zu den Baustellen nicht zulasse. Gleichzeitig schlug die Staatssekretärin im Arbeitsministerium vor, den Einstellungsbüros des EKO zusätzliche Aufgaben zu übertragen. Dort sollten die zugewiesenen Arbeitskräfte nicht nur einen Einweisungsschein für einen festen Arbeitsplatz erhalten, sondern auch Quartierscheine und Essenskarten. Die Einstellungsbüros hatten somit die Aufgabe, die Versorgung der Neuankömmlinge mit Wohnraum und Lebensmitteln durch die Ausgabe von Bezugsscheinen zentral zu regeln. Bis zum Juni 1951 hatte sich die Beschäftigtenzahl bei der Bau-Union weiter vergrößert, während sie beim EKO, das die Produktion im Herbst aufnehmen sollte, stagnierte. Mit Stichtag vom 7. Juni wurden insgesamt 5656 Baufach- und Hilfsarbeiter gezählt, darunter befanden sich immerhin 1486 weibliche Arbeitskräfte ${ }^{335}$. Im einzelnen handelte es sich um 1990 Facharbeiter, 1789 Hilfsarbeiter und 387 Angestellte. Dagegen lag die Zahl der Beschäftigten im EKO zwischen 300 und 400 und war damit gegenüber dem Frühjahr nicht sonderlich angestiegen. Trotz der von der Arbeitsverwaltung eingeleiteten Maßnahmen trug die Wohnungsknappheit auch weiterhin dazu

$331 \mathrm{BAB}, \mathrm{DQ} 2 / 1728$, Abt. Arbeitskraftlenkung am 26.6. 1951 an den Org.-Instrukteur, S. 2.

332 BAB, DQ 2/2152, Aktennotiz Krügers vom 29. 6. 1951, S. 1.

333 Ebenda, S. 3.

${ }^{334}$ BAB, DQ 2/2152, Malter am 2. 7. 1951 an Selbmann, S. 1.

335 Ebenda, Bericht der Abt. Arbeitskraftlenkung vom 2. 7. 1951, S. 2. 
bei, daß zahlreiche Arbeitskräfte in ihre Heimatorte wieder zurückkehrten ${ }^{336}$. Die Fluktuationsrate war im 1. Halbjahr 1951 stellenweise gestiegen: Während in den ersten fünf Monaten nur 150 Arbeitskräfte gezählt wurden, die abgewandert waren, stieg diese Zahl in den ersten drei Juni-Wochen auf 300337. Bis Ende Juni verließen nochmals 60 Arbeitskräfte die Bau-Union bzw. das EKO. In der Folgezeit übernahm das EKO die Beschaffung von Unterkünften für alle auf der Baustelle Fürstenberg beschäftigten Arbeitskräfte, mit Ausnahme von zwei Außenstellen. Dadurch wurde zwar der Entscheidungsweg verwaltungstechnisch vereinfacht. Eine quantitative und qualitative Verbesserung der Wohnverhältnisse hing jedoch entscheidend von der Bereitstellung von Finanzhilfen für entsprechende Wohnungsbauprogramme ab, die zunächst aber noch ausblieben.

Anläßlich einer Besprechung über das laufende Wohnungsbauprogramm, an der unter anderem Vertreter des Ministeriums für Arbeit, des Ministeriums für Schwerindustrie und des Ministeriums für Aufbau teilnahmen, wurde deutlich, daß der aufgestellte Wohnungsbauplan nicht eingehalten werden konnte ${ }^{338}$. Die Fertigstellung der sogenannten Wohnstadt zog sich sehr viel länger hin als von der Arbeitsverwaltung ursprünglich einkalkuliert. Das konnte wiederum zu einer Verzögerung des Produktionsbeginns im EKO führen, da die vorgesehenen Arbeiter erst nach Fürstenberg entsandt werden sollten, wenn die Wohnungen bezugsfertig waren. Die Mängel waren nach Ansicht eines Mitarbeiters des Ministeriums für Schwerindustrie (Hauptverwaltung Bauindustrie) darauf zurückzuführen, daß Bauleiter und Oberbauleiter gezwungen waren, „hinter [den] Planunterlagen, Investitionsmitteln, Leistungsverzeichnissen usw. herzujagen, statt dafür auf der Baustelle zu sein"339. Darüber hinaus waren Teile der Infrastruktur noch nicht vollständig ausgebaut, so daß beispielsweise die einzelnen Wohnungen noch nicht an die Kanalisation angeschlossen werden konnten ${ }^{340}$. Für die Erweiterung des Bauprogramms sollte das Ministerium für Aufbau zusätzliche Investitionsmittel in Höhe von 4,827 Millionen DM beantragen ${ }^{341}$. Für die Terminüberschreitungen bei der Fertigstellung der Wohnblöcke wurde erneut die Bau-Union verantwortlich gemacht: Die mangelhafte innerbetriebliche Organisation sowie allgemeine Planungsfehler hatten nach Auffassung des brandenburgischen Ministeriums für Wirtschaft und Arbeit zu den Versäumnissen geführt ${ }^{342}$. Nach Berechnungen des FDGB-Bundesvorstandes war nur ein Teil der rund 9000 Bauarbeiter in unmittelbarer Nähe des Werkes untergebracht. Zum Teil müßten Arbeiter, die ihre Zimmer bzw. Wohnungen in 68 Ortschaften der Kreise Frankfurt/Oder, Beeskow und Cottbus hatten, einen täglichen Anfahrtsweg von bis zu $120 \mathrm{~km}$ in

\footnotetext{
${ }^{336}$ Vgl. ebenda, Abt. Arbeitskraftlenkung am 27. 7. 1951 an das Ministerium für Wirtschaft und Arbeit in Potsdam.

${ }^{337}$ Ebenda, Amt für Arbeit und Sozialfürsorge Frankfurt/Oder am 5. 7. 1951 an das Ministerium für Arbeit (Krüger), S. 1.

${ }^{338} \mathrm{BAB}, \mathrm{DQ} 2 / 2152$, Protokoll über die Besprechung am 4. 7. 1951.

${ }_{339}$ Ebenda, S. 2.

${ }^{340}$ Ebenda, S. 3. Das bestätigte im übrigen auch Sachbearbeiter Gürteler in seinem Lagebericht vom 17. 7. 1951. Vgl. BAB, DQ 2/2152.

${ }^{341}$ BAB, DQ 2/2152, Protokoll über die Besprechung am 4. 7. 1951, S. 7.

${ }^{342}$ Ebenda, Ministerium für Wirtschaft und Arbeit in Potsdam am 10.7. 1951 an den Minister für Aufbau.
} 
Kauf nehmen ${ }^{343}$. Der FDGB schlug deshalb vor, zunächst einmal 30 Häuser für insgesamt 1000 Bauarbeiter zu errichten, wobei die Kosten durch erhebliche Einsparungen bei den Baumaterialien gesenkt werden sollten. Darüber hinaus regte der Gewerkschaftsbund die Errichtung von eingeschossigen Reihenhäusern "durch kollektive Selbsthilfeaktionen der Kollegen im Eisenhüttenkombinat" $\mathrm{an}^{344}$.

Anfang August 1951 tauchten neue Versorgungsschwierigkeiten auf, die das Gesamtprojekt gefährdeten. Die Zulieferung von Steinkohle oder Koks war offensichtlich nicht hinreichend geklärt worden, und Verhandlungen mit der Volksrepublik Polen über entsprechende Ausgleichslieferungen konnten noch nicht abgeschlossen werden. In dieser Situation schaltete der Vorsitzende der Staatlichen Plankommission (SPK) Heinrich Rau den Ministerpräsidenten Otto Grotewohl ein. Bei der Gelegenheit gestand Rau ein, innerhalb der SPK über keinen qualifizierten Fachmann „zur Beurteilung der technischen und konstruktiven Fragen des Hüttenkombinats“ zu verfügen. Er schlug vor, „das Projekt in dieser Hinsicht durch sowjetische Spezialisten prüfen zu lassen “345. Der Minister für Schwerindustrie Selbmann sprach sich für eine stärkere Beteiligung des Ministerrates bei den weiteren Planungsarbeiten für das EKO aus ${ }^{346}$. All dies waren Anzeichen für die Hilflosigkeit, die offenbar bei den beteiligten Ministerien mittlerweile herrschte: Zum zeitlichen Druck kamen nunmehr gravierende Planungs- und Abstimmungsprobleme hinzu, welche die festgesetzte Inbetriebnahme des Hüttenkombinats, die bekanntlich noch 1951 erfolgen sollte ${ }^{347}$, in weite Ferne rücken ließen.

Zur Abdeckung des Facharbeiterbedarfs im EKO griff die Arbeitsverwaltung zum Teil darauf zurück, den Betrieben entsprechende Auflagen zu erteilen. Dabei sollten allerdings Zwangsmittel nicht eingesetzt werden. Vielmehr ging es darum, Anreize in Form von Ausbildungszuschüssen zu schaffen, um bisher beschäftigungslose Frauen in den Produktionsprozeß zu integrieren. Auf diese Weise sollten männliche Arbeitskräfte der Hüttenindustrie zur Verfügung gestellt werden, wie Abteilungsleiter Heisig gegenüber dem brandenburgischen Ministerium für Wirtschaft und Arbeit ausdrücklich betonte ${ }^{348}$. Diese Auflagen erstreckten sich nur auf eng ausgewählte Personenkreise, in der Regel Spezialisten, die von den zuständigen Fachministerien nicht gestellt werden konnten. In Einzelfällen hatte sich jedoch herausgestellt, daß der tatsächliche Facharbeiterbedarf sehr viel niedriger als der angemeldete war. Ordnungsgemäß zugewiesene Arbeitskräfte waren sogar vom Baubüro Fürstenberg mit dem Vermerk „kein Bedarf“ auf der Zuweisungskarte zurückgewiesen worden. Das Ministerium für Wirtschaft und Arbeit der Landesregierung Brandenburg, das ein Rundschreiben mit entsprechenden

${ }^{343}$ Zur Begleichung der Fahrtkosten erhielten 7304 Arbeiter Wege- bzw. Fahrtgelder. Die unzureichenden Wohnverhältnisse wurden vom FDGB in kausalen Zusammenhang zur gesunkenen Arbeitsproduktivität gesetzt. BAB, DQ 2/3810, FDGB-Bundesvorstand (Abt. Arbeit und Sozialpolitik) am 23. 7. 1951 an das Ministerium für Aufbau.

344 Ebenda, S. 3.

${ }^{345}$ SAPMO, NY 4090/351, Bl. 7, Rau am 6. 8. 1951 an Grotewohl.

${ }_{346}$ Ebenda, Bl. 11 f., Selbmann am 10. 8. 1951 an Grotewohl.

${ }^{3+7}$ So sollte der Hochofen I des EKO die Produktion am 19. 9. 1951 aufnehmen. Vgl. SAPMO, NY 4090/351, Bl. 18, Minister für Schwerindustrie Selbmann am 12.9. 1951 an Ministerpräsident Grotewohl.

${ }^{3+8} \mathrm{BAB}, \mathrm{DQ} 2 / 2152$, Heisig am 27. 8. 1951 an Ministerium für Wirtschaft und Arbeit in Potsdam. 
Auflagen an die Abteilungen Arbeit bei den Räten der Kreise bereits herausgegeben hatte, kritisierte zu Recht die mangelhafte Absprache, die letztlich Fehlvermittlungen zur Folge hatte. Der zuständigen VVB, die ursprünglich zehn Bauschlosser und 70 Elektromonteure angefordert hatte, wurde schließlich vorgehalten: „Wir machen Sie darauf aufmerksam, daß - würden alle Betriebe die Arbeitskräfteanforderungen nach dem von Ihnen gegebenen Beispiel betreiben - chaotische Zustände in der Arbeitskräftelenkung eintreten müßten. “" ${ }^{449}$ Es sei ein „unmöglicher Zustand" - so der Hauptabteilungsleiter im brandenburgischen Ministerium weiter - insgesamt 70 Arbeiter aus ausgesprochenen Mangelberufen anzufordern, wenn de facto nur 40 Arbeiter gebraucht würden. Das Ministerium für Arbeit in Berlin informierte daraufhin die übrigen Landesregierungen über den gesunkenen Facharbeiterbedarf im EKO ${ }^{350}$. Dieses Beispiel machte zum einen deutlich, daß die zentrale Zuteilung von Arbeitskräften mit gewissen Reibungsverlusten verbunden war: Die aufwendig in Gang gesetzte Aktion zur Gewinnung der benötigten Facharbeiter mußte wenig später wieder abgebrochen werden. Irritationen auf seiten der Kreisverwaltungen, welche die Auflagen erhalten hatten, aber auch der zuständigen Landesverwaltung waren die Folge. Darüber hinaus zeigte sich, daß die Betriebe ihren Bedarf mitunter großzügig kalkulierten: Sie waren primär an der Aufrechterhaltung der betrieblichen Produktion und weniger an übergeordneten Zielen der Planwirtschaft interessiert.

Die SED-Landesleitung Brandenburg übermittelte der SED-Führung ungefähr Ende Oktober einen Bericht, der sich nicht nur mit der Tätigkeit der Parteiorganisation in Fürstenberg, sondern auch mit dem Produktionsablauf im EKO und in der Bau-Union kritisch auseinandersetzte ${ }^{351}$. Zwei Mitarbeiter des ZK-Apparates wurden daraufhin nach Fürstenberg geschickt, die bereits Anfang November einen eigenen Überprüfungsbericht vorlegten, der die vorgelegten Ergebnisse der Landesleitung im wesentlichen bestätigte ${ }^{352}$. Darin wurde den beiden Parteiorganisationen vorgeworfen, ihnen sei die genaue Anzahl der für die Bau-Union tätigen Subunternehmer nicht bekannt gewesen. Daraus zog der Bericht wiederum die Schlußfolgerung, es habe sich „keine gesunde Parteiarbeit entwickelt“ ${ }^{353}$. Von einem gesonderten Einsatz einer Instrukteurgruppe des ZK rieten die Mitarbeiter ab, da die Landesleitung in Potsdam bereits ähnliche Schritte unternommen hatte. Bei der inhaltlichen Analyse war auffallend, daß die Defizite im Produktionsablauf des EKO auf unzureichende Parteiarbeit vor Ort zurückgeführt wurden. Die SED-Führung nahm diesen Bericht offensichtlich zum Anlaß, die Arbeitsweise der Parteiorganisation regelmäßig zu überprüfen und direkte Anweisungen zu erteilen. Das Sekretariat des ZK setzte auf seiner Sitzung am 10. Januar 1952 eine weitere Kommission ein, der unter anderem Walter Ulbricht, Willi Stoph und

${ }^{349}$ Ebenda, Hauptabteilungsleiter Hülsen am 6. 10. 1951 an die VVB Anlagenbau Cottbus.

350 Ebenda, Abteilungsleiter Heisig am 16.10. 1951 an das Ministerium für Wirtschaft (HA Arbeit) des Landes Sachsen-Anhalt.

351 Vgl. SAPMO, NY 4182/988, Bl. 123-126, SED-Hausmitteilung von der Abt. Org.-Instrukt. (Sekt. Parteiinf.) an Ulbricht, 1. 11. 1951.

352 Ebenda, Bl. 128-132, Bericht vom 6. 11. 1951.

${ }^{353}$ Ebenda, Bl. 128. Nach Angaben der ZK-Mitarbeiter arbeiteten insgesamt 20 Subunternehmer für die Bau-Union und 27 für das EKO, darunter auch 13 Privatunternehmen. 
Fritz Selbmann angehörten ${ }^{354}$. Während technische Fragen ${ }^{355}$ eher von untergeordneter Bedeutung waren, standen Personal- und Kaderfragen im Mittelpunkt des Interesses: Nach den Vorstellungen des Sekretariats sollten sämtliche Direktorenposten neu besetzt werden. Gleichzeitig sollte der Minister für Hüttenwesen und Erzbergbau Selbmann eine Rüge erhalten: Er habe - so das Sekretariat - „die offene Kritik und Selbstkritik verhindert"; er sei „überheblich“ und betreibe „keine ernsthafte Kaderpolitik“356. Das Politbüro beschloß Anfang Februar 1952 „Maßnahmen zur Verbesserung der Arbeit des Ministeriums für Hüttenwesen und Erzbergbau, der Industriegewerkschaft Metallurgie sowie der Industriegewerkschaft Bau-Holz beim Aufbau des Eisenhüttenkombinats Ost“" 357 und erteilte Fritz Selbmann die vom Sekretariat vorgeschlagene Rüge ${ }^{358}$. Abschließend sollte nochmals hervorgehoben werden, daß die SED-Führung konkrete Beschlüsse zur Verbesserung der Kaderpolitik faßte, wohingegen die Beschlüsse zur Intensivierung des Wohnungsbaus und zur Unterstützung der Facharbeiter- und Nachwuchslenkung unpräzise und unverbindlich blieben. Die Arbeitsverwaltung und die Werksleitung konnten bei der Bewältigung dieser drängenden Probleme ${ }^{359}$ nicht mit der Zuteilung weiterer Gelder rechnen, sondern mußten im vorgegebenen Finanzrahmen des Fünfjahrplanes sowie des jeweiligen Volkswirtschaftsplanes weiterhin improvisieren. Erst Ende 1952 befaßte sich das Politbüro wieder mit dem Wohnungsbau in Fürstenberg und beschloß „Sofortmaßnahmen zur Beseitigung der Hemmnisse im Aufbau der Wohnstadt des Eisenhüttenkombinats Ost ${ }^{*} 360$. Diese konzentrierten sich im wesentlichen darauf, die Zuteilung von Baumaterialien zu verbessern und diese unter Ausschaltung des zentralisier-

354 SAPMO, DY 30/J IV 2/3/260, Bl. 1-3.

355 Der Hochofen I war - wie geplant - am 5. 10.1951 angeblasen worden, obwohl wichtige Bestandteile der Produktionsanlage noch nicht fertiggestellt waren. So war beispielsweise die Sinteranlage Anfang 1952 immer noch nicht in Betrieb. Darüber hinaus waren bei einigen Teilen der Hochofenanlage bereits nach wenigen Wochen Reparaturmaßnahmen notwendig geworden. Das von einer Ingenieurgruppe erstellte Gutachten läßt die Schlußfolgerung zu, daß der Hochofen unter hohem Zeitdruck fertiggestellt wurde und dabei Baumängel übersehen wurden. Vgl. SAPMO, NY 4182/ 988, Bl. 142-145, Gutachten über den Zustand des Hochofens I und über die Möglichkeit seines weiteren Betriebes vom 6.1. 1952. Nach Angaben des Ministeriums für Hüttenwesen und Erzbergbau hatte die Gutehoffnungshütte in Oberhausen angeboten, den Hochofen zu errichten. Da jedoch eine Bauzeit von zwei Jahren veranschlagt wurde, kam das Angebot für die DDR-Regierung nicht in Frage. Zu diesem Zeitpunkt verfügte die DDR offensichtlich nicht über erfahrene Ingenieure beim Bau solcher Hochofenanlagen, so daß improvisiert werden mußte, wie das Ministerium selber indirekt bestätigte: „Bis auf kleine konstruktive Mängel“ sei die Aufgabe "richtig gelöst" worden. Vgl. SAPMO, NY 4182/988, Bl. 135-141, hier Bl. 137, Bericht des Ministers für Hüttenwesen und Erzbergbau vom 11.1.1952 an das Sekretariat des ZK.

356 SAPMO, DY 30/J IV 2/3/263, Bl. 2-4, hier Bl. 4, Protokoll der Sitzung des Sekretariats des ZK vom 21.1. 1952.

${ }^{357}$ SAPMO, DY 30/IV 2/2/191, Bl. 6 und Bl. 7-21. Außerdem verabschiedete das Politbüro eine „Direktive zur Entwicklung von Maßnahmen zur Beschleunigung der Aufbauarbeiten im Eisenhüttenkombinat Ost", in: ebenda, B1. 37-42. Die Direktive enthielt Anweisungen für den Ausbau der Parteiarbeit im EKO und für die Verbesserung des Produktions- und Arbeitsablaufes im Kombinat.

358 Ebenda, Bl. $47 \mathrm{f}$.

359 Nach Einschätzung eines Mitarbeiters der Abt. Arbeitskraftlenkung war das Wohnungsproblem das "größte Hindernis für die Einstellung der Arbeitskräfte“. BAB, DQ 2/2153, Aktenvermerk von Oberreferent Seidel vom 9. 4. 1952.

360 SAPMO, DY 30/IV 2/2/243, Bl. 11 und Bl. 25-28, Protokoll der Sitzung des Politbüros am 4. 11. 1952. 
ten Binnenhandels direkt an die Baufirmen zu liefern. Außerdem sollten Transportanlagen (Gleise, Transportfahrzeuge) aus dem Großraum Berlin zur Verfügung gestellt werden, um den „inneren Baustellentransport“ langfristig zu gewährleisten.

Im März 1952 schalteten sich auch noch die „sowjetischen Freunde“ - vermutlich eine Kommission der SKK - in die Angelegenheit ein und forderten vom Arbeitsministerium die Bereitstellung von 1500 hochqualifizierten Fachkräften für das $\mathrm{EKO}^{361}$. Angesichts des nach wie vor bestehenden Facharbeitermangels und der nur langsam anlaufenden Programme zum Ausbau der Berufsausbildung konnte dies nur ein langfristig formuliertes Ziel sein. Noch schwieriger gestaltete sich die Gewinnung von Ingenieuren, über die die DDR zu diesem Zeitpunkt offenbar kaum verfügte. Die „sowjetischen Freunde“ wurden daher vom Politbüro gebeten, die sowjetischen Ingenieure, die im EKO kurzfristig eingesetzt worden waren, noch für weitere vier Wochen dort zu lassen ${ }^{362}$. Darüber hinaus meldete die SED-Führung einen weiteren Bedarf an erfahrenen sowjetischen Ingenieuren für das Hüttenkombinat an.

Parallel dazu begann das Ministerium für Arbeit, den Facharbeiternachwuchs langfristig abzusichern. So wurden beispielsweise Gespräche mit der FDJ mit dem Ziel aufgenommen, aus den Reihen der Jugendlichen frühzeitig potentiellen Nachwuchs für das EKO auszusuchen, um so den späteren Bedarf an Fachkräften abdecken zu können ${ }^{363}$. Der Zentralrat der Jugendorganisation erklärte sich zur Mithilfe bereit und übernahm - quasi symbolhaft - die Patenschaft über das Kombinat an der Oder. Während die damit verbundenen Mobilisierungsaktionen jedoch nicht sehr zielgerichtet und somit - mittel- und langfristig betrachtet - wenig ertragreich waren, mußte zur Verbesserung der Rekrutierung von Facharbeitern die berufliche Qualifizierung von Jugendlichen in das Blickfeld der Verantwortlichen geraten. Obwohl das Ministerium für Arbeit den enormen Nachholbedarf auf diesem Gebiet erkannt hatte, blieben konkrete Maßnahmen zunächst noch aus. Das hing zum einen mit der Überlastung der Arbeitsverwaltung durch diverse andere, ebenfalls zentrale Problemkreise zusammen: von der bereits thematisierten Wohnraumversorgung der zugewiesenen Arbeitskräfte bis hin zur Lebensmittelversorgung der Beschäftigten im EKO. Zu vermuten wäre außerdem, daß für die Arbeitsverwaltung die berufliche Aus- und Weiterbildung zu diesem Zeitpunkt noch nicht den Stellenwert eines wichtigen und vor allem eigenständigen Instruments zur Steuerung des „Arbeitsmarktes“ besaß.

Die Planung des Arbeitskräfteeinsatzes wurde dadurch erschwert, daß die Fachministerien seit der Strukturreform der Arbeitsverwaltung im Sommer 1951 mehr Kompetenzen zugeteilt bekamen. Die Auflösung der Arbeitsämter und deren Eingliederung in die Bezirks- bzw. Kreisverwaltung sowie die Tatsache, daß nunmehr die Industrieministerien inncrhalb ihres Wirkungsbereiches auch für den Einsatz des Faktors ,Arbeit' zuständig sein sollten, vereinfachten den Planungsablauf nicht. Im Gegenteil: Die Fachministerien mußten sich erst mit der

361 BAB, DQ 2/2153, Aktenvermerk Seidels vom 24. 3. 1952.

362 SAPMO, DY 30/IV 2/2/204, Bl. 14, Protokoll der Sitzung des Politbüros am 25. 3. 1952.

363 BAB, DQ 2/2153, Aktenvermerk Seidels vom 7. 4. 1952. 
neuen Aufgabe vertraut machen, bei der sie vom bisher alleine zuständigen Arbeitsministerium noch lange Zeit beraten werden mußten. Fehlende Absprachen innerhalb eines Ministeriums konnten mitunter dazu führen, daß zwei oder mehr Abteilungen mit der Planung des Arbeitskräftebestandes beschäftigt waren und dabei sogar zu unterschiedlichen Ergebnissen gelangten. So hatten etwa beim Ministerium für Hüttenwesen und Erzbergbau sowohl die Personalabteilung als auch die Abteilung Arbeitskräfte Erhebungen über den Arbeitskräftebedarf durchgeführt, die „voneinander beachtlich abwichen“ ${ }^{364}$. Minister Selbmann wurde gebeten, zu entscheiden, "nach welcher Fassung nun tatsächlich gearbeitet werden muß." Gleichzeitig mußte sich das Arbeitsministerium gegenüber der Staatlichen Plankommission zur Wehr setzen: Deren Vorsitzender, Heinrich Rau, hatte die Tätigkeit der Hauptabteilung Arbeit bei der Bedarfsplanung deutlich kritisiert. Minister Chwalek wies darauf hin, daß der „reale Bedarf an Arbeitskräften für die Arbeiten auf dem Baugelände des Hüttenwerkes für das Jahr 1952 [...] erst dann genannt werden [kann], wenn die jetzt noch fehlenden Bau-Unterlagen der Bau-Union übermittelt werden“365. Da im Frühjahr eine akute Nachfrage nach ,ingenieur-technischem Personal“ herrschte, das aus der Gruppe der Arbeitsuchenden nicht mehr gewonnen werden konnte, richtete der Minister für Arbeit eine entsprechende Anfrage an das Staatssekretariat für Kohle und Energie, einzelne Hauptverwaltungen sowie die Deutsche Reichsbahn. Die „hochqualifizierten Fachkräfte“ sollten demzufolge „produktionserfahren sein und über die nötige Arbeitsdisziplin und Arbeitsmoral verfügen“366.

Die Sowjetunion verfolgte auch weiterhin aufmerksam den Aufbau der Stahlindustrie in der DDR mit seinem wichtigsten Baustein, dem Eisenhüttenkombinat in Fürstenberg. Im April 1952 wurde eine Delegation von Moskau nach Berlin geschickt, die sich einen eigenen Eindruck verschaffen und Gespräche mit der engeren SED-Führung (Pieck, Ulbricht, Grotewohl, Rau) führen sollte. Dabei zeigte sich der sowjetische Vertreter Michalewitsch erschüttert über den Zustand des EKO: „Bevor ich aus der Sowjetunion abfuhr, waren wir bereits darauf vorbereitet, daß im EKO eine schwere Situation entstanden ist, aber das, was wir gesehen haben, hat alle unsere Vorstellungen übertroffen. Wir haben - ohne Übertreibung gesagt - ein schreckliches Bild vorgefunden, einen Betrieb, einen neuen Betrieb, der schon vollständig auseinanderfiel.“367 Im einzelnen kritisierte Michalewitsch den überhasteten Aufbau des Hüttenkombinats, der die später aufgetretenen Störungen im Produktionsablauf erst hervorgerufen habe: „Die Öfen wurden zu früh und mit einer großen Anzahl unfertiger Teile in Betrieb gesetzt, ohne zu überprüfen, ob sie zur Aufnahme der Produktion bereit sind, ohne die notwendige Anzahl von Menschen zu haben“368. Das SED-Politbüro, aber auch die sowjetische Besatzungsmacht verknüpften die Durchführung des ersten Fünfjahrplanes

${ }^{364}$ Ebenda, Minister Chwalek am 8. 4. 1952 an Minister Selbmann, S. 1.

365 BAB, DQ 2/761, Minister Chwalek am 9.4. 1952 an Rau, S. 2.

$366 \mathrm{BAB}, \mathrm{DQ}$ 2/2153, Rundschreiben Chwaleks vom 9. 4. 1952. Zu den angeschriebenen Hauptverwaltungen gehörten die HV Bauindustrie und die HV Elektrotechnik. Außerdem ging das Rundschreiben noch an die Reichsbahn Berlin.

367 SAPMO, DY 30/J IV 2/201/257, Stenographische Niederschrift der Besprechung mit den Genossen Michalewitsch und Schulgin in Berlin am 28. 4. 1952, S. 1.

368 Ebenda, S. 2. 
mit dem erfolgreichen Aufbau des EKO. Davon hing nicht nur die Errichtung der Schwerindustrie in der DDR, sondern auch der wirtschaftliche Aufbau des Landes insgesamt ab. Darüber hinaus besaß das Eisenhüttenkombinat auch eine deutschlandpolitische Stoßrichtung: Gegenüber der Bundesrepublik sollte nämlich der Erfolg des eigenen politischen und wirtschaftlichen Systems demonstriert werden, das in seiner Struktur und Funktionsweise dem westdeutschen diametral entgegenstand. Grotewohl faßte diesen Zusammenhang am Ende der Unterredung prägnant zusammen: „Gelingt es uns nicht, unseren Fünfjahrplan zu einem großen Erfolg zu machen, was vor allen Dingen zur Voraussetzung hat, daß die Produktion der Grundstoffindustrie richtig und erfolgreich entwickelt wird, dann ist es vollkommen klar, daß die gesamte politische, die magnetische Kraft der Deutschen Demokratischen Republik auf den Westen verpuffen muß.“369

Der Ministerratsbeschluß vom 20. März 1952 hatte das Ministerium für Arbeit verpflichtet, dem Ministerium für Hüttenwesen und Erzbergbau bei der Werbung und Lenkung der erforderlichen Arbeiter für das EKO behilflich zu sein. Die Zusammenarbeit zwischen beiden Ministerien gestaltete sich jedoch in dieser Frage äußerst schwierig - darauf ist bereits hingewiesen worden. Anfang Mai meldete die Abteilung Arbeitskraftlenkung im Ministerium für Arbeit, daß mittlerweile drei unterschiedliche Planaufstellungen vorlägen: zwei vom Ministerium für Hüttenwesen und Erzbergbau sowie eine von der Personalabteilung des EKO. Aus den übermittelten Zahlenangaben errechnete die Abteilung Arbeitskraftlenkung einen Durchschnittswert von 700 hochqualifizierten Fachkräften, die dringend benötigt würden ${ }^{370}$. Das Arbeitsministerium mußte anderen Fachministerien und Staatssekretariaten Auflagen erteilen, da der Bedarf nur zu einem kleineren Teil aus den Betrieben des Ministeriums für Hüttenwesen und Erzbergbau bereitgestellt werden konnte. Auf diese Weise sollten insgesamt 202 Fachkräfte gewonnen werden, so daß das Ministerium für Hüttenwesen und Erzbergbau nach wie vor die Hauptlast (ca. 500) zu tragen hatte ${ }^{371}$. Die Zuweisung von Arbeitskräften verlief aus Sicht der Personalabteilung des EKO unbefriedigend, da die übrigen Stahlwerke (z. B. in Riesa) oftmals nicht bereit waren, beispielsweise Elektriker, die nicht benötigt wurden, nach Fürstenberg abzugeben 372 . Darüber hinaus meldeten sich aufgrund der von den Landesregierungen erlassenen Aufrufe in erster Linie ehemalige Angestellte älteren Jahrgangs, die aber für die Arbeit im EKO "völlig ungenügend“ seien. Ein Großteil der Neueinstellungen im Eisenhüttenkombinat Ost war letztlich auf die Eigenwerbung des Werkes zurückzuführen, das gezielte Anfragen an größere, in der näheren Umgebung befindliche Betriebe bzw. an andere Stahlwerke (z. B. in Hennigsdorf) richtete. Auf diese Weise konnten 43 Schlosser und sieben Elektriker eingestellt werden, wie ein Mitarbeiter der EKO-Personalabteilung gegenüber dem Oberreferenten Seidel aus dem Ministerium für Arbeit berichtete ${ }^{373}$. Arbeitsminister Chwalek unterrichtete kurz darauf den Chef der Regierungskanzlei Fritz Geyer über die eingeleiteten Maßnahmen

369 Ebenda, S. 24.

$370 \mathrm{BAB}, \mathrm{DQ} 2 / 2153$, Bericht der Abt. Arbeitskraftlenkung vom 3. 5. 1952, S. 1.

371 Ebenda, S. 2.

${ }^{372}$ Vgl. BAB, DQ 2/2153, Aktenvermerk Seidels vom 10.5. 1952.

373 Ebenda. 
zur Sicherstellung des Facharbeiterbedarfs im EKO und wies erneut auf die immer noch ungelösten Schwierigkeiten der wohnlichen Unterbringung hin. Dieser Versorgungsengpaß könne nur durch zusätzliche Investitionen behoben werden $^{374}$. Auf entsprechende Anfragen hatten aber in der Vergangenheit weder die SED-Führung noch der DDR-Ministerrat reagiert.

Während sich die SED-Führung in erster Linie mit der Arbeitsweise der Parteiorganisation im EKO auseinandersetzte und Verbesserungsvorschläge unterbreitete ${ }^{375}$, versuchte das Ministerium für Arbeit die einzelnen Maßnahmen zur Gewinnung neuer Arbeitskräfte mit der Werksleitung in Fürstenberg besser aufeinander abzustimmen. Bei einer gemeinsamen Arbeitsbesprechung am 15. Mai wurde vorgeschlagen, daß das EKO die Arbeitskräftelenkung zentral übernehmen solle ${ }^{376}$. Das beinhaltete auch die Abstimmung mit den Subunternehmern, die bereits für die Bau-Union tätig waren. Dadurch sollte eine private Arbeitsvermittlung weitgehend unterbunden werden bzw. nur unter dem Dach der staatlichen Steuerung des „Arbeitsmarktes“ ermöglicht werden. Nach dem Vorbild der Wismut AG richtete das Ministerium für Arbeit mit Wirkung vom 20. Mai 1952 eine zentrale Arbeitskräftelenkungsstelle für sämtliche Betriebe, die am Aufbau der Wohnstadt beteiligt waren, sowie für den VEB Eisenhüttenkombinat Ost in Fürstenberg ein ${ }^{377}$. Diese sollte für die Lenkung der neu zugewiesenen Arbeitskräfte und für die innerbetriebliche Steuerung zuständig sein. Ein Mitarbeiter der Arbeitsverwaltung, der ebenfalls in der Zentralstelle tätig sein sollte, erhielt die Aufgabe, den gemeldeten Bedarf „hinsichtlich der Realität und in bezug auf Abdeckungsmöglichkeiten durch Frauen, Schwerbeschädigte und Jugendliche, die nicht vom Nachwuchsplan erfaßt sind" zu überprüfen ${ }^{378}$. Von dieser Maßnahme erhoffte sich das Ministerium für Arbeit eine Ausschaltung der Arbeitskräftehortung und eine Verbesserung der bedarfsgerechten Lenkung. Gleichzeitig wurde der Bedarf an qualifiziertem Fachpersonal deutlich reduziert: Vertreter des Arbeitsministeriums und des EKO vereinbarten, daß sich die akute Arbeitskräftenachfrage des Kombinats vorerst auf Schlosser, Elektriker, Rangierer, Lokheizer und Lokführer, insgesamt etwa 120 Fachkräfte, beschränken sollte ${ }^{379}$. Die zuvor eingereichten Listen über den Arbeitskräftebedarf, die deutlich höher lagen, wurden vom EKO wieder zurückgezogen. Die langfristige Bedarfsabsicherung blieb dagegen unverbindlich: Arbeitskräfte, die darüber hinaus noch benötigt würden, konnten überbezirklich gestellt werden, sobald die Wohnungsfrage abschließend geklärt war.

374 BAB, DQ 2/2153, Minister Chwalek am 12.5. 1952 an Staatssekretär Geyer, S. 2. Nach Angaben des EKO waren die Investitionsmittel, die für 1952 zum Bau von Wohnbaracken vorgesehen waren, Ende Mai noch nicht verfügbar. Vgl. BAB, DQ 2/2153, Bericht der Abt. Arbeitskraftlenkung vom 27. 5. 1952, S. 2.

${ }^{375}$ SAPMO, DY 30/J IV 2/3/289, Bl. 12 und 49, Protokoll der Sitzung des Sekretariats des ZK am 15. 5. 1952. Demzufolge erhielt die SED-Parteiorganisation im EKO den Status einer Kreisleitung und wurde der Landesleitung Brandenburg unmittelbar unterstellt. Vgl. ebenda, Bl. 12.

$376 \mathrm{BAB}, \mathrm{DQ} 2 / 2153$, Protokoll vom 15. 5. 1952.

${ }^{377}$ Ebenda, Rat des Kreises Frankfurt/Oder (Abt. Arbeit) am 17. 5. 1952 an den VEB EKO, die BauUnion und alle Subunternehmer, S. 1.

378 Ebenda, S. 1 f.

379 BAB, DQ 2/761, Bericht der Abt. Arbeitskraftlenkung über die Dienstreise am 15./16. 5. 1952, S. 1 . 
Die Tätigkeit der EKO-Zentralstelle wurde unter anderem dadurch belastet, daß die Bau-Union in dieser Einrichtung anfangs keinen eigenen Vorteil zu erkennen glaubte und daher jegliche Mitarbeit verweigerte ${ }^{380}$. Auch die Zusammenarbeit mit den Landesverwaltungen war aus Sicht des EKO verbesserungswürdig: Diese boten dem Eisenhüttenkombinat offensichtlich nicht nur berufserfahrene Facharbeiter, sondern auch Lehrlinge an, die erst im Herbst 1952 ihre Ausbildung beendeten. Das Ministerium für Arbeit bat daraufhin die Landesregierungen, die Abteilungen für Arbeit bei den Räten der Stadt- und Landkreise über die festgestellten Mängel bei der Arbeitskräftezuweisung zu informieren ${ }^{381}$. Trotz Errichtung einer Zentralstelle für die Arbeitskräftelenkung hielt die Fluktuation unvermindert an. Bau-Union und Subunternehmer versuchten deshalb, das Eisenhüttenkombinat dazu zu bewegen, keine Einstellungen von Arbeitern vorzunehmen, die zuvor bei den Subunternehmern oder der Bau-Union beschäftigt waren ${ }^{382}$. Dieses Anliegen verstieß nach Ansicht des EKO gegen das Gesetz der Arbeit und wurde von der Abteilung Arbeit in Fürstenberg abgelehnt, die in ihrem Vorgehen nachträglich vom Arbeitsministerium bestärkt wurde ${ }^{383}$. Die Bau-Union konnte in der Folgezeit ihren Arbeitskräftebedarf nicht angemessen befriedigen und wandte sich zunächst an die Zentrale Arbeitskräftelenkungsstelle. Vom Berliner Arbeitsministerium war jedoch keine Unterstützung zu erwarten: Der dortige Leiter der Abteilung Arbeitskraftlenkung teilte auf Anfrage mit, daß „wir nicht in der Lage sind, aufgrund des großen Bedarfs von Arbeitskräften für Sonderbauvorhaben, Ihnen die 450 Maurer und 700 Hilfskräfte auch nur annähernd zur Verfügung zu stellen“ 384 .

Die SED-Führung verlor die Entwicklung im Eisenhüttenkombinat Ost nicht aus den Augen, sondern ließ sich in unregelmäßigen Abständen darüber berichten. Dabei regte beispielsweise das Sekretariat des ZK Gespräche bei den zuständigen Ministerien an, um „Maßnahmen zur Überwindung der bestehenden Fehler und Mängel in der Arbeit festzulegen "385. Darüber hinaus schaltete sich die SKK Ende 1952 verstärkt in die Planungsarbeit der deutschen Verwaltungen ein: Dazu wurden dem Ministerium für Hüttenwesen und Erzbergbau Vorschläge zur Verbesserung der Kaderpolitik aber auch der Investitionspolitik in der Eisenindustrie unterbreitet ${ }^{386}$. Die sowjetische Seite regte in dem Zusammenhang an, unmittelbar nach Verabschiedung des Volkswirtschaftsplanes dem Ministerrat eine Beschlußvorlage zur Absicherung der Investitionen für das Jahr 1953 zuzuleiten ${ }^{387}$. Mit

$380 \mathrm{BAB}, \mathrm{DQ}$ 2/2153, Zentrale Arbeitskräfte-Lenkung (EKO) am 14.7. 1952 an das Ministerium für Arbeit.

381 Ebenda, Abt. Arbeitskraftlenkung am 23. 7.1952 an die 5 Landesregierungen (HA Arbeit).

382 Ebenda, EKO am 13. 8. 1952 an das Ministerium für Arbeit.

${ }^{383}$ Ebenda, Leiter der Abt. Arbeitskraftlenkung (Arndt) am 9. 9. 1952 an die Zentrale Arbeitskräftelenkungsstelle Fürstenberg.

${ }^{38+}$ Ebenda, Leiter der Abt. Arbeitskraftlenkung am 2. 9.1952 an die Zentrale Arbeitskräftelenkungsstelle Fürstenberg.

385 Vgl. SAPMO, DY 30/J IV 2/3/332, Bl. 6, Protokoll der Sitzung des Sekretariats des ZK am 16. 10. 1952.

386 Vgl. SAPMO, NY 4182/988, Bl. 203-223, Vorschlag der SKK: Maßnahmen zur Entwicklung der Eisenindustrie im Jahre 1953. Minister Selbmann ließ das Dokument in seinem Ministerium übersetzen.

${ }^{387}$ Als Beschlußvorlage sollte der SKK-Entwurf dienen. Vgl. SAPMO, NY 4182/988, Bl. $201 \mathrm{f}$., Minister Selbmann am 18. 12.1952 an Generalsekretär Ulbricht. 
dem Maßnahmenkatalog zog die sowjetische Besatzungsmacht die Konsequenz aus der Tatsache, daß sich der Aufbau des EKO erheblich verzögert hatte und daß sich vor allem Mängel in der Planungsarbeit herausgestellt hatten. Das Hüttenkombinat an der Oder war zwar der zentrale Baustein des wirtschaftspolitischen Aufbauplanes und stand deshalb im Zentrum des ersten Fünfjahrplanes. Darüber hinaus bestanden allerdings noch weitere Standorte der Eisen- und Stahlindustrie (Eisenwerke West in Calbe, Maxhütte sowie die Werke in Brandenburg, Riesa und Hennigsdorf), die nunmehr auch bevorzugt mit Investitionsgütern beliefert werden sollten, ohne daß das EKO jedoch an Bedeutung verlor. Im einzelnen sollten die Hüttenwerke zusätzliche Öfen und Walzstraßen erhalten ${ }^{388}$, um dann ihre Produktion langfristig steigern zu können. Außerdem sollte die Rohstoffversorgung abgesichert werden ${ }^{389}$, da davon auszugehen war, daß der Bedarf an Rohstoffen (Stein- und Braunkohle, Erze) infolge des geplanten Ausbaus der Produktionsanlagen zwangsläufig steigen würde ${ }^{390}$. Insgesamt fällt allerdings auf, daß der Maßnahmenkatalog zur Verbesserung der Eisen- und Stahlproduktion unter anderem Vorschläge zur raschen Rekrutierung des sogenannten ingenieurtechnischen Personals enthielt, jedoch keine Angaben zur beruflichen Aus- und Weiterbildung der Facharbeiter machte. Obwohl der Ausbau der Produktionsanlagen einen wachsenden Bedarf an Arbeitskräften erwarten ließ, war dieser Zusammenhang für die SKK offenbar nur von untergeordneter Bedeutung. So wurden auch Themenkomplexe nicht angesprochen, die - wie etwa der Wohnungsbau - unmittelbar mit der Steigerung der Beschäftigtenzahlen in den Stahl- und Eisenwerken verknüpft waren. Die deutsche Reaktion auf die Vorschläge der SKK war positiv, wie das Schreiben Selbmanns zeigt, der sich der sowjetischen Analyse fast vorbe-

${ }^{388}$ Ebenda, Bl. 204f. Zur Fertigstellung der einzelnen Investitionsmaßnahmen legte die SKK sogar Endtermine vor, die zum Teil knapp kalkuliert waren. Vgl. ebenda, Bl. $209 \mathrm{f}$.

389 Ebenda, Bl. $205 \mathrm{f}$.

390 Die unzureichende Brennstoffversorgung gefährdete im 1. Halbjahr 1953 zunehmend die Produktion in der Eisen- und Stahlindustrie nicht nur in der DDR, sondern auch in anderen osteuropäischen Staaten. Das konnte mitunter zur vorübergehenden Stillegung einzelner Produktionsanlagen führen. Vgl. SAPMO, DY 30/J IV 2/3/359, Bl. 6, Protokoll der Sitzung des Sekretariats des ZK am 2. 2. 1953. Selbmann wies gegenüber Grotewohl Anfang 1953 auf die „dringende Versorgungsschwierigkeit für die metallurgische Industrie" hin. Seiner Ansicht nach bestand sogar die „akute Gefahr, daß einige Hüttenaggregate, die auf diesen Koks [Hüttenkoks] angewiesen sind, zum Erliegen kommen. “ Ähnlich wie im Sommer 1951 drohte nunmehr die Stillegung einzelner Hochöfen. SAPMO, NY 4090/350, Bl. 13f., Minister Selbmann am 5. 1. 1953 an den SED-Vorsitzenden Grotewohl. In der Folgezeit bemühte sich Grotewohl darum, Polen und vor allem die ČSR zur Einhaltung ihrer vertraglich vereinbarten Lieferungen von Steinkohle und Hüttenkoks anzuhalten. Vgl. SAPMO, NY 4090/350, Bl. 37 f. und Bl. 62-64, Grotewohl am 19.1. und 25. 2. 1953 an den Ministerpräsidenten der VR Polen Boleslaw Bierut. Beim zweiten Schreiben ging es auch um die Lieferung von Kali und Düngemitteln. Die Fördermenge an Stein- und Braunkohle war zu diesem Zeitpunkt offenbar bei zahlreichen RGW-Staaten erheblich gesunken, so daß auch das fest vereinbarte Lieferungssystem aus den Fugen geraten mußte: So erhielt etwa die Tschechoslowakei keine Erhöhung des langfristigen Kontingentes an Steinkohle durch die VR Polen und mußte deshalb die Lieferung in die DDR erheblich einschränken, um wenigstens den Eigenbedarf einigermaßen abdecken zu können. Gleichzeitig wurde die DDR-Regierung gebeten, das gesamte jährliche Braunkohlenkontingent bereits im Januar/Februar zu liefern. Vgl. SAPMO, NY 4090/ 350, Bl. 70 f., Schreiben von Ministerpräsident Antonín Zápotocký vom 24. 1. 1953 an Ministerpräsident Grotewohl. Nachdem sich die Versorgung mit Hüttenkoks nicht wesentlich verbessert hatte, wandte sich Grotewohl Mitte Mai erneut an den Ministerpräsidenten der ČSR und wies auf die Lieferrückstände hin. Vgl. SAPMO, NY 4090/350, Bl. 83 f., Ministerpräsident Grotewohl am 18. 5. 1953 an Ministerpräsidenten Viliam Siroký. 
haltlos anschloß und nur Änderungen bei den vorgegebenen Terminen anbringen wollte. Das Politbüro bestätigte den vorgeschlagenen Maßnahmenkatalog „für den weiteren Aus- und Aufbau der metallurgischen Industrie“, der anschließend an die DDR-Regierung zur Beschlußfassung weitergeleitet wurde ${ }^{391}$. Die enge Anbindung an die sowjetische Besatzungsmacht schlug sich im übrigen auch bei der Namensgebung nieder: Die Wohnstadt erhielt den offiziellen Namen „Stalinstadt“, und das Eisenhüttenkombinat Ost wurde in „Eisenhüttenkombinat J.W. Stalin" umbenannt ${ }^{392}$.

391 SAPMO, DY 30/J IV 2/2/256, Bl. 2f. und 24-29, Protokoll der Sitzung des Politbüros am 6. 1. 1953. Anfang April nahm das Politbüro einen ausführlichen Bericht Selbmanns „über die Lage in den Betrieben der Roheisen- und Stahlindustrie zustimmend zur Kenntnis“, der die bereits bekannten Kritikpunkte nochmals zusammenfaßte. Vgl. SAPMO, DY 30/J IV 2/2/274, Bl. 2 und 6-34, Protokoll der Sitzung des Politbüros am 8. 4. 1953.

392 SAPMO, DY 30/J IV 2/2/264, Bl. 5, Protokoll der Sitzung des Politbüros am 24. 2. 1953; SAPMO, DY 30/J IV 2/3/375, Bl. 14, Protokoll der Sitzung des Sekretariats des ZK am 13. 4. 1953. 